
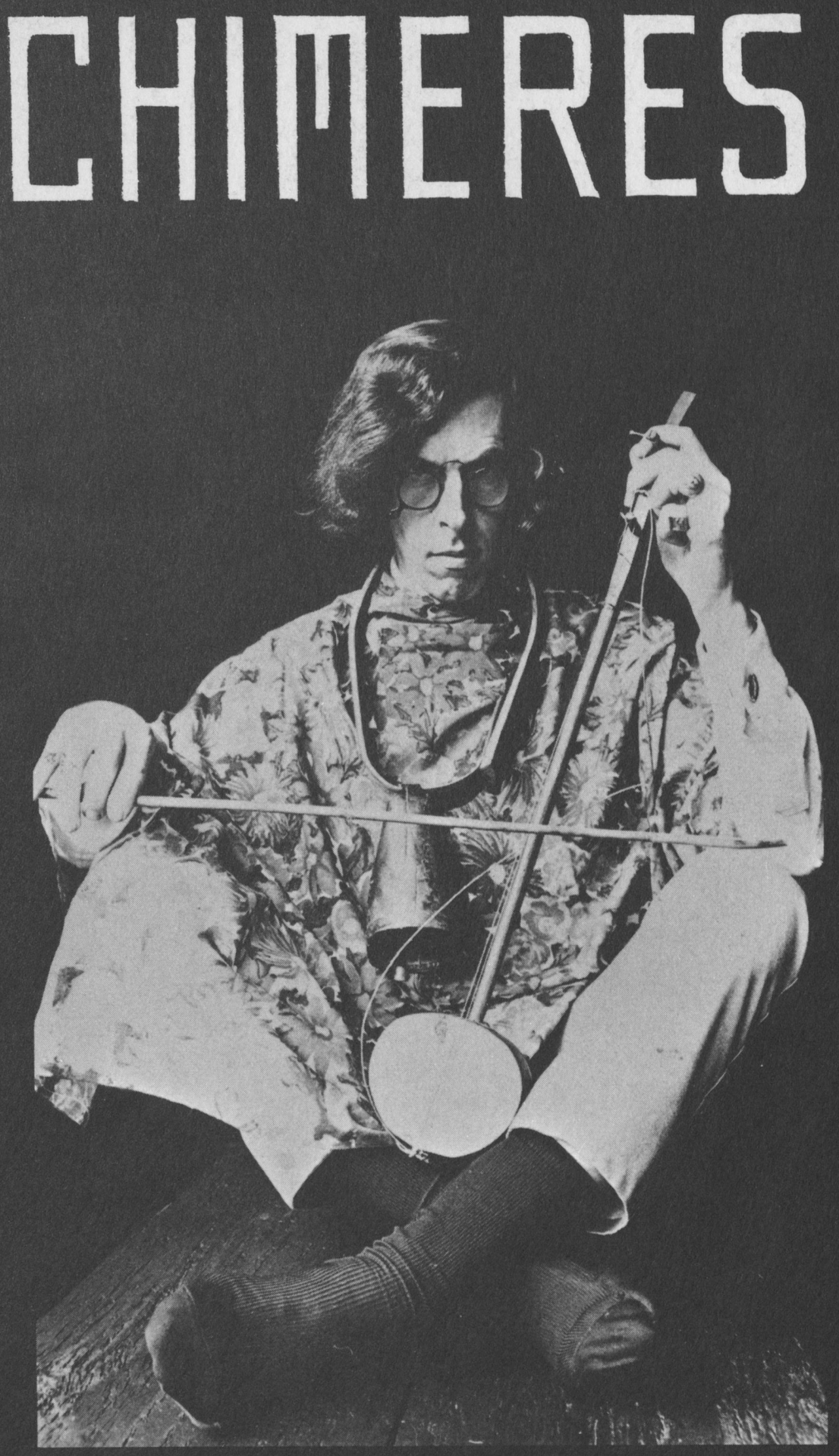


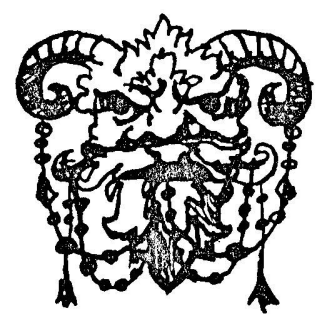

CHIMERES

Rédacteur en chef:

Lloyd Free

Rédacteurs adjoints:

Michel Coclet

Claire Dehon

Roseann Runte
Conseiller universitaire:

M. le professeur

Kenneth White

Conseiller adjoint:

M. le professeur

J. Theodore Johnson

Equipe:

Isabel le Armitage

Margriet Bruyn

Lucie Bryant

Eloise Caspall

Marie-Jo Coclet

Brigitte Desrues
Jane Hoskinson

Gregg Lacy

Hans Runte

Eugene Wee

Elizabeth Witt

Conseiller stylistique:

Anne Lacombe

Revue publiee par les étudiants graduates du Département de Français a 1 'Université du Kansas avec 1 'appui bienveillant et généreux de Z'AZZiance Française de Kansas City, Missouri, le soutien des Comédiens de l'Epervier, et la participation encourageante du College of Liberal Arts and Sciences of the University of Kansas. 


\section{TABLE DES MATIERES}

*John D. Erickson: On Literary Reviews Tried and Untried . . . . . . . . . . . . . . . . . 2

*LZoyd Free: An Editor's Astrolabe . . . . . . . 7

William H. Cannon: Les Images de la mort dans "Les Vers de la mort". . . . . . . . . . . . . . 13

Vaticine Alenvy: Récit de Trézamère... . .. 25

Isabelle Armitage: Neige d'avril. . . . . . 26

Lucie Bryant: "Jacques le fataliste" Diderot et le roman . . . . . . . . . . . . . . . 34

Mathizde: Votre tram .. . . . . . . . . 43

Michel Coclet: Le Long voyage du Père Lycan . . . 44

Hans R. Runte: La Comédie humaine: une réponse . . 55

Réflexion sans miroir........... . 63

Compte Rendu:

Eric Sellin, "The Dramatic Concepts of Antonin Artaud," par Alice Tunks........... . 64

Jean de Ia Fontaine et Cyriz Devos: Eul' Cornelle et l'ernard................. . 69

Le Fichier Bibliographique . . . . . . . . 70

*Ces deux articles exposant les buts et les méthodes d'une publication telle que Chimeres sont destinés tout particulierement au seminaire the Anatomy of a Graduate Review of French Literature: Aims, Format and Technical Realization qui sera tenu le 30 Décembre au cours de la réunion annuelle du Modern Language Association of America à Denver. C'est la raison pour laquelle ils ont été redigés en anglais. 


\section{On Literary Reviews Tried and Untried}

\section{John D.Erickson}

What justifies the creation of a literary review, one in particular by and for graduate students of language and literature? I feel the urge to say that a review publishes its justification with its first number. The mere and mighty fact of existence provides its reason. So, when all market evaluations contradict each other and all auguries spell confusion, go to press to find the answer.

On the other hand, seeing that the death ratio of new reviews comes uncomfortably close to the number founded, perhaps a concrete need should express itself before putting it on the line. It helps to know a new review will reach a readership that will respond to the editorial attitude of the review. As Charles Angoff, editor of The Literary Review, once put it, ". . . the heart of a little magazine is to be sought in its attitude." So far as graduate students are concerned, I doubt that established or professional language and literature reviews answer fully their need for a forum dealing with the particular problems that interest them, nor do they answer the need for a review a student might feel he has a chance to publish in. The attitude of established reviews generally develops around the needs of professional scholars and readers who have accumulated many grey hairs and facts, a little significant knowledge and often an inflated sense of their own importance. Established reviews to varying degrees serve as outlets for intelligent scholarly and humanistic studies, dispensers of historical-biographical and pedigogical information, club organs and ego-boosters. The attitude of these journals, along with other factors I shall mention presently, does (and sometimes should) discourage the graduate student from trying to publish in them. 
Let me relate my experience in founding a review in 1961. As a graduate student myse1f, I felt that L'Esprit Créateur, though not a graduate literary review, might open its pages to good graduate student work that would hold its own with that of seasoned scholars. I entertained a modest vision of the journal becoming a voice not only for the old and tried (people, methods and ideas) but also for the young and untried. My expectations have been fulfilled only partially. Numerous young scholars have published in L'Esprit Créateur but not an impressive number of graduate students. The reasons may be obvious.

Competition to publish in a good professional review is usually severe. It has caused us to decline a fair proportion of graduate articles submitted. A graduate student enters the lists against a formidable field of opponents, most well established in their specialty who by way of having become "established" have spent years of painstaking research and writing (they can show you drawers full of it), years of learning the ins and outs of various reviews and editors, what they want, what they' 11 take, how far they' 11 go, etc.

Another problem militating against graduate students publishing in professional reviews is that such reviews often seem rather redoutable from the vantage point of a university classroom. Or, on the other hand, their very professionalism turns away the gifted student who feels he has something new or different to say. A brief year ago, Prof. Wąllace Fowlie referred to an incident involving some young critics from an eastern school who approached him for advice about starting a new review. Their justification rested on the premise that such "staid" reviews as Yale French Studies and L'Esprit Créateur, which dominate the field of French literary studies in the United States, so the story goes, are unresponsive to young critics who throw new and startling light into dreary corners. Eh ben: Despite the effort I have made in times past to attract just such revolutionary ideas, not one of those young critics has to my knowledge ever submitted an article or review to the journal! And probably won't, for the simple test for unresponsiveness (submission of an article) matters less than the premise, which, after all, comes from the deep- 
seated desire for a review unfettered by anything resembling tradition. Truth it is, as discouraging as it might be, not that such reviews as ours dissuade new writers and new ideas but that, being "established," they inhibit them. By the mere fact of longevity (a decade equals a century in the hypertensive world of reviews) and the telltale tracks of a few well-known writers left in the drifts of its pages--a review qualifies as "established". I guess. The thing about being avantgarde is that nothing can be it all its life.

The graduate literary review offers several down-toearth possibilities. On the positive side, (1) it would provide a proper medium for the stage in research and writing that a graduate student has reached and, by so doing, (2) it would provide an outlet to that need to write (which should function as our second nature in graduate school) and a chance to go through the hot and heavy time of vision and revision needed for the printed word. (3) Finally, it would encourage a young writer to go on, by the very real fact of allowing him the luxury of an article accepted and printed.

Furthermore, the graduate review promises, looking at it negatively, (1) to obviate the expense of energy going into writing for professional reviews that could drain the graduate student as well as divert him from work immediately at hand, (2) to do away with the apprehension and disappointment in submitting to a professional review something that stands little chance of making it, (3) to make less common (I speak with the self-interestedness of an "established" editor) the submission to established reviews of articles whose style and content have not yet matured or do not aim for the appropriate readers but which nonetheless merit publication.

Little if anything exists at the moment between written class work and the professional reviews. A graduate student who feels he has sufficient background, skill and courage to reach for the open market and surmount the unfair advantage of "established" writers should receive wholehearted encouragement. But he should also ask himself whether he has prepared well enough the ground he leaps from. A graduate review 
makes an excellent trampoline for such leaps. Pascal, though not the first or last to do so, has spoken of the need to go through all the intermediate motions as we develop. It behooves us little to omit walking, in order to run early, if we run on unformed legs. The advantages mentioned earlier of a graduate review are but the most obvious ones. Other exciting possibilities arise as well in the contemplation of such an effort:

1. Robert Bly, editor of the Sixties, once criticized American little magazines as being pointless. "Instead of trying to bring a new sort of writing to birth, the editors just walk around with their eyes on the ground, looking for apples already fallen." The graduate review promises a new sort of writing. Seeing that it is a review by students for students, its attitude could allow remarkable flexibility. The possibilities inherent in experimenting with form and content are limited only by cost, imagination and the Postmaster General. Though I have referred essentially to critical writing, I assume that such a review could serve (as Chimères already does) as a medium for creative writing in a foreign language. In the United States, reviews accepting creative work in the French language are rare. One rather longlived one--1e Bayou--met its demise not long ago.

2. A graduate review could serve as a forum for the exchange of creative and interpretive techniques and ideas between students from different schools or even different countries. How much do students in American graduate schools know about attitudes of students at foreign universities? For that matter how much do graduate students know about what goes on in graduate departments at other schools?

3. Such a review could further specific projects such as scholarship drives and contests, or function generally as a public voice for graduate departments. Immense value lies in getting to know the makeup of a particular graduate department through its review--what better way than through the capabilities and interests of contributing students? Also, such a review might adapt well to particular class needs (for example, certain bibliographical material developed by students in a graduate seminar at the University of Kansas and pub- 
lished in Chimères has proved exceedingly useful to faculty and students alike).

The experience of establishing a graduate review bids fair to be not only enlightening but absorbing. Assuming the editorial staff to function as a cooperative effort that is not impossibly unwieldy in numbers (a danger even reviews begun with the most abundant resources and professional advice sometimes fail to recognize in time--a major midwest literary review in the early sixties foundered for two years in such a way), but in which a fair proportion of students will eventually take part, the result is hardfound knowledge of what goes into a review between the rough manuscript and the finished page, knowledge which will be of inestimable help later on.

I have merely gestured in the direction of a few possible roads a graduate literary review might take. The big danger is that a great deal of effort be wasted on something that turns out meaningless. To prevent it from turning into a mere grab-bag of information and repository for uninspired mechanical research, it is more important than ever to keep our eyes steadily on what we are and what we must remain as students of language and literature and the human condition. We are humanists, and such a review foretokens little if it fails to put above all else human concerns. In our time, when there prevails, as William Arrowsmith puts it, an "incredible lack of human concern among humanists," a graduate review would be better unborn than that it deal with trivia. But we can be encouraged by the fact that just such a review has a better chance of keeping its options open than have many professional reviews that subserve incredibly narrow and petty ends. Instead of contentedly sticking to the we11-traveled roads of review writing today, then, the graduate review gives promise of striking out on roads as yet untaken. No less a spirit than Baudelaire would find that the strongest of justifications. 


\section{An Editor's Astrolabe}

\section{Lloyd Free}

Few teachers and students of French would deny that a graduate review of French literature can be a valuable adjunct to higher education. But the paucity of French graduate reviews betrays a want of interest among faculty and lack of initiative among graduate students. To the benefit of the University of Kansas, the French Department has had both an enlightened faculty member, Professor Kenneth White who first suggested founding a graduate French journal, and resourceful students. Chimères was founded through the mutual cooperation of dedicated faculty members and a nucleus of students who had neither funds nor practical experience, but who took the initiative to found a literary journal. The reflections which follow are intended for equally enterprising students who would make a similar venture, and for faculty members who believe that a graduate program in French is more than classroom scholarship alone.

The graduate journal in its entirety, and even the printed page in its particulars, inevitably mirrors the basic policies of its editors. To be sure, it is no doubt possible to found a literary journal without serious forethought; but such a creation ex nihilo is distinctly inadvisable: the final product will reflect directionless editing, risk an ill-balanced layout, and worst of all will discourage a serious reading. It is essential, then, to define an editorial policy which will give direction to the general makeup of the review, before considering mechanics and problems of editing. The first object of the editors should be to respond to two primary questions: 1) to what audience is the review directed? 2) what is the function of the review in relation to this audience?

Our answer to the first question is firm, and explicitly stated on the credits page of every issue of Chi- 
mères: that the graduate review of French is written and published by graduate students of French and intended for graduate students of French. Implicitly, we assert thereby that our graduate student editors should be autonomous--free from faculty control and coercion--and that they may include anything they consider interesting and valuable to graduate students of French. But we also recognize that graduate students do not constitute an exclusive audience; indeed, we hope the review will also interest faculty and non-faculty, local and national. Thus we look continually to that resourceful editing which will find a middle ground, wherein the review will attract the graduate student and become a focal point of his interest, without excluding the general non-student audience.

A workable answer to the second question is necessarily more complex. Because of the varied and highly individual interests and education of its readers, the graduate review of French literature serves many ends: to please, interest, instruct and entertain; to provide hard found knowledge of editing and related problems to editors and contributors alike; to improve scholarship at the graduate level by providing motivation beyond the grade and classroom; to serve as an intellectual forum for students in a given university and a source of communication with students in other universities; to reflect the intellectual ethos of the French Department and the collective artistic talents of which it is composed. It is because the journal so represents the de-partment that we are concerned with its appeal and reception outside the department and the university.

These functions of the journal as we see them, as well as the audience as we have defined it, will shape the general policies and particular decisions of the editors. This prevailing editorial philosophy will effect every subsequent operation, from selection of materials for publication to format and layout. And the demanding and sometimes confusing task of keeping both the general and the particular in mind makes the editorial ideals vital to the journal's success. Those ideals are flexibility and variety.

Flexibility gives the editors the option of printing anything of literary or linguistic value that might in- 
terest students of French. Variety will sustain reader interest from cover to cover. Ideally a high standard of excellence should be the norm for publication, but variety must take precedence over excellence if excellence risks excluding original works in favor of serious scholarship. The editors must be ever vigilant to avoid the Scylla and Charybdis of 1) trivia, the scourge of the undergraduate journal and 2) reams of dul1 scholarship, the fagot of the professional literary review. Unlike the undergraduate review, the graduate magazine can honestly interest the established scholar: the neophyte critic can shed new light on matters of interest to the practiced one. Unlike the professional literary journal, whose audience is captive because it thinks of such readings as the obligatory business of its profession, the graduate review creates an interested audience through originality, variety, freshness of point of view, of style, of content. In sum, its editors are in the freest possible atmosphere for seeking out original work and for balancing and harmonizing scholarly research and original writing. This search for originality will extend even to the mechanics of the publication: format, art work, layout. Hopefully the end product will then constitute an esthetic whole and a true reflection of the student community's talents and interests.

But attention to what has been said so far will not necessarily see a first issue to print. If the end product is to be not only a first issue, but a growing, learning, and informing beyond it, the work does not stop here. Now comes the need for dedication and foresight, which can be exhausting and at times discouraging, but which is also compelling and real. Once editorial policy is determined, the founders of the graduate journal will still face four principal obstacles: apathy, time, money and inexperience. For these reasons, the role the first issue plays in perpetuating itself can hardly be overvalued. Student and faculty interest, particularly during the preparation of the first issue, is crucial. Student support is essential. Writing is hard and time-devouring work. Students may be induced or incited to contribute their efforts, but for the most part they will only do so voluntarily. Until 
the first issue is fact and the fruits of labor are clearly visible in print, most students will ignore even the efforts of the ideally enthusiastic editor and zealous staff. It is crucial, then, that faculty members patronize the journal from its inception. A far-sighted chairman and dedicated faculty members can help the student organizers immeasurably by recommending student research and creative materials which they judge suitable for publication. All things being normal, student interest will grow with each successive issue. The first issue, small and limited though it will probably be, will also have set a precedent, and with each new issue increasing numbers of students will enthusiastically submit scholarly and creative work. True growth can then begin: the standards of editorial selection can become increasingly discriminating.

A more difficult problem than student interest is one closely related to it--time. It is forever at a premium for graduate students, and the editors must make every effort to streamline publishing operations. Beware of an editorial structure that permits bickering, confusion and lost time. The object of all meetings and operations should be one practical result: the quickest, most efficient manner of getting the journal to press. The editor-in-chief will, of course, bear the principal burden of decision-making and coordinating operations. But he need not and should not take everything upon himself. He is both realistic and just if he distributes the work load by delegating major operations to the assistant editors.

Frustrating though the problems of interest and time may be, they are still secondary to finances, which are no doubt the major obstacle to finding and using student talent. Money is a factor over which students have no control, and struggling editors will probably have to grub for it. In fact, it will be difficult, if not impossible, to get money to print the first issue professionally. If necessary, mimeograph the first issue and do a linoleum block print on construction paper to serve as a cover. Go to press even if the format looks amateurish! It is essential to set a precedent, to produce something tangible at first, in order to bargain with it later. More enthusiastic departmental support, finan- 
cial and otherwise, will be forthcoming. With a copy of the first edition in hand, go to the chairman, the deans, the president of the university, the directors of outside social, fraternal, and civic organizations. Show them what you have done and propose what you would like to do: professional format and professional printing. But even then, do not ask for too much. Some professional printing processes can be overly demanding on the editor's time and energy and university budgets alike. You probably deserve some deaf ears, some nice smiles, and gentle pushes out of doors if you don't approach the printing problem with some workable compromises in mind. For example, Linotype is impractical for reasons of cost and time. Few Linotype setters know French, and the cost of Linotyping a foreign language is prohibitive. One type of printing seems best suited to the requirements of a graduate review. This is photooffset. Students who are fluent in French type the work to be published on bonded paper, within a given typing area to be photographed later by the printer. These typed pages are easily proofread and corrected by students. Art work can be drawn on the bonded paper or pasted on separate pages. Pages can be photographically reduced in size, a technique which permits the inclusion of lengthy bibliographies and like projects. The corrected photo-ready copy is then delivered to the printer who does the rest. This method of printing eliminates the high cost of setting type, problems of communication with a printer who does not know French, and the reading of galley proofs.

Lastly, a problem which can of ten be made less difficult than it might seem is student inexperience, which may discourage otherwise enthusiastic students. It is the editor's job to show them, primarily through example, that one learns by doing. The first issue of the journal may well contain some serious faults. But the second will contain fewer, as the publishing team learns what it must do to create a lively and interesting magazine. In fact, most publishing problems shrink to little or nothing when they are besieged with persistence and common sense. Common sense can be elusive; it is easy to miss or ignore. But one invaluable piece of common sense is to know where to solicit advice. Most 
universities have some kind of student or faculty publication, and those directing established publications are usually very willing to give advice if it is asked of them. The asking is a privilege which one should not hesitate to use, as often as he needs it. It might even be worthwhile to assign a continuing liaison with the university press as one of the duties of someone on the editorial staff.

But after all has been said and all possible helpful hints have been given, one looming consideration still remains: the essential thing is to begin, to have the fortitude to overcome the inherent obstacles, to improvise, to compromise, to exploit whatever immediate possibilities present themselves. All this is not an easy task. In fact, the beginnings of a graduate journal can be hard, and will demand much energy from the chosen few who are willing to give it. But once constituted, the well-directed graduate journal will quickly become a central adjunct to the advanced study of French language and literature.

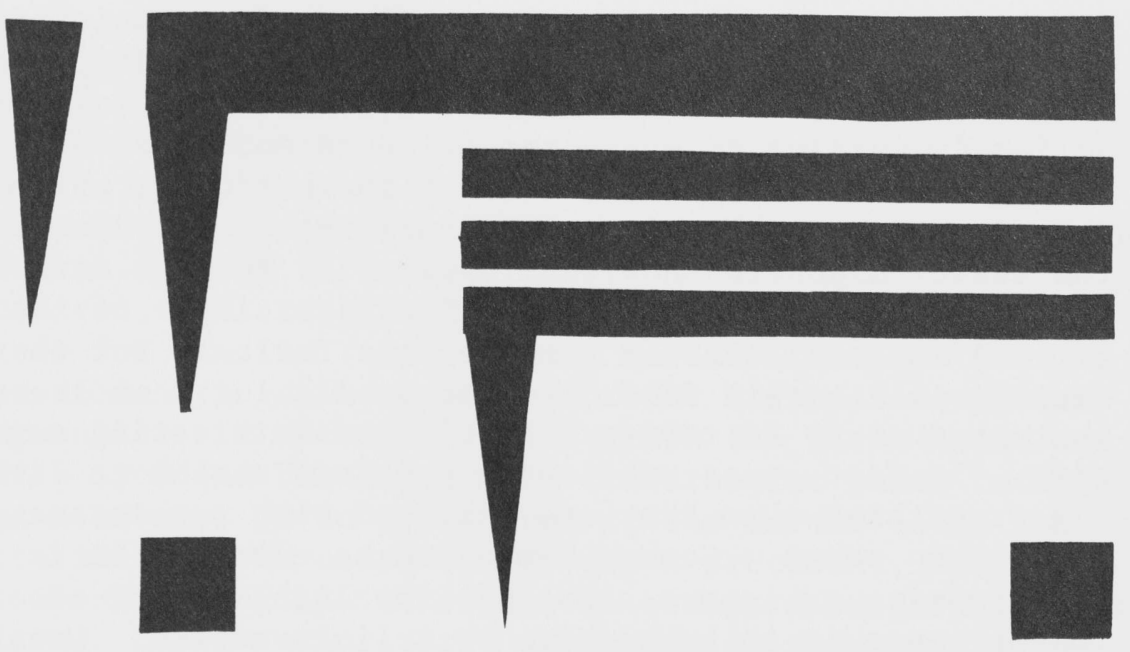




\section{Les Images de la mort}

\section{dans Les Vers de la mort}

\section{William H. Cannon, Jr.}

Hélinant, un brillant seigneur de la cour de Philippe Auguste et écrivain mondain, se fit moine dans le monastère cistercien de Froidmont, en Beauvaisis, après quelques années d'une vie frivole, occupées par le plaisir d'un jeune trouvère applaudi et recherché. Après cette vie complaisante d'un homme du monde, il devint un modèle de piété et de mortification dans le monastère. ¿uand il n'était pas engagé dans les exercices monastiques, il consacrait tout son temps aux études ecclésiastiques; après son ordination il se livra à la prédication et à l'écriture.

Ce moine est surtout célèbre à cause d'un poème sur la mort, Les Vers de 1 a Mort, ${ }^{1}$ qu'il écrivit en français entre $119 \overline{3 \text { et }} 1197.2$ L'impression que produisit ce poème "sur les contemporains et l'influence qu'il exerça sur 1a littérature du moyen âge furent profondes et durables." 3 Selon le témoignage de Vincent de Beauvais, 4 pendant le $\operatorname{XIII}^{\mathrm{e}}$ siècle ce poème jouit d'une très grande vogue et on en fit dans les églises et dans les couvents des lectures publiques. Cette étude va analyser les images de la mort qui figurent dans Les Vers de la Mort et essayer de déterminer leur source d'origine.

Selon les chroniqueurs du temps, les années 11941198 furent marquées par "de violentes tempâtes et par des inondations qui détruisirent les moissons, noyèrent un grand nombre de personnes et réduisirent à la famine des provinces entières; dans le peuple courait le bruit que 1'Antéchrist était né à Babylone et que la fin du monde approchait. L'année 1194 fut particulièrement terrible pour le Beauvaisis." 5 Dans un temps comme celui-1à, la mort régnait partout dans le pays et la pensée de la mort dominait tous les esprits ou presque. 
Il y avait ceux pourtant qui ne craignaient plus les menaces de la mort et qui s'en tenaient à la philosophie de "mangeons et buvons aujourd'hui car demain nous mourrons." Ces fous-là risquaient de perdre leur âme dans la mort éternelle, dans la damnation des feux de l'enfer. Seuls les sages redoutaient la mort.

$\mathrm{Tu}$ lieves sor toz ta maçue,

Ne nus por ce sa pel ne mue

Ne ne change son viez usage.

Morz, toi suelent cremir 1i sage:

Or queurt chascuns a son damage: ( $I, 4-8$ )

Le moment était bien choisi donc pour Hélinant d'écrire un tel poème dans lequel il charge la Mort elle-même, personnifiée, de faire une tournée édifiante de visites pour inspirer à ses contemporains la crainte salutaire de 1 a mort.

I1 veut leur rappeler en les effrayant la puissance de la mort et en même temps la fragilité de leurs personnes et de leurs biens. S'adressant à sa cruelle héroIne, l'auteur passe en revue tous ceux qu'elle doit frapper. Il nomme successivement les personnes de différentes conditions qui répondront à l'appel de la Mort: les bons et les méchants, les riches et les pauvres, les puissants et les faibles; tous seront sa proie. C'est la Mort qui fera le salut des uns et décidera de la perte des autres. Il faut se repentir immédiatement et faire profession de foi en Dieu pour ne pas être pris au dépourvu lorsque la Mort frappe subitement.

Hélinant n'a pas cherché à dissimuler ni à adoucir le côté terrible et repoussant des images qu'enfantaient ses croyances religieuses. Il a essayé au contraire de faire ressortir ce qu'il y a de hideux et de repoussant dans la mort. Il a. choisi des peintures vives et des tableaux émouvants pour frapper l'imagination des gens de la fin du XII e siècle. Il n'a pas fait une simple allusion à l'idée funèbre mais il a personnifié cette idée de la mort en lui créant une individualité qui tombait directement sous les sens, et dont les yeux, aussi bien que l'esprit, pouvaient saisir la physionomie particulière, le caractère propre, et les attributs spéciaux. Il voulait faire une vive impression sur 1'homme par ce personnage redoutable de la mort.

D'abord ce n'est pas la forme d'un monstre ou d'un 
démon que prend le personnage de la mort mais plutôt celle de la figure humaine. Elle a de la chair, une bouche, des dents, des mains, des ongles, des jambes; elle parle, ange, marche, court, monte à cheval; elle pratique les métiers des hommes: messager, chasseur, oiseleur, chevalier, moissonneur, etc. Mais ce portrait physique qu'Hélinant nous peint est imprécis et vague, ce qui laisse à l'imagination la liberté de créer son propre portrait de la mort. Cependant ces quelques détails physiques indiqués dans le poème sont developpés de manière à donner un portrait épouvantable de la mort.

La présence physique de la Mort épouvante ceux auxquels elle est envoyée (III, 12). La Mort n'a pas besoin de force ni d'éloquence pour provoquer une réponse de ses victimes; seule sa "espoentant chiere" suffit à les rendre captives (XXII, 4-6). Le visage de la Mort est celui d'une vieille, une figure odieuse (XXIV, 1, 2). Il ne semble pas qu'il s'agisse de représenter la mort dans le poème comme un squelette ou même comme un cadavre qui pourrit. Ces images n'étaient pas inconnues au XII siècle; elles ont une longue histoire que $I^{\text {'on }}$ peut retracer depuis le temps des anciens. Ces deux formes apparaissent plus tard dans le moyen âge dans la littérature et surtout dans $I^{\prime}$ art au XIV et au XV $X^{\mathrm{e}}$ siècles.

Il y a quand même quelque chose de ce "macabre", typique de la fin du moyen âge dans le portrait de la Mort et de ses victimes peint par Hélinant. N'est-il pas possible que cette "chair épouvantable" de la mort soit celle du cadavre qui pourrit? Certes c'est une image "macabre" que nous avons des victimes de la Mort, ces vils corps, puants, flasques, bien nourris, bien amollis, "faits de vers et de feu chemise" (XXIX, 10-11; XLVII, $8 ; \mathrm{XL}, 4)$. Ces images du XIV et du XV ${ }^{\mathrm{e}}$ siècle: le spectacle du cadavre, de la charogne, de la bière déclouée, du corps et du visage qui se décomposent, rongés par les vers, elles sont toutes ébauchées dans Les Vers de la Mort.

Au moyen âge la mort physique était considérée comme la plus atroce des souffrances. Il y a dans ce poème l'image des corps enveloppés dans leurs linceuls dont la Mort a cousu les manches avec son aiguille (X, 1012), ensevelis sous une couche de terre (XXXI, 4-5) dans 
la bière que la Mort leur apporte (XXII, 10-12), et plus tard lorsque $I^{\prime}$ on les déterre et les jette dans les charniers où ils deviennent cendres (XX, 9) sous $1 \mathrm{a}$ pluie et la sécheresse que la Mort fait tomber sur eux (XXIX, 1-4). Tout ce que la Mort touche meurt, pourrit, et sèche. Il ne manque pas dans ce poème des portraits de cette Mort qui fait "biauté devenir fiens" (XVII, 12), dignes du terme "macabre" employé à la fin du moyen âge.

Il y a aussi dans certaines images de la Mort un peu de la prédilection des chrétiens de la période byzantine et du moyen âge pour ces compositions tragiques et effrayantes, ces types monstrueux et fantastiques employés dans 1'architecture romanesque. Ces mains qui saisissent les hommes et ne les relâchent pas (XV, XXXI), ces ongles qu'elle fiche profondément dans les riches (XLII), ou ces dents qu'elle fiche dans les hommes et avec lesquelles elle mange tout le grain que $1^{\prime}$ 'on a moulu et ammassé, tout rappelle les monstres qui dévorent les hommes et les femmes sur les chapiteaux des églises romanes. La Mort de même embrasse et enlace l'âme $(\mathrm{V}, 10,11)$. On peut facilement s'imaginer cette Mort qui mange et avale les âmes. En choisissant ce caractère si redoutable pour représenter la mort, le poète augmente la terreur qu'une telle puissance peut inspirer.

C'est toute une série d'images, de personnifications de la Mort que nous avons dans le poème. I1 y a une grande variété de sujets qui se suivent sans aucun ordre et qui se mélangent souvent les uns avec les autres. Ce sont les attributs spéciaux de la Mort, plus que ses caractères physiques, qui donnent à l'image ses significations particulières. Les symboles ou les emblèmes qui accompagnent la Mort, principe destructeur de l'univers, sont presque tous des armes qui tranchent ou qui assomment ou celles d'un chasseur pour attraper sa proie: 1a massue, le maillet, la faux, la flèche, l'arc, le couteau, le rasoir, la fronde, le rets, la nasse, le filet, etc.

Hélinant connaissait bien la littérature classique et il aurait pu s'inspirer de ces sources classiques où un grand nombre de ces armes figuraient comme emblèmes de la mort. Il est plus probable qu'il a trouvé la source de presque toutes ses images de la mort dans la 
langue métaphorique de $1^{\prime \prime E c r i t u r e ~ S a i n t e . ~ S u i v a n t ~ l e s ~}$ textes de Romains $5: 12$ et $6: 23$, la Mort d'Hélinant est entrée dans le monde par le péché originel (XIII, 1,2).

I1 y a partout dans le poème des images qui représentent la Mort comme un chasseur à l'affût, qui guête sa proie, ses victimes qui sont les hommes. La Mort est représentée toujours comme une force active, agressive qui peut prendre le rôle d'un moissonneur, d'un voleur, d'un oiseleur, d'un pêcheur, d'un chasseur ou d'un guerrier. Ce sont ces quatre derniers motifs qui sont les mieux développés. Ils dominent le poème. Ces figures apparaissent dans vingt-quatre au moins des cinquante strophes du poème.

On trouve fréquemment dans la langue métaphorique de la Bible cette image de la Mort représentée comme chasseur, armé d'un arc, d'un couteau et de filets, qui tend des pièges pour sa proie. La Mort chasse les hommes comme le chasseur poursuit les animaux. Elle guette les sentiers où les hommes vont habituellement se souiller (III, 9, 10). E1le connaît les mauvaises voies que suivent les hommes qui ne font plus attention aux lois de Dieu et elle arpente ces sentiers impitoyablement, tombant sur sa proie inopinément (VII, 7-8). Ses armes, "son arc qui ne faut" (VIII, 5), sont rapides et tranchantes et elles ne manquent jamais leur proie. Le long de ces sentiers que fréquentent les hommes, la Mort tend des pièges pour les attraper: "Morz, qui nos as toz pris al laz" (V, 1). On parle souvent dans la Bible de ces "1acs" ou "pièges" de 1a Mort (Psaumes 18:5, II Samuel 22:6) dans lesquels sont pris tous ceux qui ne se sont pas repentis. Nous lisons à propos du méchant dans Job 18:7-11: "Malgré ses efforts, il tombera. Car il met les pieds sur un filet, il marche dans les mailles, il est saisi au piège par le talon, et le filet s'empare de lui. Le cordeau est caché dans la terre, et la trappe est sur son sentier. Des terreurs l'assiègent, 1'entourent, le poursuivent par derrière." I1 en est de même chez Hélinant. L'homme doit se tenir sans cesse sut ses gardes et ise méfier des pièges dressés pour lui par la Mort: "Or se gardent de tes engins" (XVII, 9). 
La Mort emploie d'autres armes encore plus affreuses pour tuer 1'homme. Quoi de plus épouvantable que cette image de la Mort qui se sert des gorges blanches pour aiguiser son rasoir de chasse? (X, 2, 3; XX, 5, 6). Avec son rasoir de chasse, ce chasseur porte un couteau pour fendre les gorges (XXIV, 10). La Mort traite sa proie humaine comme un animal; ses flèches, son rasoir et son couteau de chasse, tous, frappent tout d'un coup et apportent une mort pénible. Hélinant a sans doute choisi ces images essentiellement dans la Bible pour insister sur le besoin pressant pour 1'homme de se repentir car "l'homme ne connaît pas non plus son heure, pareil aux poissons qui sont pris aux pièges; comme eux les fils de l'homme sont enlacés au temps du malheur, lorsqu'il tombe sur eux tout à coup" (Ecclésiaste 9:12). Pour compléter le portrait du chasseur, le poète ajoute le cor de chasse (ou bien de guerre) que la Mort porte pour sonner à ceux à qui elle va rendre visite (VI, 1).

Deux autres images étroitement liées à celle du chasseur sont celle de 1'oiseleur; qui attrape les oiseaux avec un filet ou autre piège et celle du pêcheur; qui prend des poissons dans ses filets ou dans sa nasse. La Mort s'arme de trois sortes de pièges dans le poème: le tramail qui est un filet de pêche formé de trois rets superposés èt qui peut servir aussi de filet d'oiseleur à trois rangs de mailles; le rets, un filet pour prendre des oiseaux ou des poissons; et la nasse qui est un panier en oisier pour prendre des poissons ou bien de petits oiseaux (XX, 9, 10). La Mort tend ces trois pièges devant 1'homme pour 1'attraper à 1 'improviste. La Mort elle-même est "la roiz qui tot atrape" (XXXI, 1). Cette mort est aussi subite, inattendue et le résultat c'est la damnation éternelle de I'âme en enfer. Hélinant pensait ici sans doute à la parabole de Matthieu 13:47-50 où le royaume des cieux est semblable à un filet jeté dans la mer, ramassant des poissons de toute espèce, les bons pour être sauvés, les mauvais pour être condamnés.

L'image de 1'oiseleur se mêle à celle du moissonneur dans la strophe XII ou la Mort est figurée armée d'une faux qui coupe les têtes des "faucons et ostoirs et girfauz" qui s'en volent vers le ciel (XXII, 10-12). Ces trois espèces d'oiseaux de chasse représentent les no- 
bles, les grands qui rongent les pauvres, et les serfs. Ce sont ces derniers que la Mort vengera lorsqu'elle abat ces oiseaux en plein vol vers le ciel. Ces oiseaux sont les âmes des hommes que la Mort poursuit, abat et tue. Au moyen âge c'était une croyance populaire que 1a Mort enlevait non pas seulement le pouvoir terrestre, la beauté et les possessions mais aussi qu'elle pouvait priver 1'homme de son salut. La Mort frappe le corps tout d'un coup et enlève l'âme avant qu'elle puisse se repentir de ses fautes (XXIII, 7,8). Après 1 'avoir saisie, la Mort tient l'âme en tourment (XXI, 7). Le message donc d'Hélinant à ses contemporains est celui des Proverbes 6:5: "Dégage-toi comme la gazelle de la main du chasseur, comme l'oiseau de la main de 1 'oiseleur" et Proverbes 22:5: "Des épines, des pièges sont sur la voie de 1'homme pervers; celui qui garde son âme s'en éloigne." D'après Hélinant 1 'homme doit seulement avoir foi en Dieu, se repentir, et faire de bonnes oeuvres et il ne craindra pas la Mort. N'est-ce pas la même leçon que comprennent Proverbes 29:6 et Psaumes 124:7?

Dans cette bataille pour les âmes, la Mort apparaît souvent aussi comme un guerrier qui donne des coups meurtriers aux hommes. Il est souvent question des "assauts" de la Mort dans le poème (VIII, 12; XII, 3; XXII, 7 ; XXXIV , 8). Cette image d'un guerrier à cheval et armé d'une épée ou d'une massue aurait été très familière aux gens du XII ${ }^{\mathrm{e}}$ et XIII ${ }^{\mathrm{e}}$ siècles en France. Le champ de bataille dont "la Morz est la fin" (XXXIV, 12), c'est le monde entier. La Mort lève sur tous les mortels son étendard de victoire (XXII, 1-3). Comme un chevalier médiéval, la Mort abat d'un seul coup le roi dans son palais et le pauvre dans sa cabane (XXI, 1-3). Le combat ne cesse jamais car ce guerrier erre toujours sans repos sur le champ de bataille (XXI, 4). Ses armes sont la perrière, une ancienne machine de guerre du moyen âge qui servait à lancer des projectiles et dont la Mort se sert dans la bataille serrée; la fronde avec laquelle elle menace de loin (XXII, 8, 9); et son épée avec 1aquelle elle tranche l'âme qui est venue "tout nue a la bataille" (XXI, 12). Mais son arme la plus épouvantable c'est la massue avec laquelle la Mort meurtrit 1'âme pour l'écraser. Tout le monde tombe sous cette massue: 
"Tu lieves sor toz ta maçue" (I, 4). L'homme est écrasé comme plâtre, réduit à néant par cette arme redoutable qui "bat le siecle comme toile" (XIII, 4).

La Mort provoque au combat et fait la guerre aux riches et aux puissants qui font souffrir les pauvres et les faibles; à ces deux classes elle réserve tous ses tourments: "Morz, tu defies et guerroies (XLI, 1). C'est comme guerrier monté à cheval qu'Hélinant l'envoie aux cardinaux de Rome (XIV, 1-2). La piqûre de 1'aigui1lon de ce chevalier est plus venimeuse que celle de la tarentule $(X X V, 8,9)$. Il est très probable qu'Hélinant a pensé à l'image terrifiante du quatrième chevalier de 1'Apocalypse, lorsqu'il écrivait ce poème: "Je regardai, et voici, parut un cheval d'une couleur pâle. Celui qui le montait se nommait la mort, et le séjour des morts 1'accompagnait. Le pouvoir leur fut donné sur. le quart de la terre, pour faire périr les hommes par l'épée, par la famine, par la mortalité, et par les bêtes sauvages de la terre" (Apocalypse 6:8).

La Mort d'Hélinant n'est pas simplement une mort neutre, c'est-à-dire la séparation du corps et de l'âme qu'attend chaque homme; elle est aussi celle de la Mort comme représentation du dernier jugement. La Mort est le jugement final de Dieu sur les méchants de la terre. Après sa mort physique, l'homme doit braver une expérience plus terrible, celle du jugement: "Tuit attendons comunement / Primes mort et puis jugement" (XLIX, 1,2). La Mort n'agit pas seulement comme le messager envoyé par Hélinant pour avertir ses amis mais elle est le messager de Dieu lui-même qui erre toujours sans repos: "Por chascun semondre a son jour / De paier Dieu trestot son droit" (XXI, 5, 6). Elle représente la volonté de Dieu mais elle se réserve une certaine liberté dans le choix de ces âmes qui seront sauvées et de celles qui seront damnées en enfer: "Morz seule set et adevine / Com chascuns est a droit proisiez" (XXXIII, 11, 12). Avant d'être jugée par Dieu, 1'âme doit être choisie par la Mort pour mourir. Après s'être séparée du corps, 1'âme lit dans le livre de la mort quelles sont les conditions nécessaires au salut (XI, 2-5). Nous avons ici dans le poème une scène du jugement dernier dans 1 'Apocalypse: "Et je vis les morts, les grands et les petits qui se tenaient devant le trône. Des livres furent ouverts. Et 
un autre livre fut ouvert, celui qui est le livre de la vie. Et les morts furent jugés selon leurs oeuvres, d'après ce qui était dans ces livres" (Apocalypse 20:12). C'était une figure horrible pour les gens du XIII ${ }^{e}$ siècle que la Mort qui avait le pouvoir de déterminer le sort des hommes. Hélinant fait allusion plusieurs fois au pont qu'on représentait comme menant au paradis et qui était infranchissable aux pécheurs qui tombaient du pont dans le fleuve de l'enfer (X, XLVII, XIVIII). "Le jour amer de la mort" (VIII, 7) la Mort assaillit l'âme en lui ôtant les planches du pont menant au paradis et 1'entraîne en enfer. La Mort prend ici le rôle du geôlier qui garde 1'âme dans sa prison "tenebreuse et noire / 0 nu1 ne recuevre sa perte" (XLVI, 11, 12).

Hélinant se sert de l'idée classique et biblique de la mort comme un moissonneur: "Tu entreras au sépulcre dans la vieillesse comme on emporte une gerbe en son temps" (Job 5:26). Une des armes de la Mort c'est la faux, symbole de la brièveté de la vie; elle l'emploie pour tuer I'homme. Un autre attribut de la Mort est le tamis. C'est une image frappante que crée le poète lorsqu'il peint la Mort qui blute les âmes comme la farine pour séparer les bonnes des mauvaises, celles qui seront sauvées de celles qui seront damnées (IV, 10-12). Et plus tard il nous dit que la Mort sépare paille de grain, bran de farine, les mauvaises âmes des bonnes (XXXIII, 8). On trouve une idée semblable dans 1'Evangile de Matthieu où Jean-Baptiste parle au Christ du Saint Esprit: "Il a son van à la main; il nettoiera son aire et il amassera son blé dans le grenier, mais il brûlera la paille dans un feu qui ne s'éteint point" (Matthieu 3: 12) et dans la parabole de l'ivraie dans le champ où "le champ, c'est le monde; la bonne semence, ce sont les fils du royaume; l'ivraie, ce sont les fils du malin; l'ennemi qui l'a semée, c'est le diable; la moisson, c'est la fin du monde. . . . Or, comme on arrache $I^{\prime}$ ivraie et qu'on la jette au feu, il en sera de même à la fin du monde" (Matthieu 13:38-40). De même que la Mort sépare la paille du grain, le bran de la farine, elle sépare les purs vins des faux vins, ce qui représente les âmes pures et les âmes souillées: "Et l'ange jeta sa faucille sur la terre. Et il vendangea la vigne de la terre, et jetta la vendange dans la grande cuve de la colère de 
Dieu. Et 1a cuve fut foulée hors de la ville; et du sang sortit de la cuve, jusqu'aux mors des chevaux, sur une étendue de mille six cents stades" (Apocalypse 14: 19-20).

Hélinant représente la Mort aussi comme un meunier qui s'arme d'un maillet pour moudre le blé. Avec cette arme la Mort réduit 1 'homme en poudre, au néant par des coups successifs: "Qui par lonc mal le sés piler" (X, 8).

Tout ce qu'il y a de ténébreux, de furtif, et de mystérieux dans le personnage de la Mort est bien montré par le poète dans le portrait du larron. Hélinant demande à la Mort d'aller comme un voleur dans la nuit et de frapper $1^{\prime}$ endormi dans son plaisir avant qu'il ait eu le temps de se raser (XXIII, 10-12). La Mort vole 1'âme et I'emporte pour être jugée par Dieu. Il y a plusieurs passages dans la Bible où le jour du jugement vient comme un voleur dans 1a nuit (II Pierre 3:10; I Epitre aux Thessaloniciens $5: 2$ ) et le Christ lui-même dit qu'à $1 \mathrm{a}$ fin du monde "je viens comme un voleur" (Apocalypse 16: 15 ) et "Si tu ne veilles pas je viendrai comme un voleur, et tu ne sauras pas à quelle heure je viendrai sur toi" (Apocalypse 3:3).

La Mort "sait dénuer les riches" (III, 3) en ôtant leur plaisir, c'est-à-dire leur richesse (XVII, 11) et les laisse dans la misère $(X, 6)$. Elle vide la bourse même de I'évêque (XVI, 12). Enfin, il n'y a personne qui ait des biens, qui soit à 1 'abri des assauts de la Mort car elle "rase tous ceux qui ont quelque chose a prendre" (XX, 6). La leçon ici c'est que ceux qui ont joui des honneurs et des biens de la terre iront tous en enfer.

Dans 1'Ancien Testament Dieu fait connaître sa volonté souvent en tirant au sort: "On jette le sort dans le pan de la robe, mais toute décision vient de l'Eternel" (Proverbes 16:33). Dans les Vers de la Mort 1a Mort est fréquemment figurée comme un joueur qui tire au sort pour déterminer le destin des âmes. En fait, la Mort est de $1^{\prime}$ avis que cette lutte, cette bataille, ce combat pour les âmes n'est qu'un jeu où elle s'amuse $(I V, 8,9)$. E1le ne s'intéresse qu'à ceux qui ne la craignent pas, à ceux qui la défient et à ceux qui n'ont pas peur de Dieu. Ce sont eux qui $1^{\prime}$ excitent et c'est 
vers eux qu'elle se dirige en premier lieu (XXIX, 7-9; XXIII, 1, 3). Pour les religieux qui passent leur vie à se préparer à la mort dans la crainte de Dieu, aucun des jeux de la Mort ne peut les faire tomber (II, 7-12). Mais elle enchante comme sorcière et elle trompe tous ceux qui ne craignent pas Dieu: "Qui te poines de lui guiler" $(X, 7)$. Ces méchants n'auront jamais de chance car quant ils jettent les dés pour déterminer leur sort: salut ou damnation, les jeux sont déjà faits! La Mort a pipé les dés qui n'ont que des as et des deux. Ses victimes jetteront toujours des coups infirmes, insuffisants pour gagner contre la Mort (XV, 8, 9). La Mort ne perd jamais car elle ne peut faire un mauvais coup: "Qui nul gieu ne pert par mestraire" (XXVIII, 6).

La Mort joue un autre jeu très connu au moyen âge, celui des échecs. Elle continue cette bataille ("aves") avec les âmes jusqu'à ce qu'elle leur ait fait échec et mat: "Tant qu'aves les ait faiz o maz" (V,9). Quelque jeu que 1 'on essaie, le résultat est toujours le même pour l'homme pécheur: il perd sa vie par un coup pénible et gagne les ténèbres ardentes de l'enfer (XXIV, 10-12). C'est un jeu pour tout détruire sans jamais rien restituer (XXVIII, 2-3).

Pour faire un des portraits les plus puissants et les plus terrifiants de la Mort qui existent dans la littérature française, Hélinant a puisé ses images de la Mort en grande partie dans 1'Ecriture Sainte. Tous ces portraits peints par 1'auteur représentaient pour les hommes de son temps, riches ou pauvres, nobles ou serfs, puissants ou faibles, des aspects de la vie quotidienne: la moissonneur, le chasseur, le guerrier, l'oiseleur, le larron, le joueur, le pêcheur. Ce sont donc des images dont ils comprenaient facilement le sens et la leçon didactique qu'elles portaient.

${ }^{1}$ Hélinant, Les Vers de 1a Mort, SATF, vol 83, 1905. (Les numéros des vers cités sont ceux de cette édition). Ibid., p. xv.

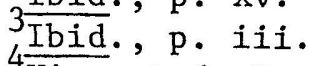

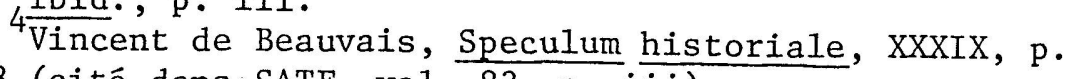
$108_{5}$ (cité dans SATF, vol. 83, p. iii). -SATF, vol. 83, p. iii. 


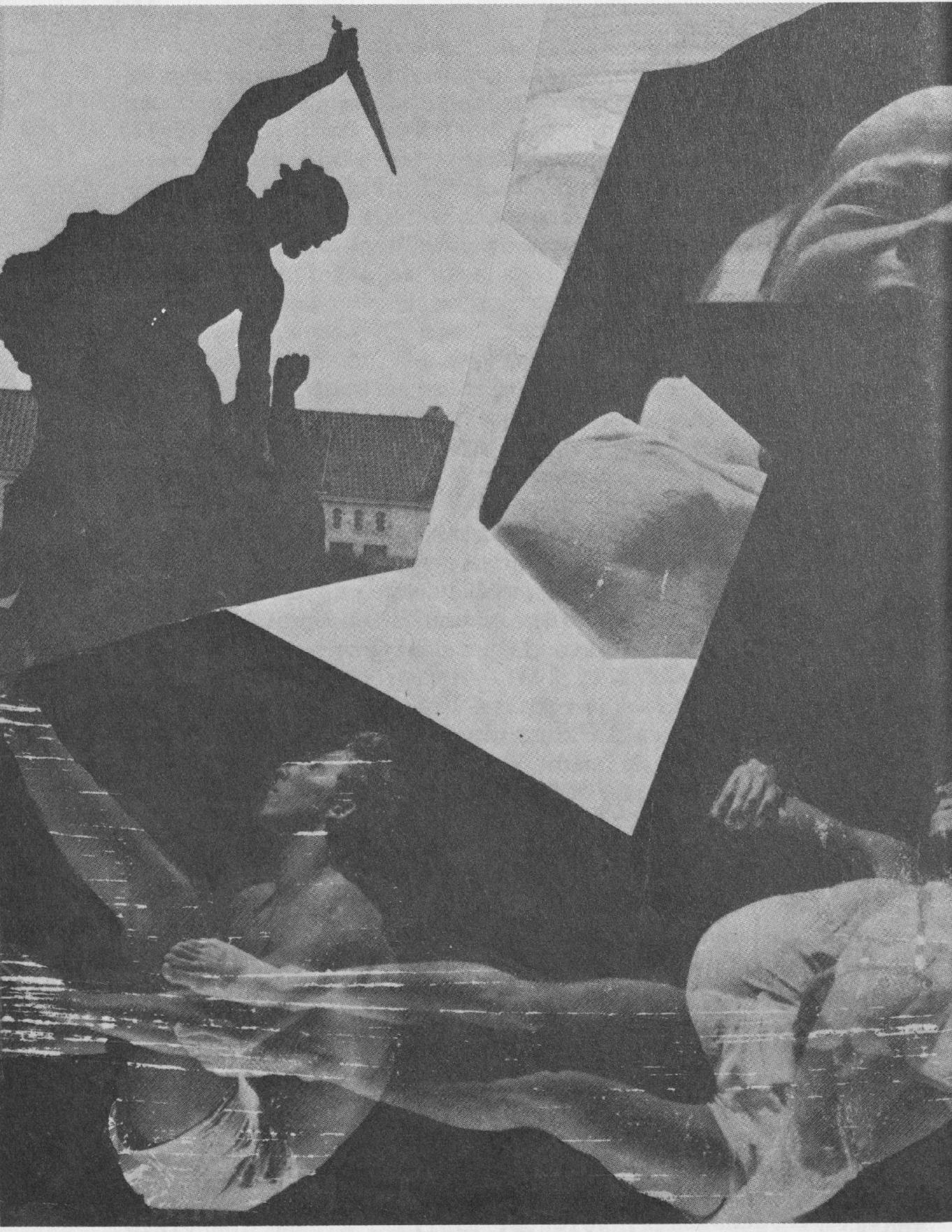




\section{Récit de Trézamēre}

Le soleil terminait. sa course, glorieuse,

Et Phoebus d'une longue journee fatigué

Quittait ces sinistres cieux sur son char ailé. Les étoiles brillaient, c'était l'heure joyeuse ou s'ouvraient les portes de la salle poudreuse. Les Dieux et les mortels lentement s'assemblaient Pour écouter, des simili dieux le secret. Soudain, après trois coups, disparut la lumière, Un silence glacé fit frémir les crinières, Polite apparut dans un éclat surnaturel II discourut avec Cèdre, vraie Jezabel Couverte d'un linceul qui pendant bien des journées Avait trẫne sans soin dans des voitures mal lavées. Devant belle Ricie, Polite encartonne Gambadait en indomptable coq mal attiffé. Soudain, les colonnes de baudruche errejntées, Devant la foule, en sillence se, sont vidées Et ô jamais de Trézamère, le récit N'eut de fin, les simili dieux ont déguerpi Sans attendre de Jobin les foudres célèbres. 


\section{Neige d'avril}

\section{Is abelle Armitage}

"A quelle heure rentreras-tu?" Agathe contint son impatience, "Vers quatre heures, comme d'habitude." Deux fois par semaine elle prenait des leçons d'espagnol et Martin posait toujours la même question. I1 ne se rappelait jamais ce qu'elle faisait, ça ne l'intéressait pas. Elle avait de la chance quand elle rentrait à temps pour l'empêcher de boire. S'il avait commencé trop tôt il était impossible d'éviter une scène à 1 'heure du dîner. Il refusait d'admettre qu'il avait un problème, et se moquait d'elle parce qu'elle ne tenait pas I'alcool.

Il avait sorti la voiture du garage laissant le moteur en marche. II ne le faisait pas vraiment pour l'aider, en fait elle aurait souvent préféré qu'il laissât la voiture à couvert jusqu'à ce qu'elle soit prête à partir. Mais elle était femme, donc elle ne connaissait rien aux mécaniques compliquées et ne comprenait pas qu'il faut chauffer un moteur, sinon $I^{\prime}$ huile n'est pas fluide et la fragile petite masse d'acier pourrait en souffrir d'une façon irréparable. Si seulement il avait eu autant de tendresse pour elle!

Le soleil d'avril était brillant, mais le fond de 1 'air était frais et elle mit son manteau ouatiné. Elle pensait au dicton de son enfance, "En avril ne te découvre pas d'un fil, en mai fait ce qu'il te plaît."

Agathe allait avoir quarante ans. Quand elle avait épousé Martin à New York, dix ans auparavant, elle n'avait jamais pensé qu'elle vivrait à Santa Fé. Elle travaillait dans la couture, et il lui avait fait croire qu'elle pourrait se faire une situation dans une revue de mode. Il était directeur artistique d'un magazine important; elle entrevoyait une association, une vie sophistiquēe, active. E1le s'était donné beaucoup de mal pour décorer leur appartement. Elle aimait la vieille maison de pierres brunes située en plein centre 
de Manhattan, avec son salon qui ouvrait sur un jardin. - Lais trois mois plus tard il était rentré du bureau et avait annoncé froidement qu'ils partaient pour le ranch. Il avait démissionné, "Je vieillis de cinq ans chaque année dans cette affreuse ville."

Il ne lui avait pas demandé son avis, ni ce qu'elle aimait. Elle était atterrée. E1le avait passé les années de guerre en France, dans la Résistance, vivant comme un animal pris au piège. Elle avait recommencé à vivre aux Etats-Unis et maintenant il voulait $I^{\prime}$ enterrer dans le désert de Californie, à vingt kilomètres du village le plus proche, sans téléphone, sans eau, sans électricité. Sans doute c'était un lieu spectaculaire, un hâvre où il était possible de se détendre après 1 'agitation de la grande ville, mais y vivre toute 1 'année!

Elle n'aimait pas déclarer forfait, en conséquence elle décida d'en prendre son parti. Elle refit une nouvelle installation. Elle devint excellente cuisinière car il y avait toujours de nombreux invités. Elle s'intéressa à toutes les entreprises de Martin, travaillant sans relâche à améliorer, à constuire, à entretenir, à lui apporter la joie et la sécurité. Elle arriva même à élever convenablement ses enfants.

Mais.elle ne pouvait pas gagner. Il vieillissait et il se faisait des illusions sur son activité, il ne savait pas quoi inventer pour s'occuper. Il la rendait responsable de ses échecs. Elle lui servait de bouc émissaire. D'ailleurs il la trouvait beaucoup trop organisée et artificielle. Ca l'étonnait qu'elle $\mathrm{n}$ 'aimât pas son costume de máison: caleçon, jottes et casquette de base-ball.

Un jour il était rentré malade d'un de ses rares voyages à Los Angeles et elle avait réussi à l'emmener à l'hôpital le plus proche, à soixante quinze kilomètres de là, pour le faire opérer d'urgence. Elle avait eu la paix pendant quelques temps après l'opération, et il avait finalement accepté le retour à la civilisation.

Tout en conduisant elle réfléchissait. La nouveauté du déménagement s'estompait. Leurs rapports empiraient, il n'avait que du mépris pour tout ce qu'elle essayait de faire. Les études, en particulier, lui semblaient du plus haut ridicule. Il riait des "petites gens" qui avaient besoin de diplômes. Il avait bien réussi, lui, 
et sans peau d'âne. Elle oublia ses problèmes grâce à l'effort qu'il lui fallait pour s'exprimer dans une langue qu'elle connaissait mal.

Deux heures plus tard quand elle sortit elle crut rêver. Sa voiture était couverte de neige. La tempête faisait rage et les flocons obscurcissaient le parebrise. Il devait y avoir dix centimètres de neige sur le sol et ses pieds étaient tout mouillés. Elle démarra et se dirigea à 1'aveuglette vers la maison. A la hauteur de la cathédrale elle eut le désir impulsif d'entrer prier. Elle n'était pas prête à confronter Martin. Elle voulait préserver quelques minutes de paix supplémentaires. Ce ne fut pas sans mal que la voiture accéda au sommet de la côte qui conduisait au parking derrière 1'église. Il était stupide de retarder ainsi son retour, mais elle n'était pas rationnelle, elle se moquait de 1'orage, elle voulait faire ce qui lui plaisait. E1le descendit de voiture et se précipita en courant vers la porte pour éviter d'être trempée. Elle glissa et tomba en arrière. Elle atterrit sur le coude gauche, le choc heureusement amorti par la doublure du manteau. Elle regarda autour d'elle, c'était une chance, personne ne $1^{\prime}$ avait vue étendue de tout son long dans la neige comme une idiote. Elle se releva toute raide, et elle tituba jusqu'à la vieille église.

Il lui fut impossible de prier, son bras la faisait trop souffrir. Elle se demanda si elle devrait aller directement à 1'hôpital, mais elle était blessée, elle ne voulait pas être seule. Elle désirait de toutes ses forces que Martin s'occupât d'elle. Elle crut qu'elle n'arriverait jamais jusqu'à la voiture. Il lui fallut dix minutes pour faire demi-tour dans la neige avec un seul bras et elle ramena la voiture au garage avec l'énergie du désespoir.

I1 était quatre heures et demie et Martin avait un verre à la main. Son regard bleu était dur et coléreux. Quoique corpulent il se tenait très droit et semblait grand bien qu'il ne mesurât qu'un mètre soixante dix. I1 lui fit penser à un juge aux enfers, Eaque peut-être. Son désir d'être protégée vola en éclats, elle était condamnée.

"Je suis tombée, mon bras me fait affreusement mal." "Tu es tombée? Sur le dos? Il faut que j'appelle le 
kinésithérapeute immédiatement. Ta colonne vertébrale doit être toute de travers." Martin détestait les docteurs en médecine, les pilules chimiques, il ne croyait qu'aux rebouteux, aux drogues naturelles. Elle le supplia, grelottant dans son manteau mouillé, elle sentait la nausée l'envahir. Il pourrait peut-être la conduire au service de secours à 1'hôpital. Ça ne coûterait rien puisqu'ils étaient assurés. Il était sourd. Sa colonne vertébrale . . le kinésithérapeute . . toute de travers. Les mots l'étourdissaient. Elle s'assit.

"Bon, appelle-le." "N'importe quoi," pensa-t-elle, "n'importe quoi, pour qu'il se taise."

"Oui, Docteur, je 1'amène tout de suite." "Viens," ordonna-t-i1, "un bon traitement et tu sera remise à neuf."

Ils s'assirent dans le salon d'attente surchauffé. Martin disparut derrière un numéro de Life. Elle ne pouvait ni lire, ni penser. Finalement on prit des radios, et comme Martin 1'avait prévu, son bras était en parfait état. On la fit monter et descendre des tables de traitement, tenant son bras "en parfait état" et sa colonne vertébrale fut craquée, tirée, tordue.

"Y a-t-il quelque chose que je puisse faire contre la douleur?" demanda-t-elle, sans espoir. "Faites des bains de sels d'epsom, ça s'arrangera."

Martin conduisait nerveusement et la voiture dérapait le long des rues boueuses et glacées. Il avait faim. Il attendit qu'elle soit couchée, sans d'ai1leurs I'aider à enlever la lourde couverture indienne qui lui servait de couvre-1it. I1 lui apporta les sels d'epsom que le docteur avait prescrits.

"Veux-tu quelque chose à manger?" Elle n'avait pas faim, mais même si ça n'avait pas été le cas la réponse qu'il attendait était "non".

Elle l'encouragea à sortir plutôt que d'avoir à nettoyer derrière lui s'il préparait son propre dîner.

En s'asseyant dans son lit elle constata que son côté gauche était mouillé. Elle souleva le bol en plastique dans lequel avait baigné son coude. Elle se rappela, c'était celui dans lequel Martin avait'fait la pâte à crèpes le dimanche précédent. I1 l'avait poussé trop près de la poële électrique et il y avait un petit 
trou sur la paroi. Son sens de l'humour prit le dessus et elle éclata de rire.

Elle se leva pour rapporter 1 'inutile objet dans 1 a la cuisine. Il lui était impossible de refaire son lit avec un seul bras et bien qu'elle essayât de se convaincre qu'il n'y avait rien de cassé chaque mouvement involontaire de son bras gauche la faisait hurler. Pourtant comme elle ne pouvait pas rester plantée là, elle retourna se coucher. Elle se rappela qu'elle devait inviter un certain nombre de dames par téléphone pour une réunion le dimanche suivant, et il y avait un appareil près de son lit. Cela 1'occupa jusqu'au retour de Martin. Il passa le nez dans la porte, ayant vérifié qu' elle était toujours là il avait satisfait son sens du devoir, et il se retira dignement dans ses appartements.

Elle avait encore un coup de téléphone à donner. Sa voix n'était pas très assurée et Marge s'en inquiéta. Elle lui raconta $1^{\prime}$ accident et son amie offrit de $1^{\prime} \mathrm{em}-$ mener à 1'hôpital. "Je vais demander à Martin et je te rappelle." Martin dormait déjà. Il avait bien bu et bien mangé. Elle pouvait aller sur la lune si ça lui plaisait. Le docteur Ramirez avait dit qu'elle n'avait rien. Si elle était hypocondre c'était son affaire.

Il fallut que Marge $I^{\prime}$ aide à s'habiller. Elle n'osait pas se regarder dans la glace, elle n'imaginait que trop bien ce à quoi elle ressemblait avec sa jupe rouge trop large, ses collants noirs et le vieux chandail dont sa fille avait presque totalement éliminé les coudes. Elle avait retiré son maquillage, et elle sentait les cernes noirs qui soulignaient ses yeux. Heureusement ses cheveux courts, faciles à coiffer, lui conservaient un semblant d'élégance. Marge lui jeta un manteau sur les épaules.

$\mathrm{Au}$ service de secours 1'infimière se moqua gentiment d'elle. Il était neuf heures et la chute s'était produite à quatre heures; un vrai cas d'urgence. Le processus se déroula, on appela le médecin de service qui prescrivit des radio, et on la mit dans un fauteuil roulant malgré ses protestations. A la sortie de l'ascenseur on la gara face au mur. Il fallait radiographier son bras de dos, de face et de profil, et chaque position était plus pénible que 1 'autre. On la roula de nouveau dans le corridor. Les radios furent dévelop- 
pées rapidement et le médecin crut détecter une fine fracture de la tête du radius.

"Il faut que vous appeliez un spécialiste, qui voulez-vous?" E1le donna le nom que lui souffla Marge. Vingt minutes plus tard une femme médecin au sourire rassurant fit son apparition. Elle prit la main gauche d'Agathe et la tordit légèrement. "Aie!" hurla Agathe. "Le médecin de service a raison, Vous avez une fracture, il faut que je mette un plâtre."

En quarante ans Agathe ne s'était jamais rien cassé, et le plâtre qualifié de léger lui semblait très lourd et plutôt malcommode, son bras était immobilisé à angle droit. La spécialiste prescrit un analgésique et lui donna rendez-vous pour la semaine suivante.

I1 était plus de onze heures quand Agathe rentra de 1'hôpital. L'affectueux pointer blanc se leva pour 1'accueillir et Martin le suivait, revêtu de sa veste de pyjama. "Marge est avec moi," le prévint-elle. Il fit une retraite hâtive, et attrappa sa robe de chambre bleue à pois blancs. Il rentra à grand bruit dans le salon. I1 portait ses bottes. "Il ne sera jamais adulte," pensa-t-elle.

"Vous voulez prendre un verre avec moi?" demandat-il à Marge. "Non merci, il est tard, il faut que je rentre." "J'en prendrais un volontiers," dit Agathe. I1 la regarda avec moquerie, "Tiens, tu te réformes?" I1 prit conscience de son plâtre et se livra à la plus grande hilarité." "Tu es contente, tu es infirme, si tu savais comme tu as I'air bête."

Marge était mal à son aise. Elle n'aimait pas la façon dont Martin la détaillait. Elle s'esquiva le plus poliment qu'elle put.

Ils étaient seuls. Agathe prit une longue gorgée de scotch et fit face à l'inévitable attaque. "Je t'avais prévenue, les docteurs en médecine sont des ânes. Qu'est-ce que tu vas faire avec un seul bras?" "Il est cassé, il fallait 1'immobiliser." "Sainte Agathe," persifla-t-il "pourquoi ton Dieu ne te guérit-il pas? Ne compte pas sur ma sympathie." C'était une sous-estimation de son attitude. Elle résista à l'envie de I'assommer avec son plâtre. Au moins il était franc. I1 avait tellement 1 'habitude de la maltraiter qu'il n'essayait même plus d'être aimable. Elle commençait à sen- 
tir les effets de 1'analgésique. "Bonsoir, je n'en feux plus."

Elle resta éveillée encore un moment. Les réverbères créaient des ombres chinoises dans l'énorme chambre. A plat sur le dos elle se sentait flotter vers le haut plafond. Les objets familiers étaient 1à. Les photos de ses enfants sur la longue table de nuit lui souriaient dans la demi-obscurité.

"Nous y voilà donc," constata-t-elle. "I1 se sent en sécurité, il pense que ma religion m'empêchera de me libérer. Mais qu'est-ce qu'il croit? Que d'être charitable signifie qu'il faut céder à l'injustice? Il a beaucoup à apprendre. Charité bien ordonnée commence par soi-même. Aime ton prochain comme toi-même. Je ferais aussi bien de commencer par moi." Et elle sombra dans un profond sommeil.

Quand elle se réveilla Martin était dans la pièce regardant son plâtre avec mépris. "Je veux divorcer," dit-elle calmement.

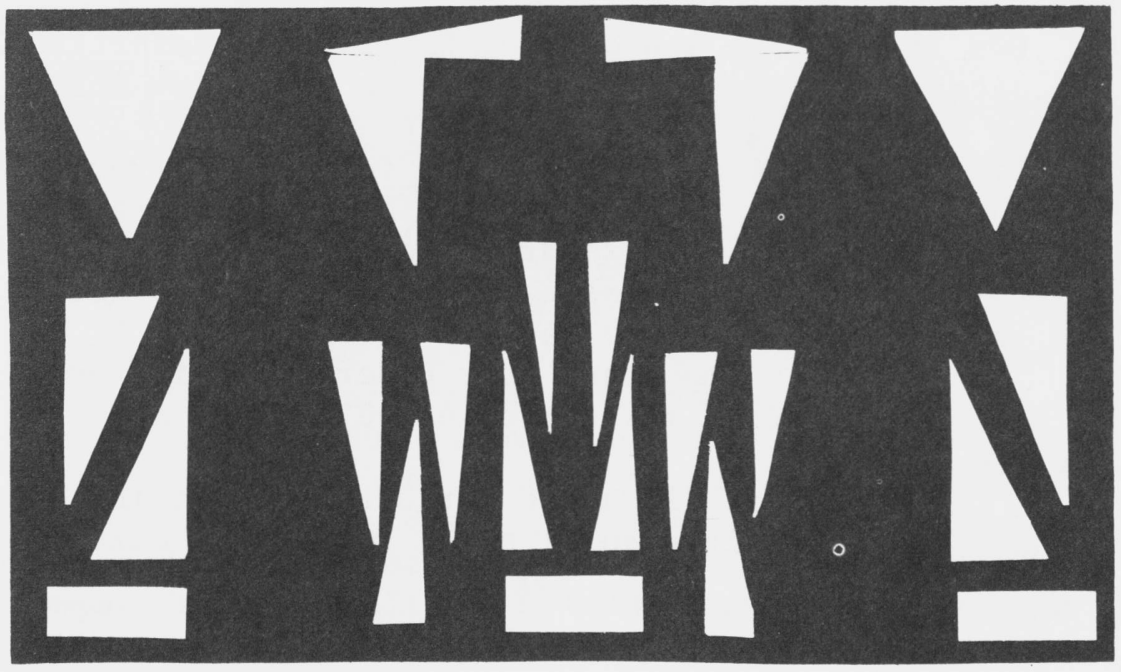




\section{"Jacques le fataliste" Diderot et le roman}

\section{Lucie Bryant}

Le dix-huitième siècle est une période de transition. Les genres dramatiques se modifient ou se meurent. Le roman se forme par tâtonnements. I1 tend d'abord vers 1 'histoire et vers les mémoires puis s'oriente vers des genres nouveaux comme le conte philosophique et le conte moral. Voilà donc une richesse de problèmes offerts à la réflexion des romanciers et particulièrement à la réflexion de Diderot.

Nous allons étudier comment Diderot envisageait $1 e$ beau et la création romanesque et pour quelles raisons cette création devait différer de celle de ses prédécesseurs. Quelles devaient être selon lui les qualités et même peut-être les défauts d'un romancier? Nous allons tenter d'évaluer dans quelle mesure il a appliqué ses théories à la création d'un de ses romans, écrit en 1773 et publié chez 1'éditeur Buisson en 1796: Jacques le fataliste.

Dès le début de son oeuvre, Diderot nous avertit que Jacques le fataliste n'est pas un roman, du moins pas un roman tel qu'on en composait avant lui.

"Il est bien évident que je ne fais pas un roman puisque je néglige ce qu'un romancier ne manquerait pas d'employer. Celui qui prendrait ce que j'écris pour la vérité serait peut-être moins dans $1^{\prime}$ erreur que celui qui le prendrait pour une fable." (p. 43)

Voilà le mot important pour Diderot: faire vrai. La nature nous offre mille modèles où choisir notre matière.

"La nature est si variée surtout dans les instincts et dans les caractères qu'il n'y a rien de si bizarre 


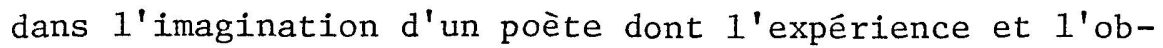
servation ne nous offrissent de modèle dans la nature." (p. 90)

Il faut faire simple, grand et large par la varié,té qui frappe, la masse qui impose. Puisée dans la nature, cette masse engendre des idées de durée, de puissance et de solidité. Seule l'expression immédiate et directe des passions dans leur forme spontanée lui semble être vraie et naturelle. C'est que pour lui l'art doit représenter la vie dans tout son flux et pour lui, la vie ce sont $1^{\prime}$ amour et la nature grâce auxquels il peut échapper à une civilisation artfficielle et brutale, génératrice de misère et de mort. Après la contrainte du XVII e siècle, Diderot veut libérer l'homme au nom de l'instinct et de la science.

La nature est $1^{\prime}$ ensemble des lois qui nous régissent et elle est matière d'art. Il faut la décrire, mais les descriptions doivent être subordonnées à un sentiment qui inspirera un personnage et elles doivent surtout représenter une richesse d'impressions. La nature instruit 1 'homme et lui suggère des idées philosophiques en multipliant ses sensations, surtout s'il s'agit d'un homme de génie. L'enthousiasme est la condition même de I'oeuvre d'art. L'inspiration naît de la passion, elle se traduit par un trouble psychique qui jette 1 'homme de génie hors de lui-même et lui fait saisir la complexité de 1 'homme et de son destin.

Pendant toute sa vie, Diderot a été conscient des nombreux paradoxes qui empêchent 1 'homme de génie de parvenir à une vérité définitive. Un des grands problèmes qui a préoccupé Diderot est celui de la liberté, liberté pour 1 'homme d'atteindre au bonheur qui est surtout fait de la connaissance de son être intime mais aussi de ses relations en tant qu'homme avec le monde extérieur. Dans Jacques le fataliste, Diderot présente les deux aspects de la question de la liberté. Le mầtre de Jacques se sent libre intuitivement et il croit à la liberté. Jacques, lui affirme que c'est une illusion et que "tout est marqué sur le grand rouleau." Tout au long du roman Jacques montre 1 'enchaînement d'une série d'épisodes qui sont en apparence commandés par un destin implacable et aveugle. Cependant notre sympathie va au maître qui veut reconnaître à chaque 
homme une essence personnelle, unique, capable de s'améliorer par 1'effort indépendant du coeur et de $1 \mathrm{a}$ volonté.

Ayant présenté ces deux positions opposées, Diderot laisse entendre que Jacques et son maître ont tort tous les deux. Il est ridicule de vivre comme si tout était inécaniquement organisé mais croire à notre liberté est une illusion. Il y a là un conflit que Diderot n'a jamais réussi à résoudre et il pense que l'homme ne peut trouver de solution définitive, du moins dans cette vie terrestre.

"Qui sait cela avant que d'être arrivé au dernier mot de la dernière ligne de la page qu'on remplit dans le grand rouleau?" (p. 287)

La dignité de 1 'homme est donc pour Diderot dans la recherche et non dans la découverte de la vérité. L'unité de 1'homme et surtout de 1'écrivain peut se trouver dans le combat qu'il mène pour rechercher et présenter la vérité relative dans toute sa multiplicité. Ainsi compris le destin de l'homme s'exprime en paradoxes qui permettent à Diderot de proposer à ses lecteurs les aspects divers d'une même question et aux lecteurs d'avoir une plus grande connaissance des problèmes traités. Un paradoxe trouble aussi le lecteur en lui proposant un choix et le force à réfléchir. Diderot oblige le lecteur à participer activement à la recherche de la vérité au lieu de suivre l'opinion arrêtée des auteurs du passé.

"Un paradoxe n'est pas toujours une fausseté. Soyez circonspect si vous ne voulez pas prendre dans cet entretien de Jacques et de son mâ̂tre le vrai pour le faux et le faux pour le vrai." (p. 90)

Voilà justement une des grandes difficultés pour l'écrivain qui veut faire vrai; la difficulté de définir la vérité. Peut-être un événement était-il vrai ou peut-être faux? sait-on jamais? Un écrivain selon Diderot ne doit pas être un fade panégyriste ni un censeur amer, mais doit offrir les faits comme ils sont et 1a chose n'est pas aisée.

"Mon cher maitre, la vie se passe en quiproquos. I1 y a les quiproquos d'amour, d'amitié, les quiproquos politiques, de finance, de magistrature, d'église, de commerce, de femmes et de maris..." (p. 81) 
Diderot accuse le monde de ne pas comprendre non seulement les intentions mais aussi les actions, qui, elles, devraient être faciles à évaluer.

"Si 1 'on ne dit presque rien dans le monde qui ne soit entendu comme on le dit, il y a bien pis, c'est qu'on n'y fait presque rien qui soit jugé comme on $I^{\prime}$ a fait." (p. 81)

Un autre aspect du problème de la difficulté de saisir la vérité èt du problème de la liberté est traité avec insistance par Diderot. Le maître croit à la possibilité d'un acte libre, choisi sans motif, sans intérêt personnel vital, un acte gratuit, accompli seulement pour se prouver qu'on est libre. Diderot montre qu'un tel acte est une illusion car un acte n'est jamais isolé, il est toujours suivi de conséquences que l'auteur de I'acte ne peut prévoir. Ainsi le mâ̂tre a raconté à Jacques les conséquences inattendues de la nuit qu'il avait choisie de passer avec Agathe. Diderot conclut alors:

"On passe les trois-quarts de sa vie à faire sans vouloir et à vouloir sans faire." ( p. 288) Diderot insiste plusieurs fois sur l'impuissance de 1 'homme à choisir son destin. "Faute de savoir ce qui est écrit là-haut, on ne sait ni ce qu'on veut ni ce qu'on fait et on suit sa fantaisie qu'on appelle raison ou sa raison qui n'est souvent qu'une dangereuse fantaisie qui tourne tantôt bien tantôt mal." ( p. 40)

I1 faut se rendre compte, nous dit Diderot, que si 1 'on pose une cause, un effet s'ensuivra et que d'une cause faible naît un effet faible, d'une cause momentanée, un effet momentané et cela souvent sans notre accord. Un fou seul, dit Diderot peut user de sa liberté sans motif.

Diderot veut que 1'artiste écrive pour être utile, pour enseigner aux hommes la situation paradoxale dans laquelle ils se trouvent, pour aider au progrès intellectuel, social et moral. Il ignore le dilettantisme et l'art pour l'art. Il brûle de communiquer ses impressions. Instruire est pour lui civiliser mais il faut avant tout attirer $1^{\prime}$ attention du lecteur sur 1a diversité de la vérité. Il est nécessaire également de plaire, d'être agréable. 
"La vérité est souvent froide, commune et plate. Un récit peut être vrai, mais pas intéressant. S'il faut être vrai c'est comme Molière, Regnard, Richardson, Sedaine. La vérité a des côtés piquants qu'on saisit quand on a du génie." (p. 64)

Diderot veut plaire et amuser pour faire réfléchir par des réflexions contradictoires. Il dit qu'il est facile de faire des contes car le conteur a la liberté de jouer avec ses personnages. Il est un dictateur qui tire les êtres du néant, les dirige suivant un ordre établi et des fins fixées à l'avance. Rien n'est, dans les contes classiques, laissé au hasard, tout est justifié mais Diderot veut renoncer aux préjugés, à la tradition, à 1'autorité. I1 rejette tout ce qui rend 1 'esprit prisonnier. Il veut avoir 1'audace de penser par lui-même. Il ne veut pas prononcer de jugements définitifs. Il veut présenter des rapports entre diverses idées. Dans L'Essai sur le mérite et la vertu, Diderot avait déjà exprimé cette idée de rapports en définissant sa conception du beau:

"J'appelle beau hors de moi, tout ce qui contient en soi de quoi réveiller de mon entendement l'idée de rapports et beau par rapport à moi, tout ce qui réveille cette idée."

Diderot utilise son intelligence pour établir des rapports et percevoir des analogies. Il aime tirer d'un principe ses conséquences les plus opposées et les plus extrêmes. Ses connaissances scientifiques lui ont révélé une foule de formes vivantes passant de l'une à l'autre dans un ordre croissant de complexités et de nouvelles espèces découvertes chaque jour, d'où la nécessité d'assouplir les ordres de classification. Diderot en tire la conséquence qu'en littérature de même les règles $n$ 'ont aucun caractère sacré. Elles consacrent les coutumes des siècles passés mais il faut créer de nouveaux types.

Des sciences naturelles Diderot a retenu qu'aucune interprétation ne résiste aux résultats d'une expérience. La loi, née en laboratoire n'a d'autre utilité que de permettre de nouveaux essais. L'expérience propre, l'intérêt présent et la voix de la conscience voilà les grands professeurs de la vie. Diderot a substitué à la notion abstraite de 1 'homme en général, la réalité vi- 
vante de l'être de chair, de ses faiblesses, de ses contradictions mais aussi de son inlassable curiosité.

Se refusant à ériger ses idées en système puisque la vérité est toujours variable et sans cesse à poursuivre, Diderot demande au romancier d'être un homme de goût. Ce goût est le fruit de l'expérience, d'une infinité d'expériences qui se réveillent devant un objet nouveau et déterminent pour un temps bref le jugement qu'on leur porte. I1 faut rechercher la vérité sans cesse. Pour cela 1'artiste doit par la réflexion et l'étude, mêlant l'expérience à la méditation, se libérer des préjugés de son éducation et de la société qui l'entoure. Il doit s'efforcer de se créer un univers intérieur où 1 'unité et 1 'harmonie sont créées par le désir d'être ouvert à toutes les possibilités humaines. La grande règle est la convenance c'est à dire l'adaptation exacte de 1 'ouvrage à son objet. Dans Jacques le fataliste, Diderot montre que la vérité est complexe diverse, contradictoire. I1 rend compte des aspects opposés de chaque question, ici du problème de la liberté, et sa curiosité, son esprit toujours en mouvement, sondent les diverses possibilités qui se présentent à la liberté humaine, mais aussi ses limitations. Il s'intéresse plus au problème qu'à la solution, nous avons vu plus haut qu'il ne croit pas aux solutions définitives. C'est pourquoi l'examen des opinions diverses sur un même sujet s'offre à lui sous la forme d'un dialogue, d'une discussion. On sent dans son effort de persuader le besoin de se persuader lui-même et d'aller au-delà des apparences. Le crime contre $1^{\prime}$ esprit pour Diderot c'est une défaillance dans la recherche de la vérité.

Dans Jacques le fataliste, Diderot divise son moi entre divers interlocuteurs. Jacques incarne son goût de $1^{\prime}$ aventure intellectuelle, sa satire du déterminisme, son admiration pour I'instinct sexuel qui est nécessairement bon, et doit être libre. Jacques et son mâttre critiquent la civilisation millénaire qui gâte I'homme et lui apporte une déchéance physique et morale. Diderot assiste au débat, partie et juge. Il contemple ses propres transports et ni sa spontanéité ni sa clairvoyance ne sont altérées.

La recette de Diderot pour créer ce qui n'est pas 
un roman traditionnel mais un roman philosophique apparaît assez simple. Il se sert de supports romanesques plaisants ou, si possible, frappants pour offrir une thèse philosophique ou une critique des moeurs, par exemple dans Jacques le fataliste. Il attaque tout ce que la société de son temps avait appris à respecter. Sa critique est aigüe, lucide, dirigée par une impétuosité sans frein. Il doit en effet se débarrasser des préjugés anciens avant de continuer sa recherche de la vérité. Ce récit endiablé contient une leçon morale, sociale ou philosophique qu'il appartient au lecteur de dégager.

"Quelque soit le récit que tu m'as promis, sois sûr qu'il ne sera vide d'instruction que pour un sot." (p. 233)

Diderot a critiqué la littérature post-classique où tout, disait-il est ordonné, conventionnel et par conséquent plat et ennuyeux. Lui-même a tenté 1'inverse en emplissant son oeuvre d'aventures piquantes et apparemment désordonnées et même, disons le mot, d'obscénités dont d'ailleurs il s'est défendu en disant qu'il voulait faire vrai et que la nature ne faisait rien d'inutile ni de superflu. Un écrivain doit avoir le courage de présenter les choses comme elles sont.

Toujours pour être conforme à cette vérité vivante, Diderot n'a pas rempli son récit des retours préparés avec soin des divers personnages. Il ne veut pas faire revenir sur la scène de son roman un personnage pour l'unique raison de continuer son récit avec harmonie. Souvent ses personnages apparaissent, représentent une idée et leurs actions sont choisies dans ce but, puis ils disparaissent pour toujours du roman et d'autres personnages font leur apparition pour quelques pages. Tout doit rester vrai et la vie est complexe. Pour cette raison il hait les portraits qui ne ressemblent pas aux originaux.

"Racontez les faits, rendez-moi fidèlement les propos et je saurai bientôt à quel homme j'ai à faire. Un mot, un geste m'ont parfois plus appris que le bavardage de toute une ville." ( $p$. 282) Pour la même raison il n'aime pas non plus les descriptions. "Ah. Jacques fais-moi grâce, je t'en prie et de la description de la maison et du caractère du docteur et de 1'humeur de la 
doctoresse et des progrès de ta guèrison; saute, saute par-dessus tout cela." (p. 105)

I1 faut présenter les choses sans rien omettre ni rien ajouter et il refuse dans Jacques le fataliste d'insérer 1a lettre d'Agathe, 1'amie du mâ̂tre de Jacques, lettre qui, dit-il se lit avec plaisir mais détruit l'idée présentée par le roman.

Pour Diderot, un roman traditionnel est une histoire dont le fond est inventé et dont la forme est arrangée, par conséquent une histoire doublement fausse. Diderot, lui, écrit une histoire doublement vraie, car il ne dit que ce qui arrive (voilà pour le fond) et à mesure que cela arrive, (voilà pour la forme). En raison de sa devise: "Vérité, vérité." Diderot se doit de présenter une histoire décousue, faite de mille événements hautement colorés qui s'échappent sans cesse et se rejoignent souvent on ne sait comment. A tout moment 1'auteur est interrompu, s'interrompt lui-même et interrompt ses interruptions. I1 y a des coqs-à-I'âne saugrenus. Diderot explique que c'est pour mieux imiter la nature qui ignore $1^{\prime}$ art des transitions et ne s'efforce pas de bien comparer et de bien organiser. On a reproché à Diderot son manque d'ordre, son style négligé, et 1 'absence de composition de son oeuvre, mais il a pratiqué le désordre de façon consciente et même systématique et quand son tempérament enthousiaste l'emportait c'était un atout de plus pour son art de romancier.

Il y a une qualité nécessaire à l'écrivain, que Diderot souligne, c'est la sensibilité. La sensibilité confère à $1^{\prime}$ homme sa noblesse d'âme et $1^{\prime}$ excite à $1^{\prime}$ 'action et à $I^{\prime}$ enthousiasme mais Diderot pense que la sensibilité est également dangereuse car une trop grande sensibilité obscurcit parfois les notions de vrai et pousse un écrivain à l'erreur; cependant un homme ne peut être génial sans une âme sensible.

Diderot a produit une oeuvre originale qui a su envisager les problèmes du roman au dix-huitième siècle. Il n'a pas résolu les questions qu'il s'est posées, il n'a pas pu établir une esthétique absolue mais il a cherché à nous présenter les données de certains problèmes esthétiques. Il a montré que pour connaître un homme il fallait être arrivé au dernier mot que l'on 
écrit sur le grand rouleau et que la vie est mouvante, fluide sans cesse renouvelée. Par les nombreuses digressions, les nombreuses aventures de Jacques le fataliste il a offert différentes facettes de 1'homme, il a aussi proposé diverses solutions mais il a affirmé qu'il pouvait y avoir d'autres solutions aussi valables.

"Jacques a dit cent fois qu'il était écrit là-haut qu'il n'en finirait pas de l'histoire. Je vois, lecteur, que cela vous fâche; eh bien, reprenez son récit où il l'a laissé et continuez-le à votre fantaisie." (p. 305)

Diderot échappait avec Jacques le fataliste aux cadres rigides d'une classification, ici raison, ici sentiment. Il devait suivre le devenir des âmes et des esprits et montrait la coexistence de deux forces qui allaient devenir à nouveau divergentes. Le dix-neuvième siècle allait tourner le dos aux théories romanesques de Diderot mais à la veille de la première guerre mondiale, André Gide devait libérer 1'art du roman selon des lignes de pensées analogues.

\section{Bibliographie}

Diderot, Denis. Jacques le fataliste (Collection Dilecta, Editions Albin Miche1, Paris, 1963). Toutes les références à Jacques le fataliste se rapportent à cette édition et seront désormais indiquées dans le texte.

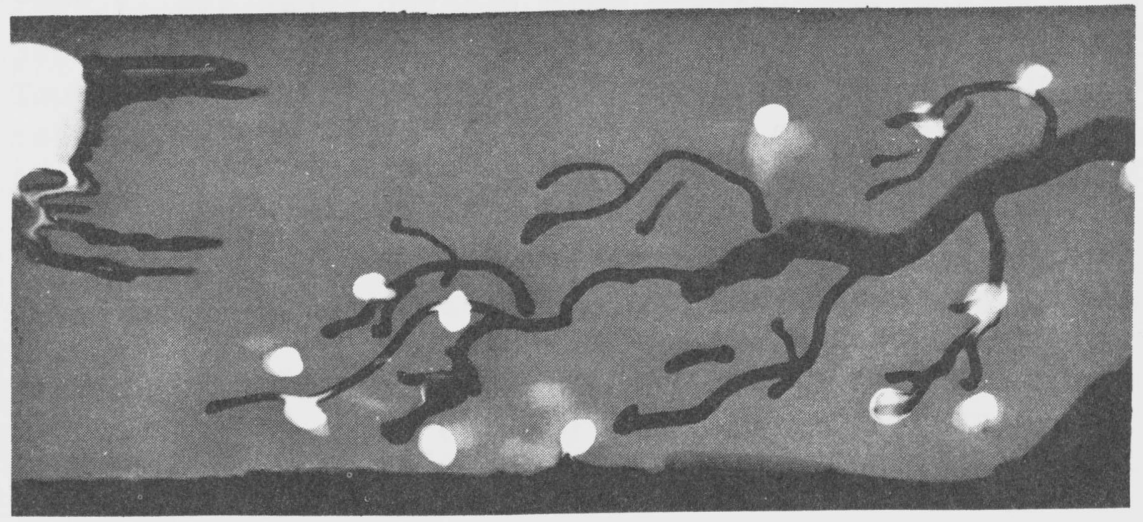


Votre tram est un paysage choisi

òu s'encaquent des mégères fantasques

Jouant du coude, sapant le bibi,

Sinistres sous leurs accoutrements flasques.

Tout en se plaignant "̀ chaque rumeur

L'estomac creux, 1a faim inopportune

Pourpres, dégoulinantes de sueur

Leurs bélements se mêlent au clair de lune.

Au clair de lune électrique et beau

Frénétiquement, non loin des arbres

Elles s'agitent comme des jets d'eau

Et ne ressemblent en rien à des marbres. 


\section{Le Long voyage du Père Lycan}

\section{Michel Coclet}

En irrespectueux hommage à un tas de gens.

Lorsque 1e Père Lycan ouvrit les yeux qu'il avait fermés quelques heures auparavant, il s'aperçut qu'il ne voyait rien. Deux hypothèses se présentèrent à son esprit, et l'esprit en question, après les civilités d'usage, les examina de la tête aux pieds, c'est-à-dire fort attentivement. Ces deux hypothèses, avouons-le, étaient loin d'être séduisantes; on peut même dire sans exagération aucune qu'elles étaient laides comme des poux. Toujours est-il que le Père Lycan s'absorbant dans 1 'examen de ces foutues hypothèses se mit à soliloquer comme suit: "Sacré nom d'un petit bonhomme! Comment-est-ce que ça se fait-il que j'y voyons rien? De deux choses l'une: ou bien $j$ 'ons perdu la vue subito presto, ou bien j'ons z'été percipité dans un grand trou tout noir, muni d'un couvercle étanche, et sans musique, sacré nom d'un petit bonhomme!"

Il faut dire pour la défense du Père Lycan qu'il était fort tard, et que par voie de conséquence les petits rouages délicats de son cerveau se refusaient obstinément à fonctionner comme ils eussent dû. Ils crissaient, grinçoyaient et crachouillaient, en sales petits rouages fainéants et mal élevés qu'ils ẻtaient; I'un d'eux alla même jusqu'à émettre un ricanement sarcastique autant que déplacé à $l^{\prime}$ adresse de la'moins séduisante des hypothèses, puis passa en roue libre sans plus de façons, de sorte que tout le mécanisme se mit à tourner à vide. Et le Père Lycan se reprit à soliloquer interminablement: "Sacré nom d'un petit bonhomme, etc, etc. . . . . " 
Quand le destin cruel au doigt crochu, à l'ongle noir et aveugle agrippe sa victime, quand le sort maléfique accable le miséreux tel un marteau pilon qui s'abat à coups redoublés, force brute et sans âme, symbole de notre civilisation mécanisée (où le matériau humain est pilé et fondu dans le grand creuset à l'instar du mil ou du sarrasin, transformé en galette et jeté en pâture aux perles et aux pourceaux), et quand le violoniste se fait Parthe (comprenne qui peut!), c'est triste.

Le petit rouage voyou et mal élevé était toujours en roue libre, coinçant la bulle sur son axe et, pour employer le langage des sciences physiques, se complaisant fort dans un équilibre indifférent. L'indifférence, heureusement, n'était point partagée par le reste des rouages qui commençaient à la trouver mauvaise. Quoi? Ce rebelle lunatique allait-il se permettre encore longtemps de troubler l'ordre? Ce propre-à-rien présentait un réel danger pour tout le mécanisme. Qu'il s'avisât de rester à l'écart une ou deux heures de plus, et les dégâts seraient irréparables. Déjà 1 'huile commençait à baisser dans le fond du carter, déjà les engrenages des niveaux supérieurs privés du précieux lubrifiant émettaient de sinistres grincements, đéjà le mouvement se ralentissait (ne confondons pas énergie cinétique et mouvement perpétue1); la terrible rouille ne tarderait pas à faire son apparition redoutée, à ronger, à corroder, en un mot à détruire. Bien sûr, il y avait toujours la possibilité de recourir à la mécano-chirurgie, mais en dépit de l'incontestable progrès que la récente découverte du degrip-oil permet dans ce domaine, les traumatismes post-opérationnels restent toujours quasi irrésorbables. De plus, 1'exemple de ce trublion était contagieux, I'anarchie rampait, un vent de fronde se levait, et ce n'était pas contre le Mazarin que ce vent là grondait. L'esprit du Père Lycan retentissait d'un tumulte inexprimable: au ronron de tous les jours s'ajoutaient les grincements des rouages privés d'huile, les récriminations des engrenages consciencieux réduits à I'oisiveté, les sifflements aigus du vent de fronde dans le mécanisme, et par dessus tout, la voix du Père Lycan qui soliloquait imperturbảblement: "Sacré nom d'un petit bonhomme! Comment-est-ce que ça se faiti1. . . etc. . . etc. . ." 
Ce pauvre Père Lycan était dans un état lamentable: de quoi émouvoir le plus insensible des rouages (un rouage au carbure de tungstène par exemple). I1 n'avait jamais été ce qu'il est convenu d'appeler un brillant sujet, mais tant qu'il s'appliquait à raisonner, si lentement que ce fût, il faisait encore bonne figure. Et même quelques instants après que le mécanisme de son esprit ait commencé à tourner à vide, son monologue était resté parfaitement compréhensible, grâce à la vitesse acquise, à la force de 1 'habitude, et un observateur non averti n'aurait rien pu déceler d'anormal. Il n'en était plus de même à présent: au fur et à mesure que le trouble se répandait en son âme, ses paroles devenaient confuses, son élocution indécise, pâteuse même, les mots s'entrechoquaient, se cabossaient, se déformaient, se recollaient comme ils pouvaient, c'était affreux. On en arrivait peu à peu mais inéluctablement à de sourds grognements inarticulés, entrecoupés de hoquets et de longs éclats de rire hystériques qui se prolongeaient et s'amplifiaient en résonnant à l'intérieur du crâne oblong du Père Lycan.

Cela affectait de plus en plus le fonctionnement déjà fortement compromis du délicat mécanisme logé dans ce crâne; et plus le mécanisme en était affecté, plus les éclats de rire se faisaient fréquents. Il y avait maintenant trois petits rouages qui avaient suivi $1^{\prime} \mathrm{e}-$ xemple du factieux, cause de tous les ennuis; les dernières gouttes d'huile s'écoulaient par le conduit d'évacuation; la fin était proche. C'est alors qu'en un élan sublime, faisant preuve d'une abnégation héroĨque, tout le mécanisme s'allia en un effort communautaire contre les éléments perturbateurs afin de les réduire et de les juguler, au risque de se perdre. Tous les rouages voisins des rebelles se déplacèrent sur leurs axes autant que le jeu nécessaire au bon fonctionnement le leur permettait, les axes eux-mêmes se déformèrent jusqu'à la limite de rupture pour permettre aux engrenages qu'ils supportaient d'atteindre les dissidents, et ceux-ci, pris entre deux et parfois trois engrenages, furent obligés de rentrer dans le rang et de se soumettre à la volonté générale. Le mécanisme était en márche. Une clameur, faible et assourdie d'abord, mais de plus en plus forte, une clameur d'allégresse s'éleva 
par dessus $\bar{l}$ e ronronnement qui reprenait, la pompe à huile se remit en route, et le premier moment de délire passé on n'entendit plus que le chant joyeux du syndicat des roues, pignons et engrenages: "Dent pour dent, dent pour dent. Dent pour dent, dent pour dent". L'alerte avait été si chaude que tout ce petit peuple laborieux, mais dont certains membres s'étaient laissé entraîner sur le chemin de la négligence et de la nonchalance, mettait à présent tout son coeur à la tâche, avec une ardeur qui faisait plaisir à voir. Jamais cela n'avait si bien marché.

Le Père Lycan ouvrit les yeux qu'il avait femés quelques heures auparavant, et $s^{\prime}$ aperçut de nouveau qu'il ne voyait rien. Mais il se sentait extrêmement bien; en fait, il ne s'était jamais si bien senti. Et lorsque deux hypothèses se présentèrent à son esprit, il leur fit un petit signe guilleret de la main et les examina comme s'il n'avait fait que cela de son existence. Plus de soliloque infiniment répété et qui ne mène qu'au désastre, plus d'élocution indécise. Il se sentait en pleine possession de ses moyens. I1 commença par classer les deux hypothèses en deux catégories. Il rangea dans la première les circonstances qui déperdaient de lui, et dans la seconde celles qui ne dépendaient pas de lui. Cette classification opérée, le Père Lycan entreprit fort logiquement d'examiner chacun des êléments du problème. Si l'hypothèse selon laquelle il avait perdu la vue s'avérait être la bonne, il n'y avait rien qu'il pût faire dans l'immédiat; cela relevait directement du domaine de la médecine ou de 1a chirurgie, voire de la mécano-chirurgie; et bien que le Père Lycan ait éprouvé dès sa plus tendre enfance un intérêt extrêne pour ces trois sciences -- eu égard à leur caractère humanitaire -- son échec au Certificat d'Etudes Primaires $I^{\prime}$ avait empêché de se consacrer, ainsi qu'il l'eût souhaité, à I'étude d'abord et par suite à $1^{\prime}$ exercice de la médecine. Toujours est-il qu'à quelque chose malheur est bon, car à supposer que le père Lycan ait eu des notions précises en ces diverses sciences, il eût été à craindre qu'il ne s'avisât de s'opérer lui-même sur le champ, avec des instruments de fortune, dans des conditions d'asepsie quasi inexistantes, courant ainsi à un échec certain. Son absence de connaissances médicales lui permit donc d'éliminer sans 
plus balancer la première hypothèse et de passer à la seconde.

Et pendant ce temps-là les petits rouages tournaient à plein rendement, avec un doux ronronnement, sans heurt et sans reproche, conscients de la noblesse de leur tâche, et ce sentiment du travail bien fait les aidaient à accepter de bonne grâce les vicissitudes de leur sort, à surmonter les moments passagers de découragement dus à la fatigue. On entendait de temps à autre des gouttes d'huile excédentaires qui tombaient de toute la hauteur du mécanisme, et leur flic-floc était aux engrenages ce que les chants d'oiseaux sont aux cantonniers; on entendait aussi parfois un gros soupir émis par 1'un des ex-trublions, mais aussitôt suivi de "Tss! Tss! Tss!" à la fois réprobateurs, compatissants, encourageants et paternels, provenant des rouages voisins qui veillaient à la rééducation des dissidents et les aidaient à réintégrer leur place dans la société. Dans la pénombre, tout ce petit peuple laborieux oeuvrait conscien cieusement.

En examinant 1a seconde hypothèse, le Père Lycan se dit: "Sacré nom d'un petit bonhomme! Si que j'ons z'été percipité dans un grand trou tout noir, muni d'un couvercle étanche et sans musique, n'y a pas à paniquer. Sauf mon respect, je me battions $I^{\prime}$ oeil que $n^{\prime} y$ a point de musique! N'y a personne qui pourrera m'accuser d'aller plus vite que les violons! Et à plus vite que j'irions, à plus vite que je serions sorti de mon hypothétique trou noir! Refléchissons, que diable, refléchissons!" Et ce faisant, il apparut au Père Lycan que si le trou était, comme il le supposait, muni d'un couvercle étanche, il lui fallait porter ses efforts sur cet élément du problème. Qui dit couvercle étanche dit couvercle; qui dit couvercle dit cooperculum et qui dit cooperculum dit couvrir. Il ne manquait plus au Père Lycan que le préfixe "dé" pour sortir de son trou. Aussitôt, méthodiquement, et avec une agilité que nul n'eût soupçonnée, le Père Lycan se mit à fouiller ses poches, à les passer au peigne fin, dans l'espoir d'y trouver ce qu'il y cherchait. Sur le sol, près de lui, s'empilait une foule d'objets hétéroclites, tels qu'il s'en trouve dans toutes les poches. Ayant accompli cette besogne exténuante, le Père Lycan s'assit sur sa chaise 
dans l'ombre et contemplant avec satisfaction le petit préfixe qu'il tenait au creux de sa main, il se mit une fois de plus à soliloquer, mais en des termes cette fois fort étranges: "Zфgxuk tekhitkswat fethekk $\phi$ ! Gekkstw $\phi-$

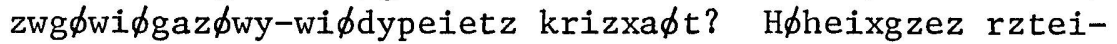
faф . . . $\phi_{w k a} . . . \emptyset_{w k a} . . . \emptyset_{w k a} . . . "$

L'esprit du Père Lycan était le théâtre d'une horreur rarement égalée, non point tant par son caractère spectaculaire que par son insidiosité. Dans l'ombre, silencieusement, sournoisement, I'hurluberlu factieux en faisait de belles: comme le Père Lycan s'acheminait lentement vers $1 \mathrm{a}$ fin de ses ennuis, au moment même où il mettait la main sur la clé du problème, ce malotru d'engrenage sans foi ni loi, ce misérable bout de ferraille était en train de commettre un acte défiant toutes les lois de la morale rouagique la plus élémentaire. Comme il ne pouvait plus ni s'arrêter, ni se mettre en roue libre, il venait de changer de langage! O horreur! Il s'était branché sur le poldave! Il tournait certes. mais poldave! Et le Père Lycan, parlant poldave, n'avait que faire de ce ridicule préfixe "dé" qu'il tenait dans ses mains. Il lui aurait fallu à présent la particule séparable " $\phi n$ ", et il ne suffit pas de parler poldave pour se retrouver ipso facto avec un assortiment complet de toutes les particules séparables de la langue poldave dans les poches! Et cette saleté de petit rouage polyglotte qui continuait à tourner poldave, et à ricaner silencieusement poldave de toutes ses dents.

Le Père Lycan alors se hissa sur ses pieds, laissa choir tristement son préfixe inutile, et l'écrasa par terre d'un coup de savate traînard et qui manquait de conviction. C'en était trop. A quoi bon! Telles étaient les profondes considérations auxquelles se laissait aller le Père Lycan. Et pour commencer, se disait-il en poldave, on peut très bien vivre dans un trou! Les mineurs par exemple, et sans couvercle même. $D^{\prime}$ accord ils ont un ascenseur et plusieurs étages. Ici pas d'ascenseur, mais c'est de plain-pied. Un peu bas de plafond peut-être. Et levant le bras pour se faire une idée des dimensions de son nouveau domicile, le Père Lycan n'eut aucune difficulté à toucher le plafond. I1 éprouva même une certaine surprise en se rendant 
compte qu'il lui suffisait de faire jouer les muscles de sa main, de ses doigts, de ses phalanges, pour que le plafond cédât sous la pression; et cela lui procurait une vive satisfaction physique. Le Père Lycan s'arrêta soudain en se disant qu'il pouvait peut-être réserver 1'usage ludique de ses muscles pour des activités ultérieures, et passer sans plus tarder aux applications pratiques du principe qu'il venait de découvrir. Il s'apprêtait à mettre à exécution cette pensée lorsque le couvercle s'ouvrit brusquement, sans grincer, mais en s'exclamant: "Eh! Jules! Ben $v^{\prime} l a$ aut' chose! Et sur une nationale! Viens voir ici!.. . Jules? Jules! Ben où qu'il est?" Puis il se tut.

Et 1à-dessus le Père Lycan se remit à penser en français, comme tout le monde. Le choc avait été trop grand pour le petit rouage (ou le rouage trop petit pour le choc): n'ayant jamais rencontré de couvercle parlant auparavant, il en oubliait de tourner poldave, tant ce phénomène le troublait. De temps à autre, comme il tentait de chasser de ses pensées cet inquiétant mystère, il revenait au poldave, puis re-tournait français, et ainsi de suite. Cela présentait un léger inconvénient pour le Père Lycan, car les transitions d'une langue à $1^{\prime}$ autre s'effectuaient avec une lenteur désespérante, de sorte que pendant de longues minutes, tout ce que le Père Lycan pouvait penser et dire se résumait à ces quelques termes: "Ah goch! Ah goch, goch, goch!" qu'il ne pouvait s'empêcher de noyer dans des flots de salive. Pendant les intervalles où sa pensée était claire, le Père Lycan se posait une foule de questions. Qu'était-ce que ce Jules? Pourquoi n'avait-il pas répondu à I'appel de son nom? Quand allait-il le faire? Ne serait-il pas judicieux de sortir de ce trou? Le Père Lycan établissait lentement une relation encore mal définie entre la venue proche de Jules et son sort personnel, et commençait à se douter que 1'un pourrait fort bien affecter $1^{\prime}$ autre. Tandis qu'il s'efforçait de formuler ce doute avec toute la clarté et la concision dont il était capable (condition nécessaire et suffisante pour passer à l'action), une scène d'une importance capitale se déroulait à la surface autant qu'à son insu.

La voix qui avait tant surpris le petit rouage anar- 

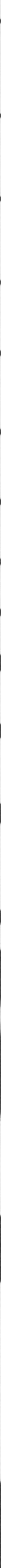
chico-polyglotte n'était certes pas venue du couvercle, mais d'un individu qui s'éloignait maintenant à grands pas à la recherche de Jules, vraisemblablement afin de lui relater verbalement les faits qu'il venait de constater, et de lui exposer son opinion en la matière. Il espérait sans doute de la sorte inciter Jules à se transporter sur les lieux dont s'agit, lui faire partager la même expérience, et, par la comparaison de leurs opinions respectives, fonder leur jugement de façon solide et certaine. Toujours est-il qu'il progressait avec une rapidité inhabituelle sur le bas-côté de la route, son corps perdant parfois tout contact avec la terre et s'élevant dans les airs, mais pour retomber ensuite et rebondir aussitôt, le même pied ne touchant jamais le sol deux fois de suite: il courait. I1 courait à la rencontre de Jules dont il apercevait la mince silhouette adossée à un poteau télégraphique distant d'une centaine de mètres; il arrêta sa course vagabonde en arrivant à la hauteur de ce poteau, et entreprit la silhouette en des termes d'une éloquence rare. Dès que Jules eut compris ce dont il était question, il se coinça un vieux mégot dans la bouche d'un geste décidé, remonta le pantalon de son bleu de travail, fit faire à sa casquette un demi-tour complet qui amena la visière par derrière, et se dirigea vers un curieux engin garé au bord de la route.

I1 est inutile de disstinuler flus longtemps la véritsable identité de Jules et son compagnon: ils étaient tous deux cantonniers de première classe, récemment promus au 3éme échelon, ce qui leur donnait droit à une augmentation de salaire non négligeable, au titre de grands manoeuvriers du destin affectés à l'exécution des basses oeuvres, et au port des insignes afférents à ce titre, sans mentionner les avantages secondaires et tertiaires. En vertu de ces avantages, ils étaient autorisés à faire fonction de gardiens du patrimoine national, dans un de ses aspects qui pour ne pas être des plus nobles n'en est pas pour autant moins nécessaire: ils étaient chargés de la réfection des routes nationales jusques et y compris la peinture des lignes jaunes et blanches, médianes et latérales, sous 1a haute direction du Ministère des Travaux Publics. La présence d'un trou, si beau fût-il, au milieu de $1 a$ 
route nationale, constituait une anomalie qui relevait donc directement de leur compétence et les deux manoeuvriers s'apprêtaient à y mettre bon ordre sans plus tarder. Jules avait en effet décidé de faire siennes les opinions de son collègue, et décliné l'invitation de celui-ci d'aller constater de visu, personnellement, et en la compagnie du collègue en question, le phénomène sus-mentionné. Ils s'étaient réparti les tâches fort équitablement, se proposant d'agir comme suit: Jules, usant du privilège que lui conférait $I^{\prime}$ ancienneté, se chargerait de diriger .l'E.P.L.J. (engin à peindre les lignes jaunes) tandis que son collègue comblerait le trou de gravillons goudronnés, ces délicates opérations devant être effectuées dans 1 'ordre normal des choses, la première d'abord et la seconde ensuite, contrairement à ce qui vient d'être indiqué.

Le Père Lycan avait pendant ce temps traversé plusieurs crises de logochée successives entre lesquelles il avait compris la nécessité urgente où il se trouvait de quitter ses pénates sub-nationales; il avait également considéré les diverses modalités de l'action qu'il envisageait d'entreprendre, et s'engageait à présent dans la première phase du processus d'extraction. I1 se tenait debout sur sa chaise et s'agrippait des deux mains aux rebords de son trou. Le piteux spectacle; cela faisait peine à voir: le coup de talon initial dont le but principal était de propulser le Père Lycan hors de son trou avait fait long feu', comme l'eût pu faire celui d'Achille après $1^{\prime}$ accident. Le second coup de talon ne valait guère mieux, et avait été suivi immédiatement par une avalanche de coups de talons successifs et précipités, le Père Lycan ayant de toute évidence sacrifié l'esthétique du geste sur l'autel de l'efficacité.

Jules avait enfourché 1'E.P.L.J. qui gronchognait maintenant, tressaillait dans un immonde fracas, vomissait des flots de fumée malodorante par un orifice prévu à cet effet, et, râclant le sol de ses pneus, s'ébranlait lentement. Le collègue de Jules, quant à lui, s'était placé dans les brancards d'une super-brouette emplie de gravillons goudronnés et la traînait derrière lui; il dépassa le trou de quelques mètres puis souleva I'avant de son véhicule, ce qui eut pour conséquence 
immédiate de faire baisser l'arrière. La brouette se trouvant alors, si $1^{\prime}$ on peut dire, en pente, le gravilIon commença à s'écouler.

Le Père Lycan jaillit hors de son trou en ouissant 1 'horrificque crépitement et s'étala de tout son long, face contre terre. Il se releva dès qu'il fut en mesure de ce faire, pour apercevoir le collègue de Jules qui proféra ces mots horribles: "Ben, mon cochon!" Le Père Lycan ne fit ni une ni deux (ni trois ni quatre). Un tonnerre monstrueux rugissait derrière lui: le soleil se couvrait d'une brume jaunâtre. I1 se tourna d'un coup et vit 1'E.P.L.J.

Alors, figé sur place, il se sentit aspiré irrésistiblement par le monstre, qui l'engloutit dans sa gueule béante aux senteurs de fuel-oil. Il perdit conscience. Quelques secondes plus tard, après avoir été broyé et mélangé à la peinture bouillante, il était recraché par l'E.P.L.J., étalé au beau milieu de la route en une longue ligne jaune fumante qui prenait par endroits des teintes orangées. Seule tressaillait encore une bulle contenant le petit rouage qui eut ainsi la joie d'assister au triomphe de șa force maléfique; il contempla satisfait le long cadavre du Père Lycan, mais peu à peu la peinture se fit opaque et il ne vit plus rien. Et Jules et son collègue, leurs travaux terminés, s'adjugèrent quelques minutes de pause en attendant cinq heures.

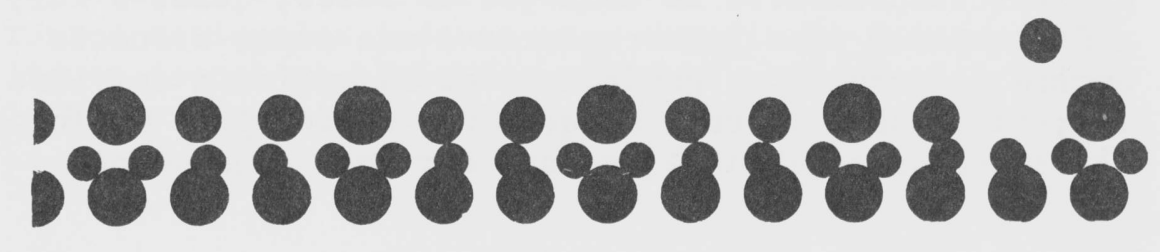




\section{La Comédie humaine}

\section{une réponse}

\section{Hans R. Runte}

"Ce n'est pas une vue bourgeoise du monde réel, c'est une vue réaliste du monde bourgeois."I

Balzac n'est pas universellement aimé. Aussi 1'amour que lui porte 1'auteur de notre aphorisme est-il bien un amour de tête. Car M. Wurmser est trop subtil (ou trop sincèee) pour dire tout nettement avec Maxime Nemo: "Je hais Balzac."2 Comment aussi aurait-il pu faire d'un livre aussi "humain"3 que 1 'est La Comédie inhumaine un livre qui suscite la haine?

Il faut donc différencier. M. Wurmser, lui non plus n'aime pas Balzac, mais c'est 1 'homme qu'il hait. I1 adore 1'écrivain. Il adore le monde balzacien parce qu'il y trouve d'innombrables illustrations de sa propre idéologie sociale.

Il déteste Balzac le bourgeois, et il n'aime le romancier réaliste que par les raisons qu'il lui procure de détester la bourgeoisie.

Le réalisme tel que le comprend $M$. Wurmser est un réalisme vu à travers une idéologie. C'est pourquoi La Comédie Humaine ne peut être "une vue bourgeoise du monde réel", la critique de l'oeuvre se réduirait alors à un pamphlet biographique, mais doit être le "monde bourgeois" détestable par principe, vu par un "réaliste", qui a le malheur d'être un bourgeois.

Il est évident que la notion wurmserienne du réalisme, prisonnière d'une idéologie, est trop étroite pour s'appliquer à la totalité de la création balzacienne. La réalité de La Comédie Humaine n'est pas exclusivement celle de 1 'or.

Pour M. Wurmser, le "monde réel" est "1e monde bourgeois." Le mérite de Balzac serait d'avoir fait de la bourgeoisie non pas l'objet purement littéraire d'un 
roman "bourgeois," mais 1'objet sociologique d'une critique "réaliste," écrite, il est vrai, par un bourgeois mais qui est d'une lucidité exceptionnelle.

Qu'on puisse voir, dans les personnages de La Comédie Humaine, des bourgeois qui tournent autour de $1^{\prime}$ or, soit. Mais le réalisme de Balzac ne s'y arrête pas.

La danse des personnages autour du veau d'or révèle une sous-réalité qui n'est plus bourgeoise, mais grotesque.

Je m'explique. Le grand fleuve de la création réaliste, qui jaillit de la source Saint-Hilaire et se jette dans 1'océan de La Comédie Humaine, coule majestueusement entre les bords de 1'analyse psychologique et de la critique socio-morale, tout en emportant avec lui les eaux plus ou moins troublées de ses tributaires romantiques ou idéalistes.

En effet, derrière l'inchangeable thème balzacien du jeune ambitieux se cache, dans Le Père Goriot, I'idéalisme du "Christ de la paternité," dans Le Lys dans la Vallée, la "Vierge de la maternité." Dans Illusions perdues coulent les flots souterrains d'un amour romantique qui rejaillit dans Splendeurs et Misères des Courtisanes, roman qui, par ailleurs, accumule de romanesques enlèvements, attentats, et déguisements.

Examinons quelques-unes des scènes où le sous-réel grotesque monte à la surface et devient visible.

Le Père Goriot est une oeuvre des "temps de douloureuse littérature, "4 autant vaut dire une oeuvre larmoyante: "l'oeuvre accomplie, peut-être aura-t-on versé quelques larmes..."(18). La scène est "entre les buttes de Montmartre et les hauteurs de Montrouge, dans cette illustre vallée de platras incessament près de tomber et de ruisseaux noirs de boue"(18) où 1'"obscure, mais effroyable tragédie parisienne"(149) se jouera dans "un océan de boue"(384). Le décor est lugubre: ".... rue Neuve-Sainte-Geneviève... Ie jour diminue et le chant du conducteur se creuse, alors que le voyageur descend aux Catacombes. ' Comparaison vraie! Qui décidera de ce qui est plus horrible à voir, ou des coeurs desséchés, ou des crânes vides?(20)... il s'y rencontrera toujours un lieu vierge, un antre inconnu, des fleurs, des perles, des monstres, quelque chose d'inoui, oublié par les plongeurs littéraires. La maison Vauquer est une de ces monstruosités ${ }^{5}$ curieuses"(33). Aussi 
Balzac s'est-il plongé avec délices dans cette mer d'où il tire au jour ce misérable père Goriot qui saisit les paroles de ses filles "comme un chien saisit un mouvement de son maître"(215). Ses sentiments paternels touchent à la démesure quand il apprend la misère de Delphine: "Mon Dieu! pleurer, elle a pleuré? -La tête sur mon gilet, dit Eugène. -Oh! donnez-le-moi"(237). Peu avant sa mort, son dévouement devient sans borne: "Mais on ne peut donc rien faire de son sang? cria le vieillard désespéré (365)...je serai plus qu'un père pour toi, je veux être une famille! Je voudrais être Dieu, je te jetterais 1'univers aux pieds" (367). Si de telles éruptions monstrueuses ont peut-être encore quelque chose de sublime, d'autres personnages, pêchés, eux aussi, dans "1'océan de boue," sont simplement macabres. Gobseck est caractérisé par une seule phrase saillante: il est "capable de faire des dominos avec les os de son père"(75). Vautrin, lui, est plus complexe, mais il a certainement un côté gigantesque:

"souvent il laissait percer l'épouvantable profondeur de son caractère (38)...cet homme, qui ne fut plus un homme, mais le type de toute une nation dégénérée, d'un peuple sauvage et logique, brutal et souple. En un moment Collin devint un poème infernal... Son regard était celui de 1'archange déchu"(311). A côté d'un tel homme, les autres paraissent des "esprits lilliputiens" (51), et cette allusion achève $1^{\prime}$ impression d'un monde fantastique que Balzac a trouvé au fond de la mer parisienne.

Une analyse stylistique du Lys dans la Vallée démontrerait qu'en matière romantique, Balzac était plus catholique que le pape. On comprendrait parfaitement pourquoi il se disait, par exemple, admirateur de Lamartine ${ }^{6}$. Je me bornerai ici à ne relever que quelquesuns des traits les plus marquants.

Natalie, dans la lettre finale du roman, résume 1 'oeuvre par ce mot révélateur: "je ne sais rien de plus monstrueux"7 (357). En effet, rien de plus violent, par exemple, que la première rencontre de Félix avec Madame de Mortsauf: "je me plongeai dans ce dos comme un enfant qui se jette dans le sein de sa mère, et je baisai toutes ces épaules en y roulant ma tête"(35). Cette explosion d'animalité se changera peu après en 
effusions sentimentales qui deviennent parfois écoeurantes: "Deux grosses larmes éclairées par un rayon de lune sortirent de ses yeux, roulèrent sur ses joues, en atteignirent le bas; mais je tendis la main assez à temps pour les recevoir, et les bus avec une avidité pieuse.. .. -Voici, lui dis-je, la première, la sainte communion de 1'amour. Oui, je viens de...m'unir à votre âme, comme nous nous unissons au Christ en buvant sa divine substance"(103). Le thème de la communion de l'amour revient à plusieurs reprises, sous les noms d'abord de fiançailles d'âmes $(73,325)$, puis de mariage d'âmes $(93,120,228,230,249,280)$. A ce symbolisme qui frôle le mauvais goût se joignent des comparaisons avec Dieu, déjà signalées dans Le Père Goriot. Voici comment Arabelle parle de 1'amour: "soumettre le monde et le ciel à un homme en dérobant ainsi au Tout-Puissant le droit de faire un Dieu... Voilà des grandeurs où n'atteignent pas les femmes vulgaires" (251). Ou bien 1'allusion de Félix lorsqu'il est auprès de Madame de Mortsauf: "tout ce que je puis avoir de grand en moi vient de vous. Ne savez-vous donc plus que je suis votre ouvrage?" (273). La scène à Clochegourde n'est pas moins lugubre lors de la maladie de M. de Mortsauf et de la mort de sa femme. Félix entre plus avant dans le coeur de son Henriette, et ce "fut une scène d'enfance à côté d'une tombe entr'ouverte" (228). Plus tard, quand Henriette est morte, Félix de s'écrier: "Ah! je 1'aimais morte, autant que je l'aimais vivante" (335). Peu de réalisme dans ces épisodes, peu de réalisme aussi dans les remarques très directes sur les caractères des trois personnages principaux. La passion de Félix "recommençait le Moyen Age et rappelait la chevalerie" (249). L'amour de Madame de Mortsauf fait lamenter Félix: "Si elle m'avait aimé, elle aurait eu pour mes souffrances cette expression de lionne au désespoir" (221). Cette lionne, Arabelle l'est parfaitement (250); et voilà Balzac au seuil de I'exotisme: "L'atonie que mettent dans $I^{\prime}$ existence de ces femmes une perfection constante dans les choses, une régularité méthodique dans les habitudes, les conduit à 1 'adoration du romanesque $^{8}$ et du difficile (245)...Aussi sa passion estelle tout africaine; son désir va comme le tourbillon du désert,...le désert plein d'azur et d'amour, avec... 
ses fraîches nuits étoilées" (247).

De semblables éléments ne se trouvent que rarement dans Illusions perdues. I1 se peut que le thème très actuel de la critique du journalisme, joint au thème directeur de l'ascension d'un jeune ambitieux, en ait rendu 1'élaboration plus concise et ait tracé des $1 i$ mites plus étroites à l'inspiration de l'auteur.

S'il y a du grotesque dans ce roman, les scènes où il est visible restent toujours au service du but réaliste de l'oeuvre. Il en résulte des saillies de comparaison qui révèlent le grand écrivain. Toute la description de la noblesse de province est comprise dans ce bout de phrase: "ces vieilles familles perchées sur leur roche de la haute ville d'Angoulême. comme des corbeaux défiants" (41); et le provincial qui vient d'arriver à Paris n'est qu'un "singulier jeune homme qui a l'air d'un mannequin habillé à la porte d'un tailleur" (171). Au symbolisme animal, déjà relevé dans Le Père Goriot (le chien) et Le Lys dans la Vallée (la lionne), nous devons cette apostrophe de De Marsay: "1e lion parisien laissa retomber son lorgnon si singulièrement qu'il semblait à Lucien que ce fût le couteau de la guillotine" (178). Cependant, le lugubre n'en est pas complètement absent. La scène de la mort de Coralie n'est-elle pas une des plus cruelles? "Lucien revint chez lui: il y trouva Coralie étendue droite et roide sur un lit de sangle... le poète se mit à sa table, auprès du corps de sa pauvre amie, et y composa les dix chansons qui voulaient des idées gaies et des airs populaires...Quelle nuit que celle où ce pauvre enfant se livrait à la recherche de poésies à offrir aux Goguettes en écrivant à la lueur des cierges, à côté du prêtre qui priait pour Coralie?" (440) Non pas macabre, mais grotesque, elle aussi, la nuit de la sérénade à Angoulême: "Après...trois salves, criées par quelques voix, trois couronnes et des bouquets furent adroitement jetés par la croisée dans 1'appartement... Le succès du grand homme de province était trop antipathique aux moeurs immobiles d'Angoulême pour ne pas avoir été mis en scène par des intérêts ou par un machiniste passionné, collaborations également perfides" (547-548).

Si Balzac s'est abstenu, dans Illusions perdues, de trop de monstruosités, il en comble, pour rattrapper 
son rival Eugène Sue, une de ses dernières oeuvres, les gigantesques Splendeurs et Misères des Courtisanes. Ce roman ne reprend qu'au second plan la grande idée ba1zacienne du jeune homme qui veut faire fortune, et traite, en précurseur du roman-policier, le combat souterrain que se livrent deux partis également clandestins. "Infernal" y est l'épithète dominant. Balzac n'aurait-il pas été conscient de l'ironie tournée contre lui-même quand il écrivait: "Après avoir acheté la vie de Lucien... Collin lui avait proposé 1 'un de ces pactes infernaux 9 qui ne se voient que dans les romans" (103), même s'il inwoque les procès-verbaux des Assises pour se justifier? De même trouve-t-on "dans les romans" seulement "une ardoise sur laquelle... Peyrade trouvait parfois des marques bizarres... Cette espèce d'algèbre infernale offrait aux initiés des significations très claires" (145). Aussi "1'activité vraiment infernale" d'Asie ne peut-elle empêcher le suicide de Lucien. Dans $1^{\prime}$ affreux ${ }^{10}$ univers balzacien les anges côtoyent les monstres. "Esther...n'était plus une courtisane, mais un ange qui se relevait d'une chute" (56). Et Collin, ce "dompteur de bêtes féroces" (84), dit d'elle avec une cruauté satanique: "Eh bien, isther est un gibier après lequel je vais faire courir... Nucingen." -Esther ne voudra jamais, dit Lucien. -Ça me regarde. -Elle en mourra. - Ça regarde les Pompes funèbres" (101). L'adversaire de Collin n'est pas moins monstrueux: "Le crâne... avait 1 'insensibilité d'une tête de mort, et, sans quelques cheveux à $1^{\prime}$ arrière, on eût doûté qu'il fût celui d'un homme vivant" (127). Aussi macabre que cette description est la scène du suicide de Lucien quand Collin arrive "à la cellule où gisait Lucien, qu'on avait mis sur le lit. A cet aspect, il tomba sur ce corps et s'y colla par une étreinte désespérée... -Laissez-moi 1à!...dit Jacques Collin d'une voix éteinte, je n'ai pas longtemps à le voir, on va me l'enlever pour... Il s'arrêta sur le mot enterrer" (477). $C$ 'est dans ce demi-monde de demi-vivants et de diables humains que se déroulent les tentatives de suicide, les enlèvements et escroqueries, les espionnages et déguisements, les meurtres et arrestations, les procès et, finalement, les suicides accomplis. 
Revenons à présent à M. Wurmser. Si La Comédie Humaine était "une vue bourgeoise du monde réel," ne seraient morts ni le père Goriot, ni Madame de Mortsauf, ni Lucien de Rubempré. Mais en les laissant périr par les forces déstructrices inhérentes à la bourgeoisie, Balzac fait oeuvre de critique, il présente "une vue réaliste du monde bourgeois."

Interprétation possible, et non des moins valables. Mais elle est aussi étroite que le monde balzacien est vaste. Ou autrement dit: elle ne s'applique, en naissant d'un système, qu'au système de Balzac.

Or, tout système ampute la réalité. Aussi l'opinion de M. Wurmser comme les théories de Balzac ne sont-elles qu'une vue partielle de la réalité de La Comédie Humaine. Balzac lui-même semble en avoir été plus conscient que ne l'est son critique. Car dans les passages que je viens de citer, il a prodigué tous ses efforts pour échapper à une société qu'il s'est imposé lui-même de décrire. Peut-être le véritable romancier se cache-t-il dans ces "digressions" où il crée les Goriot, les Mortsauf, les Coralie et les Esther.

Autant pour le "monde bourgeois."

Quant à la "vue réaliste," Balzac la garde même pendant ses excursions dans les mondes du grotesque et du monstrueux. Il n'abandonne ni la description soigneuse ni 1'analyse précise de ses anges et ses diables. Ces personnages "inhumains" sont aussi "vrais" que les autres comédiens de 1 'humanité. S'ils nous paraissent monstrueux, c'est par leur réalisme même: la monstruosité est l'effet d'un manque de différenciation de la part du créateur qui décrit ses êtres extraordinaires avec les mêmes moyens que les habitants de son système. Le réalisme, propre à Rastignac ou à Nucingen, mène chez Madame de Mortsauf ou le père Goriot à un décalage trop marqué entre forme et contenu pour que le goût du lecteur n'en soit pas choqué.

Avant de déclarer Balzac poète baroque, j'arrête en complétant $1^{\prime}$ avis de $M$. Wurmser dans ce sens:

La Comédie Humaine, "ce n'est pas une vue bourgeoise du monde réel, c'est une vue trop réaliste du monde inhumain." 
1 André Wurmser, "Variations sur la sincérité de Balzac," dans Europe, no. 429-430 (janvier-février 1965) p. 231 Maxime Nemo, "
$429-430$, pp. $324-325$

3 Maurice Regard, "Un gros volume qui se dévore avec passion", dans Europe, no. 429-430, p. 271

4 p. 17; toutes les citations des romans étudiés renvoient aux éditions du "Livre de Poche" et seront indiquées désormais dans le texte.

5 C'est moi qui souligne

6 cf. la dédicace de César Birotteau

7 C'est moi qui souligne

8 C'est moi qui souligne

9 C'est moi qui souligne

10 cf. 1'article de Pierre Citron, "Les affreux du miroir," dans Europe, no. 429-430 (janvier-février 1965) pp. 94-104

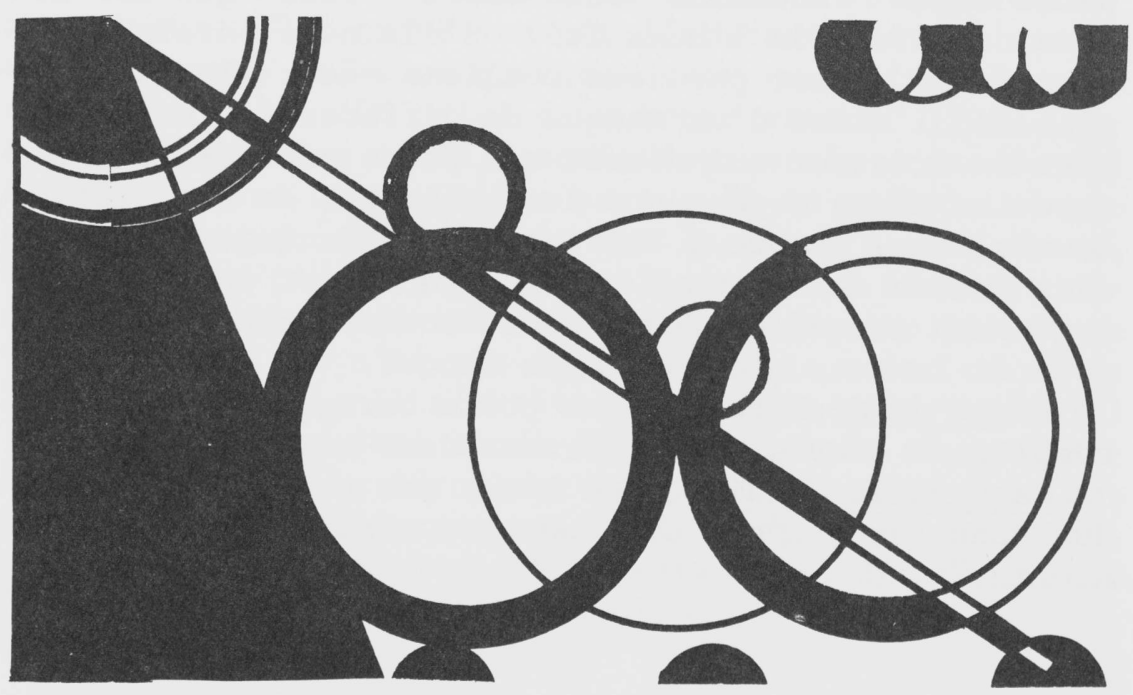


Te souviens-tu?

Est-ce que tu te souviens . . .

Vaguement de la mer de

la source sale et. . .

Te souviens-tu?

Est-ce que tu te souviens ...

Du sable ou les traces déçues

de nos améres (mal dériveśs) qui

sont, par le reflux de la mar emportees comme des cygnes

mal armés...

Non?

Tu es sans merci . . .

Un césarien avant Macbeth

Un edelweiss sans Montaigne

(Que ses jeux sont déRacinés!)

Encore non?

Tu ne ses pas que

l'immortaliste ne gît plus

$\underset{\mathbf{S}}{\mathbf{a}}$

ou moins que de puits

la grande sécheresse

(le contraire de nos éclairs qui

annonçaient autre que les orageons

et les misanthropes... )

Mais si...

Tu $n^{\prime}$ est pas sans ressource

Et de ton visage glacé

C'est bien et vide dans

son expression

que Darwin avait raisin

en dévignant que le

vin noble n'oublie pas l'eau de vie

$\mathbf{m}$ même quand 1 'île fait sec ...

'a M. grand Goutier et sa fame

les parens (these) de tout

plage qu'il y a.

BIBERONS. 


\section{Compte Rendu}

Sellin, Eric. The Dromatic Concepts of Antonin Artaud. Chicago: University of Chicago Press, 1968. Pp. 190. $\$ 6.50$.

Les controverses souvent sordides qui font rage depuis la mort, en 1948, du poète Antonin Artaud, ont eu pour effet, non seulement de ralentir considérablement la publication complète de ses oeuvres, mais également de freiner toute production critique sérieuse à son égard. Les revendications ou éloges exagérés qui constituent encore les témoignages de ses amis font souvent figure de pièces à conviction et montrent que, du moins en France, 1e "cas" Artaud n'est pas encore résolu. Aux Etats Unis, où Artaud bénéficie de plus de détachement, deux volumes sérieux ont déjà paru parmi un nombre toujours croissant de publications critiques. Le premier d'Eric Sellin et le dernier de Bettina Knapp illustrent le grand pas en avant effectué. par la critique amêricaine à l'égard du poète français.

Antonin Artaud, que beaucoup de ses contemporains comme Jean Louis Barrault n'hésitent pas à élever au rang de prophète, fait figure de révolutionnaire surtout en ce qui concerne les théories dramatiques exposées dans son manifeste: Le thêâtre et son double. Dans le domaine de la poésie, Antonin Artaud rejoint une lignée glorieuse de visionnaires et de poềtes maudits par la société: Nerval, Rimbaud, Baudelaịre et Lautréamont. C'est le théoricien dramatique qui fait l'objet du livre de M. Sellin publié en 1968, vingt ans après la mort du poète. Le livre de M. Sellin a le mérite de constituer le premier ouvrage d'importance consacré à la contribution dramatique d'Artaud qui soit exempt de parti pris. Comme Bettina Knapp dans son livre Antonin Artaud Man of Vision (New York: David

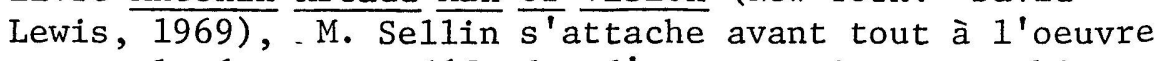
sans malgré tout se défendre d'une certaine sympathie 
pour la fascination qu'exerce la personnalité de l'écrivain. L'oeuvre d'Antonin Artaud y gagne en stature et en authenticité.

M. Sellin divise son étude en trois parties: 1a première et aussi la plus longue traite de ces domaines du thêâtre et de la culture qui ont directement influencé la vision dramatique d'Artaud. Dans la seconde, 1 'auteur resserre son étude autour de l'originalité propre des idées d'Artaud et il se concentre, dans la dernière phase de son livre, sur la mise en scène de cet idéal dramatique.

M. Sellin s'attache tout d'abord à définir les termes dont il se sert pour illustrer deux genres dramatiques opposés. Si les termes "solaire" et "Iunaire" n'offrent à priori rien de nouveau à la critique dramatique, ( 1 'auteur reprend le thème des forces antagonistes familier à Nietzsche) ils servent à intensifier le sens rituel qu'Artaud attribue au thêâtre. M. Se1lin identifie le thêatre "solaire" avec l'action, la révolte, l'ascendance mâle. Au contraire, le théâtre "Iunaire" est statique, acquiesçant et soumis à I'influence féminine. Parmi les quelques productions "solaires" pour la plupart étrangères à la France, l'auteur note Thyestes de Sénèque et certaines pièces de vengeance élisabéthaines. Des auteurs comme Tchekov,

Strindberg, Jarry, Ionesco et Beckett semblent avoir été tentés par la tradition "lunaire". Artaud aurait été influencé par ces tendances opposées, optant finalement pour la tradition "solaire" dont sa pièce, Les Cenci serait un exemple. La distinction un peu obscure du début entre les deux définitions (nous relevons une erreur d'impression page 14) et la fragilité de la ligne qui marque la séparation entre les deux conceptions (particulièrement en ce qui concerne 1 'at" .ibut de "rationalisme" à l'une plutôt qu'à 1'autre) prêtent à quelque confusion. Sans doute la distinction est-elle utile et fonctionnelle comme point de départ, mais une adhérence trop stricte à ces définitions risquerait de compromettre l'originalité d'Artaud. M. Sellin sait s'en éloigner pour se concentrer sur Artaud lui-même. C'est en étudiant 1 'influence de 1 'ancienne culture mexicaine sur la conception dramatique d'Artaud qu'il éclaircit plusieurs conclusions contenues dans Le Thêâtre et son 
double: d'abord que la culture et la vie ne font qu'un et que le thêâtre doit se confondre avec la vie et en adopter le rythme; d'autre part, que le thêâtre tend, comme la culture et $1 \mathrm{a}$ vie, à renaître à travers un acte sacrificateur. La cruauté, thème essentiel du thêâtre conçu par Artaud, est 1'expression d'une force abstraite et pure qui dépasse les limites de la morale humaine. Elle a pour objet de placer le spectateur dans une attitude d'acquiescement propre à lui rendre accessible le domaine pur de la métaphysique. M. Sellin malheureusement n'insiste pas assez sur l'originalité ou 1'effieacité de cette théorie et se borne à la redéfinir dans le cadre de la vision artaudienne. Bien des questions se posent encore sur la réalisation pratique d'une telle conception dramatique et M. Sellin a raison de souligner la part du poète et du visionnaire dans $1^{\prime}$ attrait qu'elle présente. Il arrive fort justement à la conclusion que l'efficacité et la force de ce thêâtre résident surtout dans la forme de son expression poétique, à savoir symboles, rythme etc. . . Que 1'écrivain doive son ascendant plus à ses dons de visionnaire et de poète qu'à la vraisemblance de sa conception métaphysique ne devrait laisser aucun doute. Pourtant, se reprenant, M. Sellin regrette des excès dans le symbolisme qui constitueraient un obstacle à la communication "rationnelle". Certaines inventions lui semblent sortir tout droit de "1'alchimie médiévale". L'auteur déplore aussi la tendance d'Artaud à rendre physiologiquement les phénomènes métaphysiques. Pourtant ce symbolisme n'est-il pas la seule expression poétique possible pour Antonin Artaud qui exige que son thêâtre soit un "mirage", un ensorcellement magique, pour lequel il faut à tout prix créer un nouveau langage poétique? La troisième partie qui traite de la mise en scène est extrêmement intéressante et témoigne d'une solide documentation. L'auteur rend réelle et accessible la conception du spectacle telle qu'Artaud l'envisageait et telle que Jarry $I^{\prime}$ avait déjà esquissée avant lui.

La place importante que I'auteur accorde tout au long du livre à l'art pictographique, à la conception de $1^{\prime}$ espace et surtout à la nature du rythme dans ce théâtre semble bien souligner son caractère avant tout 
esthétique et $l^{\prime}$ on regrette qu'il n'ait pas insisté davantage sur la valeur symbolique et dramatique du verbe même d'Artaud. Alors que M. Sellin se penche le plus souvent sur des données extérieures pour arriver à plusieurs de ses conclusions sur Artaud, Bettina Knapp arrive, à travers une analyse experte et minutieuse des symboles artaudiens, à retrouver et à isoler la pensée du poète dans sa totalité reconstituant pour nous une vísion poétique singulièrement révélatrice de l'idéal dramatique d'Antonin Artaud. Il n'y a rien à redire quant à la compétence ou à $1^{\prime}$ isance avec lesquelles $\mathrm{M}$. Sellin dirige son étude mais en refermant son livre le lecteur attentif se demande encore obscurément si Antonin Artaud, dans son manifeste à la posterité, n'avait pourtant pas rêvé de sphères plus vastes, d'espaces encore inexplorés.

A1 ice Tunks

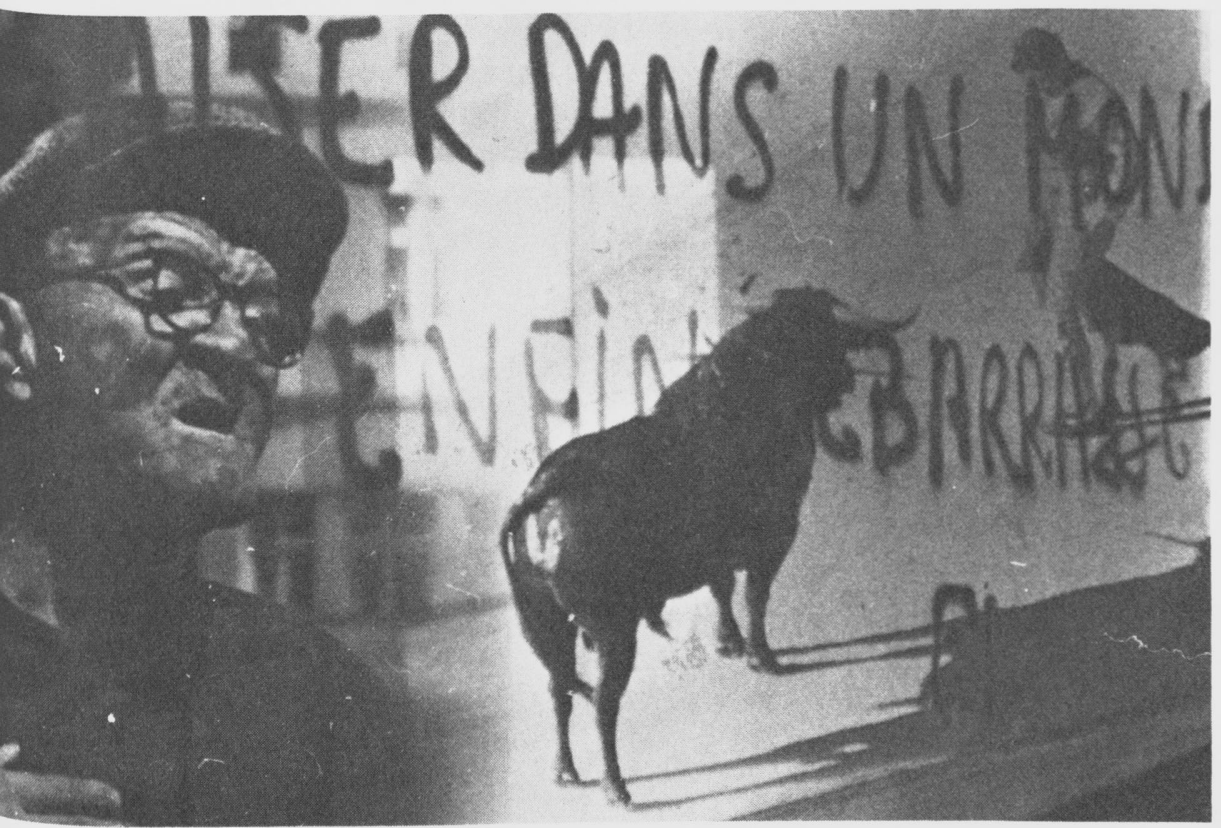




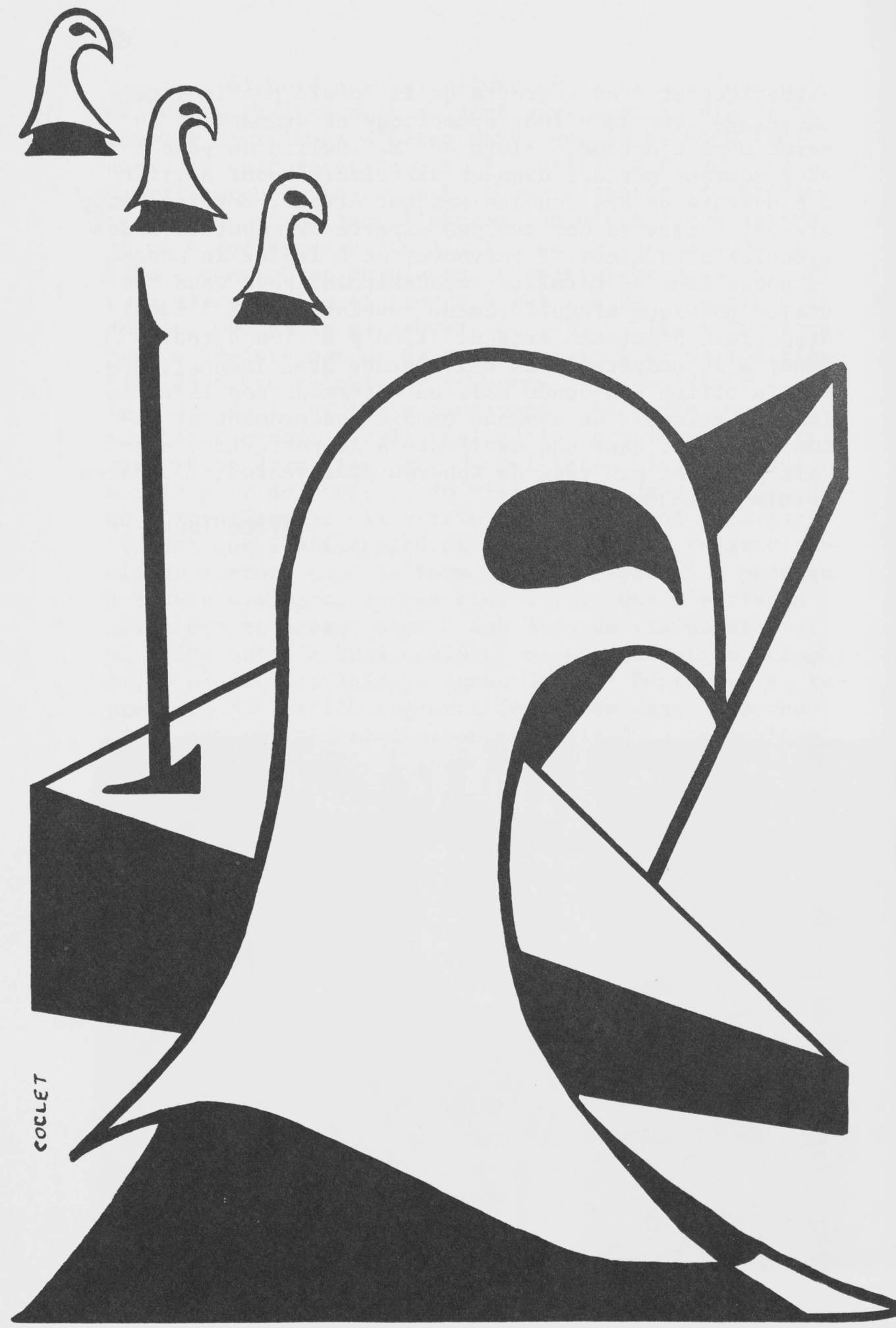




\section{Eul'cornelle et l'ernard}

Inn'm'tite cornelle perchie su' in aleu

Etnot dins sin long bec in morceau d'vil fromache. Arrife Monsi 1'ernard erniflant du museu

Qui interprind 1 'ojeu dins sin fin babillache:

"Bonjour eum'tite cornelle,

Alors, et c'min qu'i va?

Min Dji Elisse qu't'es belle!

Je $n^{\prime} t$ 'arconnossos pas.

Ch'est- $i$ ' ben vous mam'zelle?

$\mathrm{Si}$ te chantes comme t'es belle

$J$ 'donne eum'tiête à coper

Qu't'es T'reine des bos pou' 1'vo et l'jolité!"

Inn'intindant cheul'lal eul cornelle tout contente

Elle ouv' tout grind sin bec pour pousser sa gouellante

Et laisse tcherre eul fromache droit dins l'bouc du l'ernard

Qui 1 'avale in riant in dijant:

"Tout flatteu, tout minteu;

Et pour ceusses qui l'acoutent

Eh ben, tant pire pour eux.

Déchindez, j'paye la goutte!"

Not' cornelle tout'honteusse

Sacra, sacré milliard, qu'in n'li r'fro jamais pus.

JEAN DE LA FONTAINE

ET CYRIL DEVOS 


\title{
Le Fichier Bibliographique
}

\author{
"Liste sélective des revues savantes dans le domaine de la littérature française"
}

La liste que nous publions ici est le rêsultat d'un projet d'équipe réalisé dans le cadre du cours Français 392, "Bibliographie et méthodes de recherches." Le projet avait été conçu dans le double but de servir d'instrument pour évaluer les ressources de la bibliothèque universitaire dans le domaine des périodiques et de moyen pour mieux connaître les multiples revues qui pourraient éventuellement intéresser tout francisant travaillant dans la littérature au sens le plus large. On a d'abord dressé une liste des revues savantes et importantes pour l'étude de la littérature et de ses rapports avec d'autres disciplines, surtout dans les domaines de la philologie, de la littérature comparée, des beaux-arts, de l'esthétique et de la philosophie. Dans cette liste, chaque participant du séminaire a choisi une quinzaine de revues qui correspondaient à ses pro-jets personnels de recherche. Pour faciliter et systématiser l'analyse de la série complète d'une revue, nous avons dressé un formulaire. Sur le formulaire sont indiqués les noms d'éditeurs, les adresses utiles, les renseignements sur les abonnements ou cotisations, le genre d'articles ou domaines (critique littéraire, inédits et textes originaux, philologie, enseignement, civilisation, beaux-arts, philosophie, etc.), une analyse du contenu d'un numéro type, bibliographies, les tendances ou intentions des éditeurs aussi bien que 1 'historique de la revue et 1 'analyse de son format (langues, citations, style MLA ou autre, la longueur maxima des comptes rendus et articles, etc.) Ce formulaire, accompagné de pages types xérographiées, forme le dossier de chaque revue. Ces dossiers sont à la disposition de tout chercheur dans la section des instruments de travail bibliographique de la salle de lecture du département. Ces dossiers représentent un instrument de travail précieux pour ceux qui préparent des thèses ou des articles et qui comptent les publier dans une revue soit consacrée à la littérature, soit consacrée à un domaine interdisciplinaire.

La liste que nous présentons ici est sélective. Elle ne comprend que le résumé des dossiers des revues les plus souvent consultées ou auxquelles sont destinés la plupart des articles rédigés par les jeunes chercheurs américains. En raison du peu d'espace dont nous disposons, nous avons inclus ici les renseignements concernant 1'abonnement seulement là où les jeunes chercheurs ont le plus grand intérêt à s'abonner. Les abréviations sont celles adoptées par la PMLA (voir la bibliographie annuelle, numéro de mai). Nous donnons aussi les cotes (système Dewey) et les sẻries (ang. runs) à l'Université du Kansas. La liste, nous sommes les premiers à $1^{\prime}$ 'avouer, est grandement sélective. On n'y trouvera pas, par exemple, les innombrables annales des universités françaises, américaines ou étrangères. Les quelques exceptions donnent une faible idée de la richesse qu'il y a dans ce domaine. Nous ne citons pas non plus les revues consacrées surtout à 1 'enseignement ou destinées au grand public. On n'y trouvera pas les périodiques tels L'Année balzacienne ou Cahier Canadien Claudel. Pour les périodiques consacrés à l'étude $\mathrm{d}^{\prime}$ un seul auteur, $\mathrm{d}$ 'une seule région ou d'une seule époque spécifique, nous renvoyons nos lecteurs à notre rubrique dans Chimères (printemps, 1969), pp. 28-31, et à 1'article excellent de M. Gilbert Nigay, "Les Bulletins et publications de 'Sociétés d'Amis' (19001967), dans RHL, 67 année (oct.-déc., 1967), 794-804.

Il y a, certes, de graves omissions. Mais ce projet bibliographique aura réussi si nos lecteurs, au lieu d'y voir une liste définitive, y voient plutôt un travail heuristique auquel $\mathrm{ils}$ pourront participer en nous faisant parvenir des titres de revues et des résumés pour un prochain numéro de Chimères.

Ce project bibliographique a été lancé par les participants du séminaire au printemps: Madame Christine Asch, Mlles Frances Backus, Claire Dehon et Mary Ellen Naylor et $2 M$. Gregg Lacy et Murle Mordy. Il a été mené à bien par les participants du séminaire d'automne: Mesdames Maria Huettig, Marie-Luce Parker, Caroline Pensec, Roseann Runte et Maaris Vlach, Mlle Margriet Bruyn et MM. Richard Bales, Michel Coclet, H. William Huttanus, Hans Runte et Kenneth Tarr. Enfin les listes ont été complêtées et êditées par Madame Mary Johnson, Mlle Anne Lacombe et MM. Gregg Lacy et J. Theo. Johnson.

1.

Académie Royale de Belgique. Annuaire pour 1'année.. 506/Ac15a 65 (1899)-Publié depuis 1899 par 1'Académie Royale de Belgique, paraît une fois I'an; articles écrits par les académiciens, indifférement en français et en nêerlandais, portant sur 1a critique littéraire, 1 'histoire de l'art, et les personnalités belges; liste des membres, rapports sur les réunions. 
critiques sur la littérature française, mais des comptes rendus de thèses de doctorat et de conférences; liste des "livres reçus"; s'adresser à 47, rue des Ecoles, Paris $5^{\mathrm{e}}$.

4. Archiv Archiv für das Studium der neueren Sprachen und Literaturen de langue; $20 \%$ de la publication consacrés aux langues romanes; articles écrits en allemand, anglais, et français.

5. AHDLMA Archives d'Histoire Doctrinale et Littéraire du

$189 / \operatorname{Ar} 251(1926)--$

\section{Moyen $\mathrm{Age}$}

Revue annuelle publiêe avec le concours de C.N.R.S. à Paris; présente, en langue française, anglaise ou allemande, des études critiques et des éditions de texte avec appareils critiques; s'occupe essentiellement de la religion et de la philosophie du Moyen Age, mais touche constamment la littérature française.

6.

\section{Archives des lettres modernes}

Publication des Lettres Modernes, 73, rue du Cardinal-Lemoine, Paris $5^{\mathrm{e}}$ : au minimum 6 livraisons bimestrielles et au maximum 10 livraisons selon la longueur des articles par an. Prix: $27 \mathrm{NF}$. Chaque fascicule est consacré à un seul sujet: étude sur un auteur ou sur une tendance littéraire.

7. AUMLA

Journal of the Australasian Universities Language

405/Au78 1(1953) -and Literature Association

Publié par 1'University of Canterbury (N.Z.), et paraissant deux fois par an, en mai et en novembre; articles critiques en anglais; citations dans la langue originale; pas de bibliographie, mais des listes de "livres reçus"; d'excellents comptes rendus et un index annuel; s'adresser à l'éditeur, AUMLA, School of Modern Languages, University of Canterbury, Private Bag, Christchurch, N.Z.

8. AJFS

Australian Journal of French Studies

440.5/Au78 1(1964)--

Revue publiée trois fois par an à Melbourne en français aussi bien qu'en anglais pour les textes et les citations; comprend des études critiques, des études sur l'histoire de l'art; bibliographie sélective et index cumulatif; abonnement de six dollars; s'adresser à Chesshire's Subscription Department, 338 Little Collins St., Melbourne (Victoria), Australia.

9. $\underline{B R P}$

Beiträge zur romanischen Philologie

$479.105 / B 387$

$$
1(1961)--
$$

Publié deux fois par an, comportant des articles écrits en allemand et en toutes les langues romanes, qui traitent plutôt de questions philologiques; bonne documentation (bibliographie, etc.), et des comptes rendus de dimensions importantes; s'adresser à: Redaktion, BRP, Berlin w8, Clara-ZetkinStr. 1 .

10. BLM Bonniers Litterära Magasin

050/B6431 1(1932)-Publication de langue suédoise qui paraît tous les mois de janvier à mai, et de septembre à décembre, avec un numéro au cours de l'étê. Outre des articles littéraires et des comptes rendus, cette revue publie des comptes rendus sur le théâtre, et des oeuvres originales de poésie et de prose. Etudes critiques sur des auteurs anglais, français et américains.

Publication trimestrielle de 1'University of Oklahoma (Norman), contenant des articles en anglais sur la littérature contemporaine et plus de 240 comptes rendus sur les publications récentes de la littérature mondiale; s'adresser à l'Univ. of Oklahoma Press; souscription annuelle - $\$ 5.00$. 
Publiê en anglais par the British Society of Aesthetics, et paraissant quatre fois par an; citations dans le texte original; sujets portant surtout sur des mouvements et des conceptions esthétiques; très rarement une bibliographie (sélective), et pas d'index; abonnement: $\$ 7.50$ par an; s'adresser: The Hon. Secretary, c/o The Department of Philosophy, Birkbeck College, Malet Street, London, W.C.1.

13. BBSIA Bulletin Bibliographique de 1a Société

$809.93 / \operatorname{In} 8 b 3(1951)--$ Internationale Arthurienne

Revue bibliographique publiée une fois par an sous l'égide de la Société Internationale Arthurienne par Lewis Thorpe et E.K.C. Varty; présente, en langue anglaise ou française, une bibliographie critique de livres et d'articles sur la "matière de Bretagne"; contributions groupées par nationalité et par genres; publie des listes de membres et les compte rendus des congrès arthuriens.

14. $\underline{B B F}$

Bulletin des Bibliothèques de France

$027.044 / \mathrm{B} 874$ $2(1957)--$

Bulletin publié par le ministère de 1'Education Nationale tous les mois; contient une rubrique des livres publiés dans le mois, sur un sujet déterminé, et des articles concernant les méthodes de recherche bibliographique, ainsi que les problèmes de la consommation livresque (gô̂ts du public...); s'adresser à la B.ì., 58 rue de Richelieu, Paris $2^{\mathrm{e}}$.

15.

Bulletin signalétique. Sciences humaines

(suite de Philosophie, v. 1-14)

$016.505 / \mathrm{F} 844 \mathrm{cb} / \mathrm{S} . \mathrm{M} 24$

Publication mensuelle du Centre de Documentation du C.N.S.R., 15, quai Anatole France, Paris $7^{\mathrm{e}}$; dont six fascicules consacrés aux sciences humaines.

16. Cahiers d'Analyse textue1le

Cahiers de parution irrégulière rédigés sous la direction du professeur L. Remacle par une équipe d'anciens êlèves de l'Université de Liège. Secrétariat: Pau1 Delbouille, 9, rue Fr. Jacquemart, Embourg (Liège).

17. $\underline{\mathrm{CCM}}$

Cahiers de Civilisation Médiévale

$940.105 / C 119$

1 (1958)--

Publication trimestrielle en français du Centre d'Etudes Supérieures de la Civilisation Médiévale; contient des articles sur le Moyen Age aussi bien que des comptes rendus (exemple: l'ancien français, l'art et l'architecture romans, la philosophie); bibliographie des sujets traités dans les articles et livres reçus par le CESCM.

18. CAIEF

Cahiers de l'Association Internationale des Etudes Françaises

$840.5 / \mathrm{C} 119$

Publication annuelle de langue française contenant les interventions et les communications plutôt littéraires que linguistiques portant sur des sujets délimitês, quí ont lieu lors des congrès de L'Association Internationale des Etudes Françaises. "Les Belles Lettres," (95, boulevard Raspail, Paris, 6e).

19. CS Les Cahiers du Sud

$840.5 /$ C11 38(1951)--

Publié six fois par an et d'un intérêt capital pour le développement moderne de la littérature française; une grande partie de la revue consacrée aux oeuvres originales; peu d'articles critiques; ni bibliographie ni index; s'adresser chez Ballard, 10, Cours d'Estienne-d'Orves, Marseille (1 $\left.{ }^{\mathrm{er}}\right)$.

20.

Les Cahiers Ferdinand de Saussure

408/C119 1(1941)--

Publication annuelle s'adressant presque exclusivenent aux spécialistes de la philologie romane; écrite essentiellement en français, tiais parfois en allemand ou anglais; documentation faible; ni bibliographie ni index; s'adresser chez Droz, Genève.

21. $\underline{\mathrm{CRa}}$

Cahiers Raciniens

$842.45 /$ G3/C119 2 (1957)--

Publication semestrielle en français de la Société Racinienne, consacrée 
aux études critiques sur Racine, et à d'autres sujets se rapportant au thêâtre de Racine $(60 \%)$; annonce des représentations thêâtrales déjà données ou à venir; chronique et rouvelles de la Société; s'adresser au siège de la société, 45 bis, rue Madeleine Michelis, 92 Neuilly-sur-Seine.

Cahiers paraissant six fois par an, consacrés au thêatre international en général mais aussi à la littérature mondiale (Goethe, Pirandello, Flaubert, Thêâtre USA, etc.); études critiques (50\%); oeuvres originales (50\%); s'adresser à la Librairie Gallimard, 5, rue Sêbastien-Bottin, Paris.

Publication annuelle des Syndics of the Cambridge University Press (London); articles presque uniquetment sur I'histoire sociale de l'Angleterre mídiëvale; en anglais; avec bibliographie sur le sujet.

24. CandM Classica et Mediaevalia

$480.5 / \mathrm{C} 565$ $1-13(1938-52), 21(1960)--$

Publication de la Societas Danica Indagationis et Medilaevi (Copenhague); annuelle (2 facs.); traitant des études critiques des traditions anciennes et classiques; le plus souvent en français, mais aussi en anglais et en allemand; contient aussi des articles sur la civilisation antique, à l'exception de l'histoire de 1 'art.

Périodique en anglais avec des citations en langues originales; 4 fois par an depuis le printemps 1967; études critiques et historiques sur le thêâtre; imprime des reproductions, des diagrammes, etc.; études interdisciplinaires encouragées par les éditeurs; index de l'année dans le numéro d'hiver; abonnement de $\$ 3.50$ par an; s'adresser: Comparative Drama, Department of English, Western Michigan University, Kalamazoo, Michigan 49001.

\section{Comparative Literature}

$805 /$ C731 1(1949)--

Revue trimestrielle publiée par 1'University of Oregon; articles sur les relations entre les littératures, sur la théorle littéraire, sur les genres; les auteurs, les époques littéraires; revue officielle de 1'American Comparative Literature Association; $\$ 4.50$ par an; s'adresser: Univ. of Oregon Books, Eugene, Ore. 97403.

Publication trimestrielle le plus souvent en anglais de l'University of I1linois (anciennement Univ. of Maryland); articles sur 1'histoire littéraire des idées, surtout les rapports littéraires de l'Europe avec l'Amérique du Nord et 1'Amérique du Sud; études critiques et comptes rendus; de rares numéros consacrés à un seul sujet (la critique, l'art et la littérature, le symbolisme).

Comparative Literature Studies (Cahiers de

$805 / \mathrm{C} 73$

Littérature Comparée)

$9(1943)-24(1946)$

Revue galloise, publiée trois fois par an; fondêe en 1940 pour continuer la publication d'études de littérature comparée pendant l'interruption des numéros du RLC; la plupart des articles traitent de sujets français ou anglais; plusieurs articles sur la littérature norse et celtique.

29. CritQ

Critical Quarterly 805/C869 1(1959)-Publié 4 fois par an, par Oxford Univ. Press; articles de critique littéraire $(80 \%)$ et pièces originales $(20 \%)$, surtout en anglais; revues de livres; s'intéresse surtout à la littérature du $20^{\mathrm{e}}$ siècle.

30.

\section{Critique}

$010.5 / C 869$ I0(1954)--

Publication mensuelle de langue française étudiant, à partir d'ouvrages récents, les sujets les plus variés et contenant des comptes rendus; Paris: Editions Minuit. 
32.

33. DSS

34. Drams

35. ETJ

36. ECS

37.

38. $\underline{E C r}$

39.

40. $E A$
Publiēe 3 fois par an par 1'University of Minnesota Press; revue spécialisée dans la littérature anglophone; publie des articles de critique littéraire envoyés par des enseignants de littériture anglaise des universités amëricaines; aucun rapport direct avec la littérature française, si ce n'est du point de vue de la critique littéraire elle-même, et de ses méthodes.

Diderot Studies

$848.5 / D 56 / G 3 / D 561$ 1 (1949)--

Publication irrégulière consacrée aux études critiques sur Diderot, la littérature, la philosophie, les sciences politiques, la musique, etc. du XVIII siècle (70\%); comptes rendus, dont la plupart sont très détaillés (30\%); s'adresser chez Droz, Genève.

\section{Dix-septième siècle}

$944.03 / D 64217(1953)--$

Publication trimestrielle de la Société d'Etude du XVII e siècle "avec le concours du C.N.R.S, et de la Direction Générale des Arts et des Lettres"; revue consacrée aux études critiques sur la philosophie, la littérature, les institutions et la société, les arts, la musique, le théâtre, l'éducation, la pensée du XVII ${ }^{e}$; quelques études sur la rhétorique et la grammaire; s'adresser au siège de la société, 24 Boulevard Poissonnière, Paris 9e.

\section{Drama Survey: A Review of Dramatic Literature 792.05/D7901 1(1961)--} and the Theatrical Arts

Publication en anglais de la Bolingbroke Society; 3 fois par an depuis. 1961; articles critiques surtout sur le thêâtre européen et américain; rêsumés des saisons thêâtrales des pays européens; interviews de gens de thêâtre; critiques des productions; photographies et reproductions; (abonnement de $\$ 2.50$ par an; s'adresser aux éditeurs, Box 4098 , Untversity Station, Minneapolis, Minnesota 55414).

Educational Theatre Journal

371.332505/Ed83 1(1949)--

Publication trimestrie1le de 1 'American Educational Theatre Association; articles traitant principalement des techniques thêatrales; $5 \%$ des articles consacrés à quelques aspects historiques et littéraires de thêâtre français; comprend des communications de 1 'Association, des comptes rendus, et une liste des premières représentations des pièces; s'adresser à l'éditeur, ETJ, Dept. of Drama, U. of Texas (Austin).

Eighteenth Century Studies: A Journa1 of Literature and the Arts

Salle des périodiques $1(1967)--$

Revue trimestrielle en anglais de 1 'University of California à Davis; articles sur la littérature anglaise et américaine surtout, mais aussi la littérature de I'Europe continentale; s'intéresse surtout aux rapports entre la littérature du dix-huitième siècle et la théologie, la philosophie, 1'histoire, la peinture, l'architecture et la musique.

\section{Esprit}

Pas de cote

Revue mensuelle de langue française portant sur la critique littéraire et surtout les sciences sociales et la philosophie; quelques oeuvres originales et inédites; des comptes-rendus, et un index de 1 'année précédente dans le premier numéro de l'année.

\section{L'Esprit Créateur}

840.5/Es66 1(1961)--

Parait 4 fois par an; articles de critique littéraire sur un auteur ou un mouvement, en langues modernes; comptes-rendus de livres; s'adresser à $M$. John D. Erickson, Editeur, ECr, Box 222, Lawrence, Kansas, 66044; (MLA Style; articles: max. de $4 . \overline{000}$ mots; revues: max. de 700 mots); souscrip. annuelle: $\$ 4.00$.

\section{Essays in Criticism}

$$
\text { 820.5/Es73 1(1951)-- }
$$

Revue trimestrielle publiée à oxford (Angl.) comportant des articles critiques en anglais sur la littérature, parfois d'un point de vue linguistique; comptes-rendus; index des vols. 1-15 au numéro de décembre 1966.

Etudes anglaises

$$
820.5 / \text { Et } 81 \text { 1(1937)- }
$$$$
19(1966), 28(1968)
$$

Revue française qui paraît quatre fois par an, avec le coucours du C.N.R.S; 
études critiques en français et en anglais, sur la littérature de la GrandeBretagne et des Etats-Unis.

41. EC1

Les Etudes Classiques

480.5/Et81 1(1932)--

Publication de langue française paraissant 4 fois par an; apparemment réservée aux enseignants catholiques belges; articles traitant de la morale, de l'histoire de l'art, de l'histoire, de la géographie, du latin, du grec, des mathématiques, des sciences, et de la critfque littéraíre françalse $(20 \%)$.

42. $\underline{E G}$

\section{Etudes Germaniques}

$830.5 /$ Et81 1(1964)--

Revue trimestrielle publiêe par la Société des Etudes Germanlques à Paris sous 1a direction de M. Colleville; contient une bibliographie critique, des comptes rendus de livres et d'articles récement parus, aussi bien que des articles critiques, surtout sur le Moyen Age et la linguistique; en allemand, en français, et en langues scandinaves.
43. $\underline{E P}$
Etudes Philosophiques
$105 /$ Et 81
s.2,1(1946), 5(1950)--
Revue trimestrielle publiée par la Société des études philosophiques de France (chez P.U.F.); compurtant des essais philosophiques et des comptes- rendus des ouvrages philosophiques; en langue française.

44. Europe

$477(1967)--$

Publication des Editeurs Français Réunis; fondée en 1923 par un groupe d'écrivains en collaboration avec Romain Rolland. Parution mensuelle. Chaque fascicule est dédié à l'étude d'un auteur ou à un aspect particulier de la Iittérature moderne. Prix: $40 \mathrm{NF}$ par an; 21, rue de Richelieu, Paris.
45. Exp1
The Explicator
805/Ex7 1(1942)--

Publication de Virginia Commonwealth University, paraissant tous les mois pendant l'année scolaire (de septembre à juin); de petit format, traite surtout des littératures anglaise et américaine; articles critiques, mais très courts, le plus souvent une explication de texte; index bibliographique pour les tomes I - XX.

46. FL Figaro Littéraire

Salle des périodiques

Publication (sous format de revue) hebdomadaire de langue française; articles portant sur les lettres, les arts, les spectacles, les sciences, les enquêtes, et les loisirs; destiné au grand public; s'adresser à la revue, 37 , rue du Louvre, Paris $2^{\mathrm{e}}$.

47. Flambeau Flambeau, Revue belge des questions politiques et 050/F61 (1919)-littéraires

Paraissant en gênéral tous les deux mois en langue française, contenant des études critiques sur la littérature française, iais aussi étrangère, et sur l'histoire de l'art; parfois un index cumulatif, des critiques sur les nouvelles parutions; s'adresser à Le Flambeau, administration, rédaction et publicité, 75, ave. Emile de Béco, Bruxelles 5.
48. Fi1
Le Français Moderne
440.5/F84 1(1933)--
Revue paraissant quatre fois par an aux éditions d'Artrey; articles en français présentant des études critiques, des articles sur la philologie, la linguistique, la grammaire, la phonétique. du français moderne (depuis 1500); s'adresser à Madame d'Artrey, administratrice, 17 rue de la Rochefoucauld, Paris $9 e$.

49. FHS

French Historical Studies

$944.005 / 7889$ 1(1958)--

Organe de 1a Society for French Historical Studies; paraît irrégulièrement deux fois par an en anglais mais contient des citations en français; articles et bibliographie à tendance historique.

\section{FR The French Review}

440.5/F88 1(1927)--

Publication de 1'American Association of Teachers of French; 6 fois par an; en français et anglais; contient surtout des articles critiques, littéraires pour la majeure partie (depuis $1 \mathrm{e} 16^{\mathrm{e}}$ siècle), mais aussi linguistiques; s'adresser à: J. Henry Owens, Eastern Michigan Univ., Ypsilanti, 
Mich., 48197.

51. $\underline{\text { FS }}$

French Studies

840.5/F887 1(1947)--

Revue publiée par la Society for French Studies, paraissant tous les trois mois, s'occupant presque exclusivement des questions de littérature française, en de longs articles très érudits; ni bibliographie ni index, mais une liste de "livres reçus" constituant plus de la moitié de la revue et d'un intérêt considérable; s'adresser à Dr. C. A. Burns, Department of French, The University, Southampton, England; abonnement: $\$ 9.10$ par an.

52. GL General Linguistics

405/G286 I(1955)-4(1960)

Revue semestrielle, plus des suppléments irréguliers, qui présente des articles de linguistique sur les langues modernes et classiques, en anglais; publiée par le Department of Modern Languages, Univ. of Kentucky (Lexington).

Une série de volumes annuels en allemand contenant des études critiques et une bonne bibliographie critique et sélective destinée surtout aux bibliophiles; chaque volume consacré à un sujet particulier; ne touche pas directement à la littérature française, mais peut être utile pour les renseignements bibliographiques; Frankfurt (a/Main): Gesellschaft der Bibliophilen e. V.

54. IL

L'Information littéraire

$840.5 /$ In 3 iv, 2; 1952

Paraft tous les deux mois pendant l'annëe scolaire; articles écrits en français sur des sujets qui vont de l'étude d'un auteur à un point de grammaire bien particulier; publication qui s'adresse surtout aux professeurs de lycée; s'adresser à J.B. Ballière et fils, 19, rue Hautefeuille, Paris $6^{\mathrm{e}}$.

55. IMU

Italia Medioevale e Umanistica

480.5/It1 4(1961)--

Revue annuelle contenant des articles critiques le plus souvent en italien sur la littérature médiévale, la civilisation médiévale, et un peu sur la linguistique de l'italien; bibliographie critique très sélective; index cumulatif; êd. Antenore (Padova).

56. JAAC

Journal of Aesthetics and Art Criticism

705/J82 1(1942)--

Publication trimestrielle de 1 'American Society for Aesthetics and The Cleveland Museum of Art, consacrée à l'esthétique, la littérature, (les études esthétiques), la philosophie, la musique, la danse, et les beaux arts $(80 \%)$; comptes-rendus $(12 \%)$; communications ( $4 \%)$; Nouvelles de la Sociêté (3\%); s'adresser à: ASA, Cleveland Museum of Art, Cleveland, Ohio, 44106.

57. Names Journal of the American Name Society

929.405/N151 1(1953)--

Publication en anglais de 1'American Name Society, paraissant 4 fois par an; articles en anglais, traitent de 1 'onomastique en littérature, philologie et linguistique; comptes rendus de livres et d'articles.

58. KFLQ

Kentucky Foreign Language Quarterly

405/K419

1-13 plus supp1.(1954-67)

Publication trimestrielle du Dept. of Modern Foreign Languages, U. of Kentucky; consacrée à tous les aspects de l'étude et de 1 'enseignement des langues anciennes, mẻdiévales, et modernes; études critiques sur la littẹrature et la stylistique (80\%); 1a linguistique (10\%); l'enseignement de la langue (10\%); après 1967 I'intention aussi bien que le titre changent: Kentucky Romance Quarterly (KRQ), q.v.

59. KRO

Kentucky Romance Quarterly

$405 / \mathrm{K} 41914$ (1) (1967)-Anciennement KFLQ; revue trimestrielle publiée par I'U. of Kentucky consacrée aux études critıques sur des sujets romans - littérature, histoire et société (90\%); "document" (10\%) réservé aux interviews et aux commentaires biographiques.

60. $\mathrm{KR}$

The Kenyon Review

050/K42 1(1939)--

Publié 5 fois par an, par Kenyon College; articles de critique littéraire 
(50\%) et oeuvres originales (50\%), surtout écrits en anglais; revues de livres; peu de sujets français; s'adresser à $\underline{K R}$, Box 73, Gambier, Uhto, 43022 .

61. LangQ

Language Quarterly

Pas de cote 1(1962)--

Publié 4 fois par an, par The Univ. of South Florida; articles de critique littéraire $(60 \%)$, de linguistique $(30 \%)$ et de méthode pédagogique $(10 \%)$, en anglais, espagnol, allemand, français ou russe; revues de livres; s'adresser à l'Editeur, LangQ, The Univ. Of South Florida, Tampa.

62. LetN

Les Lettres Nouve1les

050/L5692 (1959)--

Revue publiée depuis mars 1959 par les éditions Denoël, 14, rue Amélie, Paris $7^{e}$; paraissant tous les mois soit la revue, soit un ouvrage original, uniquement en français; aussi des critłques, des articles sur l'histoire de $1^{\prime}$ art, de la publicité pour des oeuvres littéraires; s'adresser: LetN, service abonnement, 26, rue de Condé, Paris $6^{\mathrm{e}}$.

63. $\underline{L R}$

64. MSS

65. $\underline{M u K}$

66. $\underline{\text { MAE }}$

67.

68. $\underline{\text { MLN }}$

69. MLQ

70. $\underline{M P}$

71. MA
Les Lettres Romanes

470.5/L569 1(1947)--

Publication trimestrielle de 1 'Université Catholique de Louvain; consacrée à l'êtude des littératures romanes; articles en français; bibliographie critique très sélective; revues des livres; s'adresser à: Directeur de rédaction, 55, rue des Flamands, Louvain (Belgique).

Manuscripts (also Autograph Collector's Journal) 091.505/M319 8(1955)--

Publication trimestrielle de la Manuscript Society; articles traitant des problèmes de ceux qui collectionnent des manuscrits; en anglais; revues des expositions des collectionneurs.

Maske und Kothurn

792.05/M379 1(1955)--

Publication trimestrielle de l'Institut für Theaterwissenschaft an der Universität Wien; articles traitant de la littérature et des techniques thêâtrales; $5 \%$ des articles consacrés au thêâtre français; comptes rendus des livres; articles écrits en allemand, en anglais, et en français.

\section{Medium AEvum}

405/M469 1(1932)--

Publiê 3 fois par an, par la Soctety for the Study of Mediaeval Languages and Literature; articles de critique littéraire (10\%), de linguistique $(40 \%)$ sur le Moyen Age, en langues modernes; revues de livres (section importante); s'adresser à J. A. W. Bennett, Editeur, MAE, Magdalene Co11., Cambridge (England); souscription annuelle: 40/-.

Modern Drama

W. 05/M72 ou

792.05/M72 1(1958)--

Périodique trimestrielle en anglais avec citations en langue originale; articles critiques sur le thêâtre; comptes rendus de travaux sur le théâtre; articles limités à 4000 mots et comptes rendus limités à 500 mots; abonnement de $\$ 2.00$ par an; manuscrits reçus par Prof. A.C. Edwards, Department of English, University of Kansas, Lawrence, liansas 66044 .

\section{Modern Language Notes}

405/M72 1(1886)--

Revue mensuelle de John Hopkins University comportant outre des articles de langue italienne, espagnole, française, allemande, et sur la littérature comparée, des numéros spéciaux.

Modern Language Quarterly

405/M723 1(1940)--

Publication mensuelle, portant sur les littératures européennes; en anglais; citations dans l'original; section excellente de "livres reçus"; index au mois de décembre; de nombreux comptes rendus; s'adresser à MLQ, Parrington Ha11, U. of Wash., Seattle 98105 .

Modern Philology

405/M722 1(1903)--

Publication trimestrielle de 1 'University of Chicago; en anglais; consacrée plutôt à la recherche dans le domaine de la littérature médiévale et moderne; comptes-rendus, et une bibliographie critique des livres.

Le Moyen Age

940.105/M874 1(1888)-- 
72. MandL Music and Letters

780.5/M974 1(1920)--

Publication trimestrielle; articles traitant de philologie et d'histoire littêraire médiévale; bibliographie arrangée par sujet dans le no. 4 de chaque vol.; index cumulatif dans ņo. final du vol.; en français; éd. la Renaissance du livre (Bruxelles).

Revue trimestrielle en anglais publiée par 1'Oxford Univ. Press, consacrée aux rapports entre la musique et la littérature; études critiques (65\%); comptes rendus des livres $(14 \%)$ et de la musique (5\%); correspondance (2\%).

73. Neophil Neophilologus 405/N35 1(1916)--

Articles traitant des langues modernes et de leurs littératures, et de l'influence des langues et des littératures classiques; articles ( 8000 mots maximum) généralement en anglais, mais aussi en français et en néerlandais; index cumulatif pour les vols. 1-30; êd. Wo1ters (Groningue).

74. NRs

Neue Rundschau

$050 /$ N39

1890-93, 1905-33, 1945--

Publication trimestrielle de langue allemande comportant des articles de création, de critique, et de civilisation surtout contemporaine; $10 \%$ consacrés à la littérature française; s'adresser à: S. Fischer Verlag, Berlin 33, Hohenzollerndamm 125-126.

75. NM

Neuphilologische Mitteilungen

405/N397 28(1927)--

Publication trimestrielle de Modern Language Society of Helsinki; articles en anglais, en allemand et en français; $50 \%$ des articles sur des sujets littéraires; $50 \%$ sur des sujets philologiques; liste des livres reçus, et quelques comptes rendus.

76. $\mathrm{NCF}$

Nineteenth Century Fiction

$823.098 / \mathrm{N} 62$

$1(1945)-11,14--$

Revue trimestrielle publiée par I'University of California Press (Berkley); jusqu'en 1949 sous le titre The Trollopian: a Journal of Victorian Fiction; portant sur la critique littêraire des ouvrages anglais, et même sur la philosophie et l'étude psychologique de l'époque.

77. NFS

Nottingham French Studies

Salle des périodiques $1(1962)--$

Revue publiée deux fois 1'an par l'University of Nottingham; comprend des articles écrits par les professeurs de 1'université et par leurs anciens étudiants; articles critiques écrits en anglais sur les auteurs français et sur tous les aspects de la littérature française; s'adresser à l'éditeur, NFS, Univ. of Nottingham (England).

78. NMS

Nottingham Medieval Studies

$805 /$ N849 1(1957)--

Publication annuelle de 1'Universitê de Nottingham; études critiques en anglais de la littêrature et de la civilisation du Moyen Age; numéro spêcial sur Dante, ix(1965); les éditeurs acceptent parfois les MSS des sources non-affiliêes à 1'Univ. of Nottingham.

79. NRF La Nouvelle Revue Française

050/N856 Séries NRF et NNRF incomplètes, Nouvelle série, 1(1953)--

Revue mensuelle fondée par Gide, publiée en français, composêe à part égale d'oeuvres originales et d'articles critiques, plus un certain nombre de revues littéraires, thêâtrales, artistiques; s'adresser au siège de $1 a$ revue, 5, rue Sébastien-Bottin, Paris 7 e.

80. NL Nouve1les 1ittểraires

Salle des périodiques

Publication hebdomadaire de langue française; articles sur les arts, les sciences, les spectacles, les lettres; destiné au grand public; s'adresser chez Larousse, 17, rue du Montparnasse, Paris $6^{\mathrm{e}}$.

Revue publiée 3 fois par an, en anglais, consacrée à des essais littéraires et des revues critiques; contient peu d'oeuvres originales; s'intêresse surtout à la littérature anglaise et américaine; s'adresser aux éditeurs, Box 1934, Brown Univ., Providence, R.I., 02912. 
82. $\mathrm{OL}$

83. $\mathrm{OB}$

84. $\mathrm{PR}$

85.

86.

87.

88. PMLA

89. RTAM

90. RMS

91. RenD

Orbis Litterarum

805/0r1 1(1943)--

Revue d'abord annuelle, puis trimestrielle depuis 1954, portant sur les rapports des courants littéraires américains et européens; articles en allemand, en anglais et en français; index cumulatif dans v. 8, puis dans le no. final de chaque vol.; comptes rendus des livres; Copenhagen: Hunksgaard.

Ord och Bild

050/0r1 1(1932)--

Publication de langue suédoise paraissant six fols par an, comportant des articles contemporains sur divers sujets littéraires et sur des problèmes d'actualité; chaque numéro consacré à un seul sujet: auteurs français, le thêâtre, le cinéma, etc.; section bibliographique des nouveaux livres de 1 'année.

Partisan Review

$335.05 /$ P25 1(1934) -

Revue publiêe en anglais, non exclusivement littêraire, présente des oeuvres originales - prose et poésie - ainsi que des articles, dont peu sur des sujets français; s'adresser à PR, Rutgers, 542 George St., New Brunswick, N.J. 08903.

\section{Philological Quarterly}

405/P54 1(1922)--

Publication trimestrielle en anglais comportant des études sur les langues classiques et modernes et leur littérature; liste des livres reçus; quel-pues comptes rendus; s'adresser à la revue, School of Letters of the University of Iowa.

\section{Preuves}

$328.105 /$ P928 $115(1960)--$

Revue mensuelle chez Firmin Didot; publie en langue française des articles d'actualité concernant la politique ou les relations internationales; s'intéresse à tous les aspects de la civilisation mondiale et peut donner de très bons articles sur la littérature française, son histolre ou les différentes approches critiques qui ont été faites. Réserve également une place aux livres qui viennent de paraître, et en donne la critique. Intéressante du point de vue de l'actualité.

Publication de 1a Faculté des Lettres de I'Université de Strasbourg

$378.44 /$ St.8Ip.s1

nos. $52,69,126-128,131-148$

Livraisons irrégulières; chaque numéro présente un sujet spécial: un auteur, un mouvement, une langue, et la civilisation d'un pays ou d'une région; bibliographie sélective du sujet; index cumulatif pour les nos. jusqu'au 69; en français; Paris: Les Belles Lettres.

\section{Publications of the Modern Language Association $\quad 406 /$ M72 1(1884)--} of America

Revue paraissant sept fois par an, publiẻe par la Modern Language Associa tion, 62 Fifth Avenue, New York; contenant des articles critiques sur la littérature des langues modernes; des numéros spéciaux: annuaire des membres (septembre), programme du congrès annuel (novembre) et bibliographie compréhensive (mai); pour tous renseignements s'adresser à la M.L.A.; cotisation: $\$ 15.00$ ( $\$ 7.00$ pour étudiants).

Recherches de Théologie Ancienne et Médiévale

205/R2431 26(1959)--

Revue trimestrielle publiée par l'Abbaye du Mont Cêsar, Louvain, de parution irrégulière, en français, en anglais, et en allemand, qui traite presque uniquement des problèmes théologiques; quelques bons articles sur la philosophie et la théologie médiévales; excellent index au dernier no. de chaque vol.; de nombreux comptes rendus.

Renaissnnce and Modern Studies

050/R291 1(1957)--

Revue annuelle de 1'University of Nottingham; publie surtout les travaux des membres de 1 'université; articles en anglais portant sur la littérature et la civilisation dans le domaine vague des humanités; s'adresser à Sisson and Parker, Ltd., 25 Wheeler Gate, Nottingham, England.

Renaissance Drama

$822.05 / R 311$ 1(1955)--

Publication en anglais avec des citations en d'autres langues; origines à la MLA Conference on Research Opportunities in Renaissance Drama; parution 
92. $\mathrm{RN}$

93. $\operatorname{Ren} P$

94.

95. RALF

96. RECTR

97. $\mathrm{RBPH}$

98.

99.

100. RLC

irrégulière depuis 1955; études critiques sur le thêatre de la Renaissance et ses précurseurs et successeurs; s'adresser à l'éditeur: Mr. Samuel Schoenbaum, Jepartment of English, Northwestern Univ., Evanston, Illinois.

Renaissance News

$940.2105 / R 291(1948)-$

Publication trimestrielle de la Renaissance Society of America, distribuée seulement aux membres de 1'association, 1161 Amsterdam Ave., New York 27, New York; cotisation $\$ 6.00$; tous les articles en anglais, surtout consacrés à la critique littéraire, mais aussi à l'art, à la musique et à la philosophie; chaque numéro comporte une bibliographie, et des comptes rendus sur les différentes réunions des associations de la Renaissance.

\section{Renaissance Papers}

806/R289r 1(1954)--

Publication annuelle de 1a Southeastern Renaissance Conference; articles choisis des conférences présentées à la réunion annuelle de la Sociétê; en anglais et traitant de différents aspects culturels de la Renaissance.

Renascence; a critical journal of letters

805/R29 1(1948)--

Revue critique trimestrielle publiêe par la Catholic Renascence Society; études en anglais sur la littérature de divers pays, surtout de la France; comptes rendus; pas de bibllographie; index tous les ans dans le volume d'été; s'adresser à la revue, Marquette Univ., Milwaukee.

\section{Répertoire analytique de littérature française}

\section{Salle de lecture Dept. of French and Italian 0ct. 1969--}

Publication bimestrielle avec la participation de la section de langue et littêrature française de la Faculté des Lettres et Sciences humaines de 1 'Univ. de Bordeaux et avec l'intention d'informer ses lecteurs des nouveautês concernant leur propre discipline, de l'activité scientifique des "francisants" dans le monde; double présentation: bulletin et fiches: le bulletin comporte des articles de bibliographie, d'histoire littéraire, intermédiaire des chercheurs; les fiches classées par siècle, puis alphabétiquement, comportent une description bibliographique complète et une analyse rédigée par un spécialiste; $120 \mathrm{~F}$ pour toute la série (M.A., $16^{\mathrm{e}}$, $17^{\mathrm{e}}, 18^{\mathrm{e}}, 19^{\mathrm{e}}$ et $20^{\mathrm{e}}$ siècles); s'adresser à: 17 , rue Hustin, 33 Bordeaux.

Restoration and 18th Century Theatre Research Pas de cote 1(1962)-Périodique en anglais; 2 fois par an (mal et décembre); études critiques

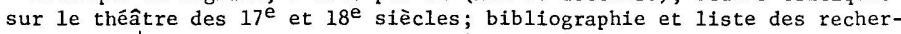
ches en cours; brefs comptes rendus d'oeuvres critiques sur le théâtre; s'adresser aux éditeurs, RECTR, Loyola University, 6525 North Sheridan Road, Chicago, Illinois 60626 .

Revue Belge de Phtlologie et d'Histoire

805/R328 2(1923)--

Revue trimestrielle publiée par la Société pour le Progrès des Etudes Philologiques et Historiques; articles critiques, écrits en anglais, français, allemand, italien, espagnol, latin et néerlandais, traitant de philosophie, d'art, de philologie, de linguistique; bibliographie; index aux vols. 1-5 comprenant 1 'Index au Bulletin Philologique et Historique.

Revue de 1'Enseignement Supérieur

$378.4 \quad 1956-65$

Publiée par le S.E.V.P.E.N. trimestiellement sous la direction du Directeur Général des Enseignements Supérieurs et un comité d'enseignants; écrit par un professeur d'université française, chaque volume est consacré à un sujet pédagogique; index des décrets concernant 1 'enseignement; intérêt du point de vue de la civilisation de la France.

Revue de 1inguistique et de philologie comparée $\quad 405 /$ R328

$$
1(1867)-48(1916)
$$

Revue parisienne comportant des articles sur la linguistique française; comptes rendus des ouvrages récents; index du volume au dernier numéro.

Revue trimestrielle publiée généralement en langues romanes et germaniques, avec le concours du C.N.R.S.; articles sur la littérature des langues modernes; comptes rendus; index du volume au dernier numéro; s'adresser à la revue, 15, rue du Dr. Jacquemaire-Clemenceau, Paris $15^{\mathrm{e}}$. 
101. RMM

102. $\underline{\operatorname{RdP}}$

103. $\underline{\mathrm{RDM}}$

104. RLR

105. RLM

106. RSH

107. $\underline{\mathrm{RE}}$

108. RHSA

109. RHT

110. $\underline{\text { RHL }}$

111. $\underline{\text { RIPh }}$

Revue de Métaphysique et de Morale

105/R322 1(1893)--

Publication trimestrielle en français qui traite de sujets philosophiques. Contient articles, études critiques, correspondance, notes critiques, section bibliographique sur le sujet, et publicité des publications récentes.

\section{Revue de Paris \\ $050 /$ R324 1(1894) --}

Revue mensuelle de langue française comportant des études critiques, des oeuvres originales, des études de linguistique, et de civilisation; peu de documentation, quelques comptes rendus; s'adresser au siège de la revue, 114, avenue des Champs Elysées, Paris $8^{\mathrm{e}}$.

Revue des Deux Mondes

$050 / R 325$ s.2,8(1857)--

Revue paraissant le $1^{\text {er }}$ et 1 e 15 de chaque mois qui présente en langue française surtout des ouvrages originaux et inédits, avec des comptes rendus des événements de la vie actuelle: les beaux arts, le cinéma, le thêâtre, les disques, la politique, etc.; s'adresser au siège de la revue, 15 , rue de $1^{\prime}$ Université, Paris $7^{\mathrm{e}}$.

$\underline{\text { Revue des Langues romanes }}$ 470.5/R32 53(1910)--

Revue annuelle de la Faculté des Lettres et des sciences humaines de 1'Université de Montpellier; articles en français sur la littérature et 1a linguistique des langues romanes, citations dans les langues originales; de nombreux comptes rendus.

La Revue des Lettres Modernes $\quad$ 805/R3281 1(1954)--

Sous-titrée Histoire des idêes et des littêratures, la revue paraît douze fois par an, livraison irrégulière, en langue française; se proposant d'étudier le rapport entre les différentes littêratures étrangères; travaille à $I^{\prime}$ échelon de 1 'Europe et même de 1 'Amêrique; "fichier critique", détachable, à $I^{\prime}$ usage des lecteurs, et portant sur des traductions venant de paraître; articles qui continuent dans plusieurs numéros réunis dans les Cahiers des Lettres Modernes.

Revue des Sciences Humaines 109/R328 105(1962)--

Revue trimestrielle de parution irrégulière de la Faculté des Lettres et Sciences humaines de l'Univ. de Lille comportant des sujets variés dans le cadre du titre; écrite en français par des critiques connus et des professeurs; peu de documentation supplémentaire; s'adresser à: RSH, 9 , rue Auguste-Angellier, Lille, France.

Revue d'Esthétique

705/R321 1(1948)--

Revue trimestrielle de langue française publiée avec le concours du C.N.R.S., organe de la Société française d'esthétique; articles sur l'esthétique et sujets s'y rapportant; comptes rendus.

Revue d'histoire des sciences et de leurs $\quad 509 / R 32$ 1(1948)-applications

Revue trimestrielle paraissant aux P.U.F. comportant des articles en français sur I'histoire des sciences et leur influence sur la vie quotidienne de l'époque; section consacrée aux analyses d'ouvrages venant de paraître dans le domaine de 1 'histoire des sciences.

Revue d'Histoire du Théâtre: Revue de la

$842.09 / R 3281(1948)--$ Sociétê d'Histoire du Thêâtre

Publication trimestrielle de la Société d'Histoire du Thêâtre (J.-L. Barrault, président) en français avec bibliographie en langues ëtrangères; études critiques sur le thêâtre; chaque numéro consacré à un seul auteur dramatique ou à un seul genre; le numéro d'octobre consacré à une bibliographie du thêâtre dans le monde; abonnement et adhésion - $\$ 6.00$ par an; s'adresser au siège de la société, 98, boulevard Kellermann, Paris $13^{e}$.

Revue d'Histoire Littéraire de la France $\quad 840.5 /$ R32 1(1894)-Publication trimestrielle de la Société d'Histoire littéraire de la France; langue française; purement littéraire; bonnes bibliographies et nombreux comptes rendus; Paris: A. Colin.

Revue Internationale de Philosophie

105/R324 6(1952)-- 
Revue belge paraissant 3 fois par an consacrée à 1'étude des rapports entre philosophie, civilisation et littérature; liste des ouvrages et des revues reçus; index au dernier no. de chaque vol.; plusieurs comptes rendus; s'adresser aux éditeurs, 99, ave. de 1'Université, Bruxelles S.

\section{Romance Notes}

479.105/R6611 1(1959)--

Publication semestrielle consacrée aux études critiques des langues romanes sous forme de "notes", de courts commentaires sur un aspect particuliẹr d'un auteur ou d'un sujet $(95 \%)$; langage, philologie, remarques sur traductions $(5 \%)$; envoyer les notes, qui ne doivent pas dépasser le format de 6 pages dactylographiées, à 1 'éditeur, Dept. of Romance Languages, U. of North Carolina (Chapel Hill).

113. $\underline{\mathrm{RPh}}$

Romance Philology

470.5/R663 1(1947)--

Revue critique publiée par trimestre comportant des articles en anglats, des comptes rendus en anglais et en français traitant en général la philologie; pas de section bibliographique; index dans I'Index international des périodiques; éditeur: Yakov Malkie1, Rm. 4333 Divinelle Hall, U. of California, (Berkeley).

114.

115. $\underline{R R}$

116. $\underline{\mathrm{RF}}$

117. $\mathrm{RJ}$

118.

119. $\underline{\mathrm{SR}}$

120. SuF

\section{Romania}

$$
\text { 470.5/R66 1(1872)-- }
$$

Revue trimestrielle fondée par Gaston Paris, consacrêe à l'étude des langues et des littêratures romanes; en français; articles critiques, comptes rendus, périodiques, chronique; publiée par la Société des amis de la Romania; s'adresser à M. Pierre Cézard, 67, rue Claude-Bernard, Paris $5^{e}$ (abonnements); ou à M. Félix Lecoy, directeur, 2, rue de Tournon, Paris $6^{\mathrm{e}}$ (rédaction).

\section{The Romanic Review}

$$
870.5 / \text { R66 1(1910)-- }
$$

Revue critique publiée quatre fois par an par le Department of Romance Languages à Columbia University; dédiẻe à la recherche, à la publication de documents et de textes, à des articles de critique; en anglais, français et italien portant surtout sur la littérature; comptes rendus; pas de section bibliographique.

Romanische Forschungen

470.5/R664 1(1883)--

Revue trimestrlelle publiant en allemand et en anglais des études sur les langues et les littératures romanes; contenant de nombreux comptes rendus; Frankfurt am Main: Klostermann, (Allemagne).

\section{Romanistisches Jahrbuch}

470.5/R662 1(1947)--

Publication annuelle du Romanisches Seminar, Ibero-Amerikanisches Forschungsinstitut der Universttät Hamburg, Allemagne; articles traitant des aspects de critique littéraire, surtout le moyen âge, aussi des questions d'un intérêt philologique; la plupart en allemand, quelques-uns en français, en espagnol et en italien; listes des dissertations en études romanes acceptées par les universités d'Allemagne et titres des dissertation en voie de développement.

\section{Scriptorium}

Special Collections CURR/D-7 1(1946)--

Revue internationale des études relatives aux manuscrits, publiée deux fois 1'an par les Editions scientifiques "Erasme"; articles en français, anglais, allemand, italien et espagnol; comprend des notes sur les manuscrits; bibliographie critique; index annuel.

\section{Sewanee Review}

$050 / \operatorname{Se} 86$ 1(1892)-(quelques lacunes)

Revue trimestrielle de l'University of the South, Sewanee, Tenn.; consacrée aux ouvrages originaux, essais critiques sur les littératures classiques et modernes; quelques comptes rendus; en anglais.

\section{Sinn und Form}

050/Si65 1(1949)--

Revue allemande bimensuelle publiée à Berlin-Est sous I'égide de l'Académie des Beaux-Arts par Wilhelm Girnus; présente, en langue allemande seulement, des ouvrages inédits originaux d'auteurs allemands et étrangers, ainsi que des articles critiques; ne permet pas d'appareil critique; s'adresser à: Rütten \& Loening, 108 Berlin. 
121.

122. $\underline{\mathrm{SF}}$

123. SN

124. SP

125. SIR

126.

127. S Ren

128.

129.

130. TR

131. $\mathrm{Te} 10$

Speculum

805/Sp3 1(1956)--

Revue trimestrielle de la Mediaeval Academy of America, en anglais; contient des articles, des comptes rendus sur la civilisation médlévale, ainsi que le procès-verbal de la réunion annuelle de 1a MAA; $\$ 10.00$ par an (MAA, 1430 Mass. Ave., Cambridge, Mass. 02138).

Studi francesi

$840.5 /$ St94 1(1957)--

Revue italienne rédigée par 1 'Institut de Langue et Littérature françaises de la Facultê des Lettres de L'Université de Turin, dédiée à la culture et à la civilisation françaises; articles en diverses langues (anglais, français, italien); contient plusieurs sections de grande valeur pour les recherches en littérature française: états présents, textes inédits, documents rares, discussions et communications, comptes rendus, bibliographie, résumés des congrès de littérature française.

Studia Neophilologica

405/St94 32(1960)--

Publication paraissant deux fois par an, consacrée à l'étude de la philologie germanique et romane; articles critiques généralement en français, allemand et anglais, et comptes rendus; liste des livres et des revues reçus; s'adresser à $\mathrm{Ab}$ Lundequiska Bokhandler, S-753 22 Uppsala.

Studies in Philology

405/N81 1(1906)--

Publée cinq fois par an, surtout en anglais et en français; articles critiques sur la littérature en général; parfois une bibliographie, parution irregulière; s'adresser à I'University of North Carolina Press, Box 510, Chape1 Hil1, N.C.

\section{Studies in Romanticism}

805/ST94 1(1961)--

Publication trimestrielle de la Graduate School, Boston Univ., comportant des articles sur tous les sujets se rapportant à la conception du Romantisme: littérature et musique surtout; s'adresser à: Editor, 236 Bay State Road, Boston 15, Mass.

Studies in Short Fiction

$809.305 /$ St94 1(1963)--

Publication trimestrielle de Newberry College, Newberry, South Carolina; articles écrits pour la plupart en anglais, quelques-uns aussi en français, en espagnol et en allemand; articles et comptes rendus considèrent surtout les dỉférents aspects du roman dans la littêrature contemporaine.

Studies in the Renaissance

$$
940.21 / \text { St94 I(1954)-- }
$$

Revue publiêe par la Renaissance Society of America, une fois par an, dédiée aux études sur la Renaissance; études critiques, en anglais, qui traitent de la littêrature, de la musique, de la philosophie; pas de bibliographie, pas de comptes rendus; index: vols. 1-10, 1954-1963.

\section{Symposium}

405/Sy68 1(1946)--

Revue trimestrielle du Department of Romance Languages, Syracuse Univ. (New York), comportant des articles relatifs aux langues modernes étrangères (sujets américains et anglais exclus); écrits en toutes langues modernes, surtout en anglais; bibllographie sélective et liste de "livres reçus"; quelques comptes rendus; s'adresser à: Secretary of Ed. Board, 205 H.B. Crouse Hall, Syracuse Univ., Syracuse, N.Y. 13210.

\section{Synthèse}

050/Sy78 6(1953)--

Revue mensuelle de langue française contenant des études critiques, de la poésie, des articles sur l'histoire de l'art; parfois une bibliographie lors d'un numéro śp̣écial; index cumulatif pour les numéros 1 à 100, des critiques sur les nouvelles parutions, des reproductions; s'adresser au siège de la revue, 4, rue Guisarde, Paris $6^{\mathrm{e}}$.

La Table Ronde

$050 / \mathrm{T} 114$ 168(1962)--

Revue mensuelle de langue française dont les articles comprennent des études critiques et des ouvrages de fiction inédits; index cumulatif en décembre; s'adresser à la Société d'éditions et de publications artistiques et littéraires, 23, rue du Renard, Paris $6^{\mathrm{e}}$.

\section{Te1 Que1}

$840.5 / T 23520(1965)--$ 
132. TM

133. TDR

134. TN

135.

136. ThS

137.

138. TCL

139.

140. VR

Revue trimestrielle de langue française comportant des articles sur la littérature, les beaux arts, la philosophie, la linguistique, etc. et leurs rapports avec la vie contemporaine; peu de comptes rendus; s'adresser aux Editions du Seuil, 27, rue Jacob, Paris $6^{\mathrm{e}}$.

Les Temps Modernes

Salle des Périodiques

Revue mensuelle fondée par Jean-Paul Sartre en 1945; articles importants dans le domaine de la littérature et de la critique; à tendances phflosophiques et politiques.

The Drama Review (anciennement Tulane 808.2/T82 1(1955)-Drama Review)

Publication de Tulane Univ. entre 1955 et l'été 1967, puis de la School of the Arts, New York Univ.; quatre fois par an en anglais; êtudes critiques sur le théâtre; pièces dramatiques originales; comptes rendus de productions dramatiques; interviews avec des gens de thêatre; bibliographie; reproductions et photographies; renseignements pédagogiques et professionnels; abonnement $\$ 5.00$ par an; s'adresser à Richard Schechner, éditeur.

Theatre Notebook: A Quarter1y Journal of the 792.0942/T3406 History and Technique of the British Theatre $\quad$ (1),2(1946)--

Publication en anglais de la Society for Theatre Research, London; 4 fois par an depuis octobre 1945; études critiques et comptes rendus sur 1e thêatre anglais; 1iste des programmes de la Society for Theatre Research.

Theatre Research / Recherches thêatrales

792.05/T3405 1(1958)--

Publication en anglais et en français de 1'International Federation for Theatre Research; 3 fois par an depuis mars 1958; études critiques et surtout techniques sur le thêâtre; bulletins des réunions et des séminaires de la Fédération; comptes rendus des travaux critiques sur le thêâtre et des production thêatrales; guides sur le thêâtre de divers pays; numéros consacrés aux conférences internationales de la Fédération; abonnement et adhésion 15 francs suisses; manuscrits reçus par Alan Downer, Department of English, McCosh 22, Princeton University, Princeton, New Jersey.

\section{Theatre Survey: The American Journal of \\ $792.05 /$ T3406 1(1960) --} Theatre History

Publication en anglais de 1 'American Society for Theatre Research; 1 fois par an entre 1.960 et 1963, 2 fois par an (mai et novembre) depuis 1963; articles surtout sur. 1'histoire du thêâtre; s'adresser à: ThS, 1117CL, University of Pittsburgh, Pittsburgh, Penn. 15213.

Travaux sur Voltaire et le Dix-huitème Siècle

$842.56 \mathrm{D} / \mathrm{B} 464 \mathrm{t} / \mathrm{1} 955$ 1 (1955)--

Publication de parution irrégulière, plusieurs fois par an, de l'Institut et Musêe Voltaire à Genève; certains numéros traitent des réunions du Congrès du Siècle des Lumières, d'autres contiennent des articles sur des sujets précis; paraît également sous le titre sous le titre de Studies on Voltaire and the Eighteenth Century; parfois une bibliographie d'études critiques, aux numéros réecents.

Twentieth Century Literature. A Scholarly and 805/T918 1(1955)-Critical Journal

Revue critique, publiée en anglais quatre fois par an, portant uniquement sur la littérature anglaise et américaine; bibliographie critique des ouvrages ou articles récemment parus; biographies d'auteurs; s'adresser à: Immaculate Heart College, 2021 N. Western Ave., Los Angeles, Ca1. 90027.

Vie et Langage 405/V67 1(1952)--

Revue paraissant le premier de chaque mois, à la Librafrie Larousse; publie de temps en temps les décrets de l'Office du Vocabulaire Français; se spécialise en courts articles portant sur un problème précis de philologie ou de langage; index cumulatif à publication irrégulière.
Vox Romanica
$470.5 / V 948$ 6(1941)--

Revue semestrielle publiant en langues romanes et en allemand des études 
de linguistique romane et quelques rares études littéralres; assez régulièrement des comptes-rendus; jerne: Francke Verlag.

141.

142. $\underline{\text { YFS }}$

143. $\mathrm{YR}$

144.

145. ZFSL

146. ZRP

147. ZVS

149. BHR

148.

Word

405/W892

$1(1945)-14(1958), 16(1960)-$

Revue du Linguistic Circle of New York, publiée trois fols par an, plus des suppléments (sur un seul sujet), en anglais; articles portant sur la linguistique des langues modernes et antiques; comptes rendus; bonne liste des livres reçus; s'adresser au Business Manager, 206 Stieglitz Hall, City College of New York.

Yale French Studies

$840.5 /$ Y12 1(1948)--

Revue publiée deux fois par an sous l'égide du Department of French à Yale Univ.; articles exclusivement en anglais; chaque numéro se consacre à un seul. thème ou à un seul auteur; s'adresser à 323 w.L. Harkness Hall, Yale Univ., New Haven, Conn. 06520.

The Yale Review

305/Y1 1(1892)--

Revue trimestrielle, publiée en anglais, très rarement consacrée aux études françaises; s'adresser à J. E. Palmer, 28 Hillhouse Ave., New Haven, Connecticut 06520.

\section{Yearbook of Comparative and Genera1 Literature 805/Y32 1(1952)-}

Publication annuelle de 1 'Université d'Indiana; discussions des problèmes dans l'enseignement de la littérature comparée: choix de textes et de traductions, distinction entre la littérature comparée, générale et mondiale, problèmes de l'établissement d'un cours de littérature comparée, etc; comptes rendus des publications de littérature comparée.

\section{Zeitschrift für Französische Sprache und \\ $440.5 / 23$ Literatur$$
10,12(1888,90)--
$$

Revue allemande publiée irrégulièrement quatre fois par an à Wiesbaden par E. Gamillscheg et J. *ilhelm; présente, en langue allemande ou française, d'importantes études critiques dans le domaine de la littérature française; des Supplement-Hefte consacrés à des auteurs individuels, à un genre littéraire ou à un problème spécial; Index (01) pour les volumes 1 à 50 publié en 1929 .

\section{Zeitschrift für Romanische Philologie \\ $470.5 / 231(1877)--$}

Revue publiant 3 fois par an, dans les langues romanes, allemande, et anglaise, des études sur les littératures romanes; de nombreux comptes rendus; d'excellentes bibliographies publiées dans les suppléments; Tübingen: Niemeyer Verlag.

\section{Zeitschrift für vergleichende (Sprachforschung) 405/23 1(1852)--}

Périodique trimestriel à publication irrégulière portant sur la linguistique historique et générale, surtout des langues indo-germaniques orientales; articles écrits en allemand avec citations dans la langue d'origine; index aux vols. 11-20 (1862-72) dans v. 20; comptes-rendus et index de mots discutés; s'adresser: Prof. Dr. Fritz Mezger, 303 Hughes Rd., King of Prussia, Pa.

Addenda

Adan. International Review

820.5/Ad13 1(1929)--

Revue de parution très irrégulière, è anglais et en français; publie des textes et des études critiques, souvent des sujets spéciaux (Proust); s'adresser à la revue, 28 Emperor's Gate, London S.W.7.

Bibliothèque d'Humanisme et Renaissance, $\quad 840.5 /$ B47 1(1941)-Travaux et documents

Organe de 1'Association Humanisme et Renaissance; parait trois fois par an; principalement en français, en anglais et en allemand; articles sur la littérature et la civilisation de la Renaissance; bibliographie des articles (jusqu'en 1966 - puis séparément dans la Bibliographie Internationale de 1 'humanisme et de la renaissance); notes et documents, chroniques, et 
150.

151.

152. GBA

153.

154.

155. MFS

156. MLJ

157. MLR

158. 는

Criticism (Wayne State)

050/.C869 1(1959)--

Revue trimestrielle en anglais; articles portant sur la littérature et les arts; citations dans 1a langue originale; comptes rendus; s'adresser à la revue, Wayne State University Press, Detroit.

Etudes française

$840.5 /$ Et81 1(1925)--

Revue trimestrielle des lettres françaises et canadiennes-françaises; numéro spécial en août; plusieurs sections: articles, notes et documents; comptes rendus; textes originaux.

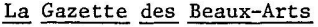
$705 / \mathrm{G} 25$ 1(1859)--

Revue mensuelle fondée en 1859; articles, notes, comptes rendus et une rubrique qui incorpore dans GBA 1 'ancienne Chronique des arts, revue importante pour les activités artistiques surtout à Paris; revue essentielle pour les rapports entre la littérature et les beaux-arts.

Journal of the History of Ideas

$105 / J 8221(1940)--$

Revue trimestrielle de critique littéraire internationale; articles, notes, et comptes rendus; index du volume dans le dernier numéro; s'adresser - la revue, City College of New York, N.Y. 10031.

Mercure de France

050/M53 100(1912)--

Revue mensuelle de langue française publiant surtout des ouvrages originaux; comptes rendus; s'adresser au siège de la revue, 16, rue de Condé, Paris $6^{\mathrm{e}}$.

Modern Fiction Studies

$805 / \mathrm{M} 72$

$1(1955)-5(1960), 7(1962)--$

Revue trimestrielle publiee par The Modern Fiction Club of the Purdue University Department of English; articles en anglais sur la littérature; 1iste descriptive des livres reçus; s'adresser au Department of English, P.U., Lafayette, Ind. 47907.

Modern Language Journal

405/M721

$$
1(1916) \text { - 51(1967) }
$$

Publication de la National Federation of Modern Language Teachers Association, paraissant huit fois par an; articles et comptes rendus en anglais surtout sur le problème de l'enseignement des langues modernes; s'adresser à M. Robt. F. Fleming, U. of Wisconsin-Milwaukee; Milwaukee, Wisc. 53201.

\section{Modern Language Review}

405/M726 1(1905)--

Revue trimestrielle britanique de littêrature et de philologie médiévales et modernes; organe de la Modern Humanities Research Association; articles en anglais portant sur les langues médiévales et modernes, et leurs littératures; de très nombreux comptes rendus; index général et séparé à commander chez l'imprimeur: Dawson \& Sons, Ltd., 16 West Street, Farnham, Surrey, U.K.; aux U.S.A. s'adresser à Dean Calvin Linton, Columbian College of Arts and Sciences; George Washington Univ., Washington, D.C. 20006 , pour tous renseignements.

\section{Modern Languages}

406/M722 1(1919)--

Revue trimestrielle de la Modern Language Association britanique, publiée en différentes langues (modernes); articles portant sur les langues et leurs littératures, et surtout leur enseignement; liste des membres; comptes rendus surtout des textes pour 1 'enselgnement des langues modernes; index pour 1'année publié à part; s'adresser à la M.L.A., 2 Manchester Square, w.1 (London). 


\section{Amis de Chimeres}

Le comité de rédaction remercie chaleureusement tous les amis qui ont bien voulu contribuer de leurs deniers aux frais d'impression du numéro spécial d'hiver de Chimeres. En particulier Messieurs et Mesdames:

Amis fondateurs:

Isabelle Armitage Raymond Cerf Barbara M. Craig H. W. Huttanus

J. Theodore Johnson, Jr. Norris Lacy Jacqueline $S$. Curtis Ophélie de Marée Marilyn Stokstad Betty Thomas John D. Erickson Kenneth S. White Lloyd R. Free

Amis bienfaiteurs: William J. Argersinger, Jr.

Klaus et Margaret Berger Lucie Bryant

Brigitte Desrues

Simone A. Johnson

Mona Lefebvre

Murle Mordy

Elizabeth S. Witt 


\section{TABLE DES MATIERES}

Eugene Wee....... couverture et page 67 John Beckley . . . . . . . . . . . . page 24 B. J. Price.... . . . . . . . page 28 Roseann Runte... . . . . . . . . page 42 Marie-Jo Coclet . . . . . p pages 12335462 


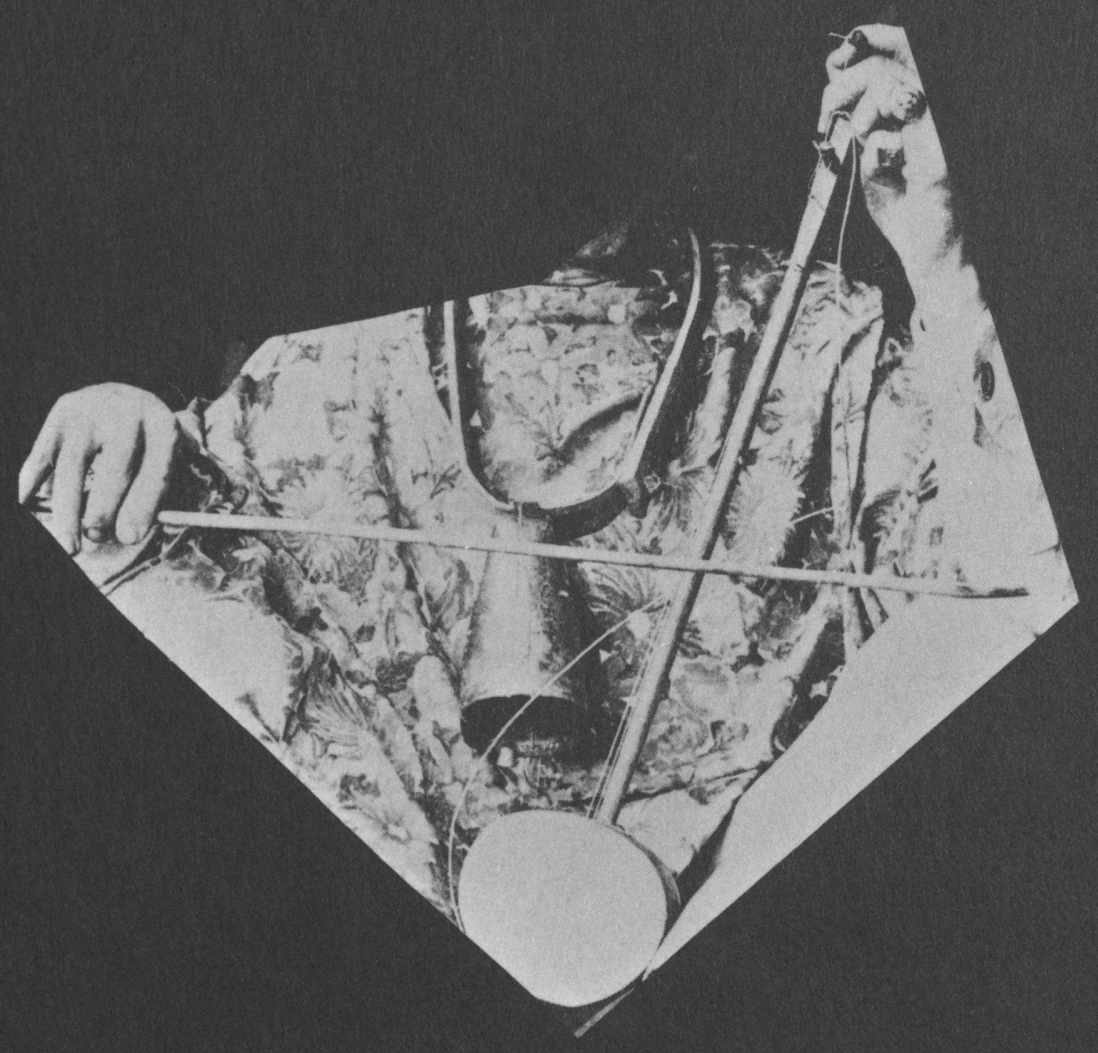

prix.un dollar 